\title{
Mesostructured Hydrophobic-Oleophobic Silica Films for Sustained Functionality in Tribological Environments
}

Aaron J. Kessman

West Virginia University

Follow this and additional works at: https://researchrepository.wvu.edu/etd

\section{Recommended Citation}

Kessman, Aaron J., "Mesostructured Hydrophobic-Oleophobic Silica Films for Sustained Functionality in Tribological Environments" (2011). Graduate Theses, Dissertations, and Problem Reports. 4741.

https://researchrepository.wvu.edu/etd/4741

This Dissertation is protected by copyright and/or related rights. It has been brought to you by the The Research Repository @ WVU with permission from the rights-holder(s). You are free to use this Dissertation in any way that is permitted by the copyright and related rights legislation that applies to your use. For other uses you must obtain permission from the rights-holder(s) directly, unless additional rights are indicated by a Creative Commons license in the record and/ or on the work itself. This Dissertation has been accepted for inclusion in WVU Graduate Theses, Dissertations, and Problem Reports collection by an authorized administrator of The Research Repository @ WVU.

For more information, please contact researchrepository@mail.wvu.edu. 
Mesostructured Hydrophobic-Oleophobic Silica Films for Sustained Functionality in Tribological Environments

Aaron J. Kessman, B.S.

Dissertation submitted to

the

College of Engineering and Mineral Resources

at West Virginia University

in partial fulfillment of the requirements

for the degree of

Doctor of Philosophy

in

Mechanical Engineering

Darran R. Cairns, Ph.D., Chair

Edward Sabolsky, Ph.D.

Xueyan Song, Ph.D.

Konstantinos Sierros, Ph.D.

Charter Stinespring, Ph.D.

Department of Mechanical and Aerospace Engineering

Morgantown, West Virginia

2011

Keywords: hydrophobic-oleophobic, sol-gel, coating, supramolecular templating, mesostructure, tribology 


\section{ABSTRACT \\ Mesostructured Hydrophobic-Oleophobic Silica Films for Sustained Functionality in Tribological Environments}

\section{Aaron J. Kessman}

The primary goal of this research was to synthesize water- and oil-repellent coatings that offer sustained functionality and durability. Engineered low surface energy materials generally suffer from a lack of mechanical robustness, which makes them susceptible to damage by abrasive wear. Fluorinated silanes are often combined with alkoxide precursors via sol-gel cocondensation to create coatings with high hardness and good substrate adhesion. However, a common problem with these materials is that the organic moieties that provide low surface energy also become surface segregated and highly concentrated at the solid-air interface. With such a structure, mechanical removal of the top surface by abrasion, for example, reveals subsurface areas that are then much less concentrated in terms of functional chemistry. The material developed in this study was designed to overcome this problem by means of a tailored and templated mesostructure that effectively encapsulated the low surface energy functional moieties, and thus achieves sustained functionality during abrasive wear. This material, applied as a thin coating to a variety of substrates, has the potential to reduce waste and pollution and the environmental degradation of materials and structures. Improving the performance of such materials can benefit a wide variety of applications. These include optoelectronic devices including photovoltaic panels; automobile and aircraft; architectural structures; the chemical, food, and medical industries for hygienic and anti-fouling requirements; textiles; and household applications. This approach has further implications in areas such as boundary lubrication and drug delivery systems.

Hydrophobic-oleophobic mesoporous fluorinated silica films were synthesized via sol-gel cocondensation and coated on glass substrates. Fluorosilane and surfactant template concentrations were varied to elucidate the effect of organic functionality and porosity on performance. Structural, chemical, mechanical, surface, and tribological properties were investigated to examine the performance of functionalized mesostructured thin films in abrasive environments. Analytical techniques included XPS depth profiling, porosimetry, AFM and friction force microscopy, nanoindentation, contact angle goniometry, and stylus profilometry. Controlled abrasion was conducted using a lab-built instrument. Hydrophobic and oleophobic properties were monitored ex-situ during abrasion to observe and quantify changes in functionality as the material is worn.

Experimental results show that surfactant templating aids in generating an internal mesostructure that facilitates encapsulation of functional moieties. This encapsulation allows exposed surfaces to be sacrificially worn away while maintaining much of the original functionality. The results of tribological measurements, as observed through abrasive wear testing, friction force mapping, and wear rate calculations, suggest that the low-friction surface generate by fluorosilane moieties grafted to internal pore surfaces mitigates to some extent the detrimental effect of film porosity on hardness and wear resistance. 


\section{ACKNOWLEDGEMENTS}

I am sincerely grateful to my advisor, Dr. Darran Cairns for his continued guidance and encouragement during this research project. Thanks for the opportunity! I would like to thank my committee members, Dr. Ed Sabolsky, Dr. Xueyan Song, Dr. Charter Stinespring, and Dr. Konstantinos Sierros for their support of my Ph.D. study. Kostas in particular gets many thanks for countless lengthy discussions on the subject of tribology, which he taught me nearly singlehandedly. I would also like to thank Dr. Stephen Kukureka at the University of Birmingham, UK for his support - he is an unofficial sixth member of my thesis committee.

The myriad contact angle and thickness measurements were only possible due to the helpful assistance of a team of junior lab members: Corey Snyder, Sean Cronin, Sarah Zimmerman, Emmie DeFusco, and Andrew Hoover. I am thankful also to Kolin Brown, Harley Hard, and Dr. Weiquiang Ding of the WVNano shared facilities for their patient guidance.

Finally, Amber: your unfailing love and support made all of this possible!

This work was financially supported by the Department of Defense (DoD) through the National Defense Science \& Engineering Graduate Fellowship (NDSEG) Program, a Graduate Research Fellowship from the National Science Foundation, an Arlen G. \& Louise Stone Swiger Doctoral Fellowship, and a WVNano Bridge Award. 


\title{
TABLE OF CONTENTS
}

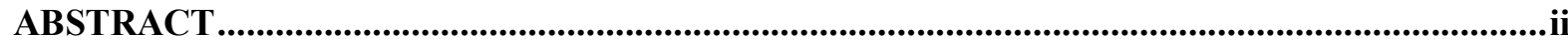

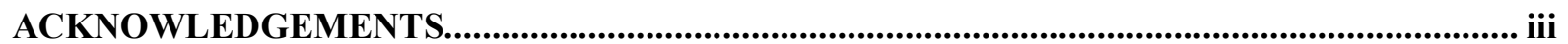

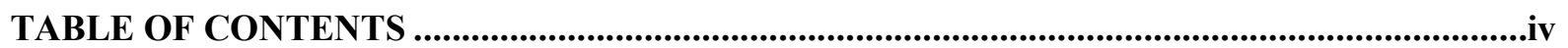

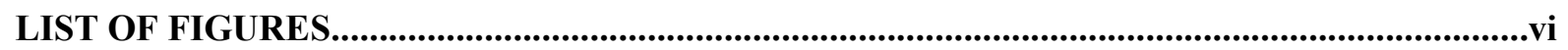

1. GENERAL INTRODUCTION ................................................................................................ 1

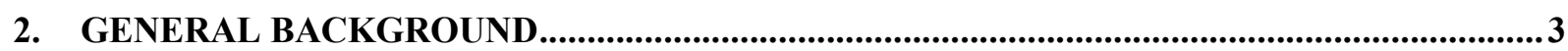

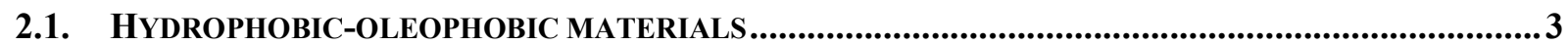

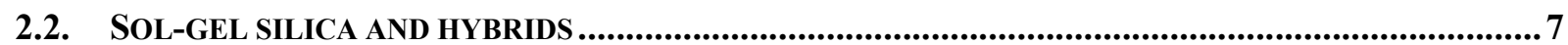

2.3. SURFACE FUNCTIONALIZATION OF SOL-GEL SILICA...............................................................

2.4. SUPRAMOLECULAR TEMPLATING OF SOL-GEL SILICA .......................................................11

2.4.1. MESOPOROUS THIN FILMS AND EVAPORATION INDUCED SELF ASSEMBLY …….......................... 12

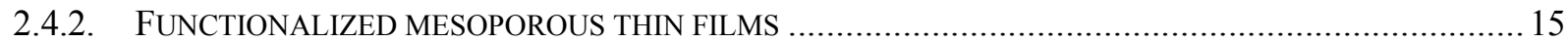

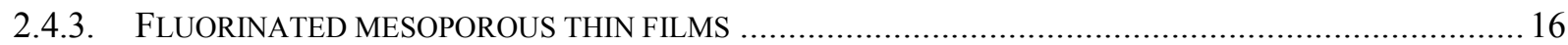

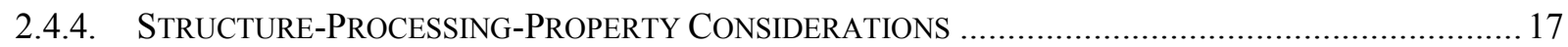

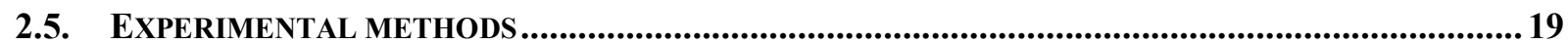

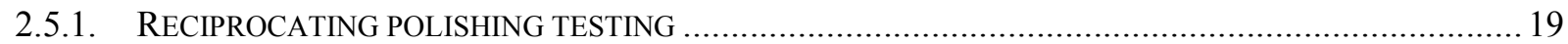

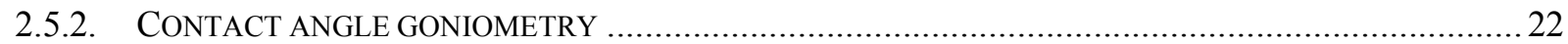

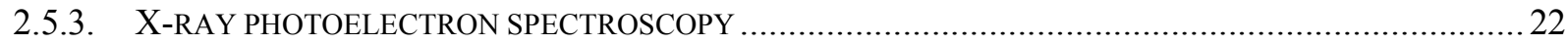

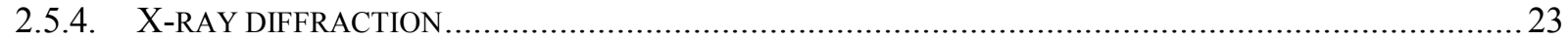

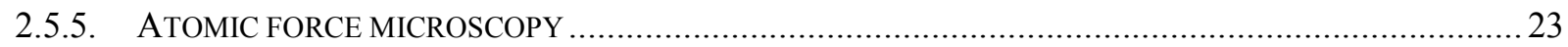

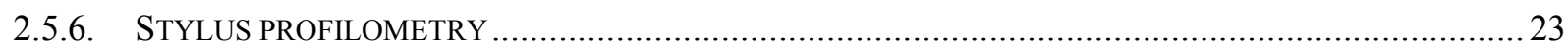

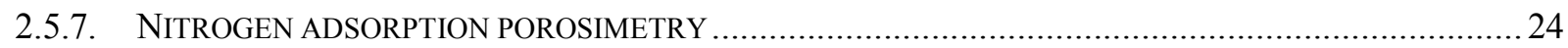

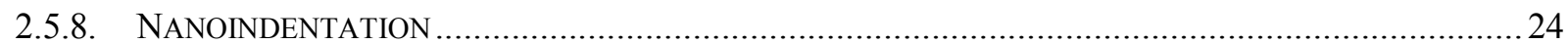

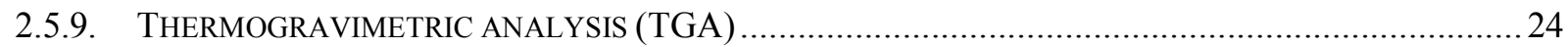

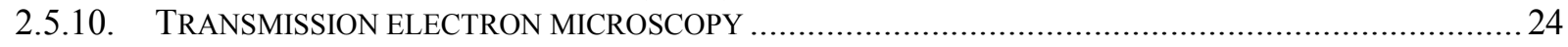

3. TEMPLATE-ASSISTED ENCAPSULATION OF FLUORINATED SILANES IN SILICA FILMS FOR SUSTAINED HYDROPHOBIC-OLEOPHOBIC FUNCTIONALITY ........................25

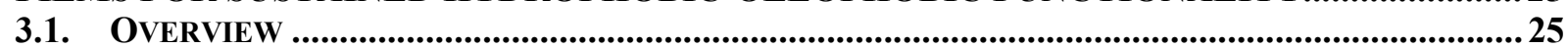

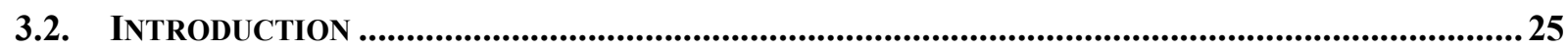

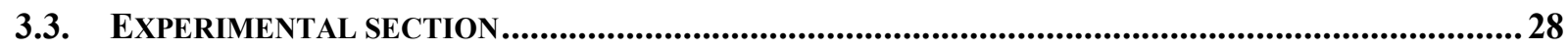

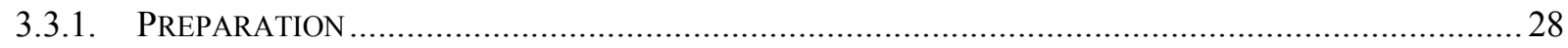

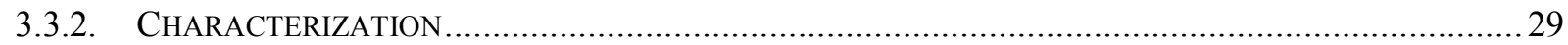

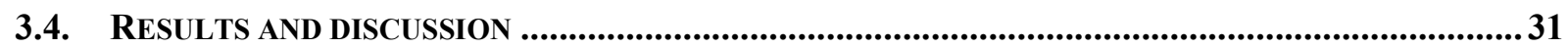

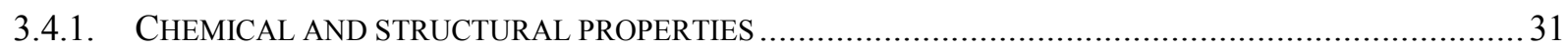

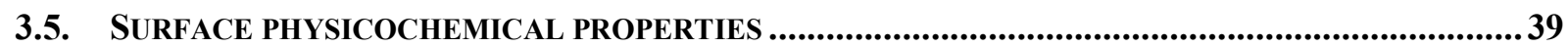

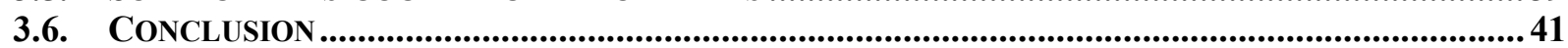


4. STRUCTURAL, MECHANICAL, AND TRIBOLOGICAL PROPERTIES OF SILICA FILMS WITH ENCAPSULATED HYDROPHOBIC FUNCTIONALITY: EFFECT OF FUNCTIONAL MOIETY AND SURFACTANT TEMPLATE CONCENTRATIONS …..........................................43

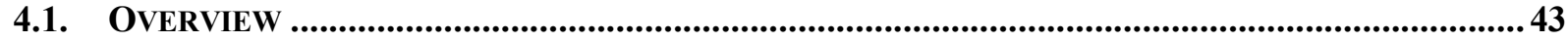

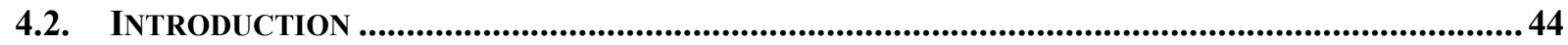

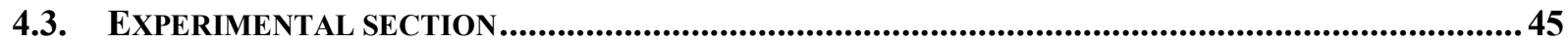

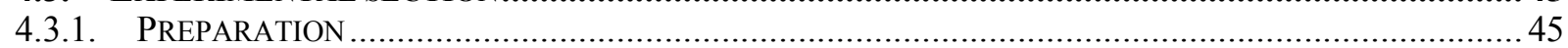

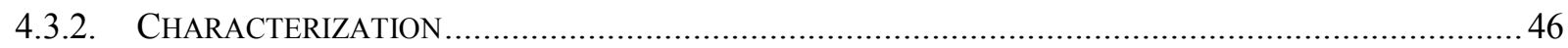

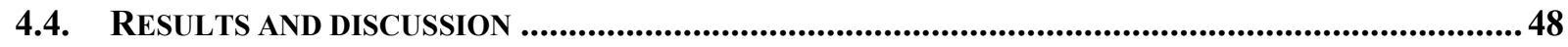

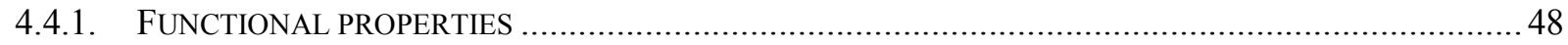

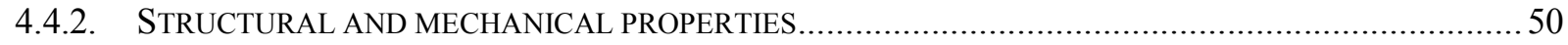

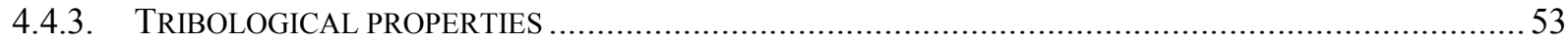

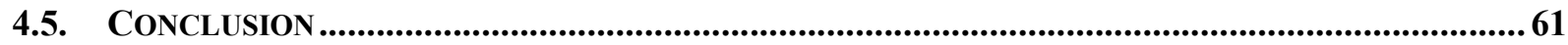

\section{MICROTRIBOLOGICAL STUDY OF INTERNAL SURFACES OF FLUORINATED}

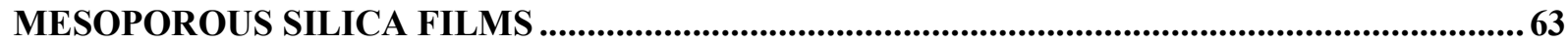

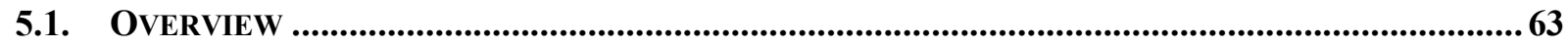

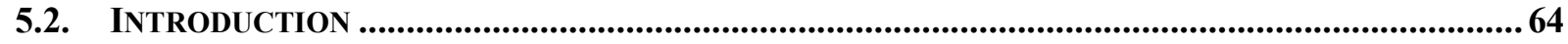

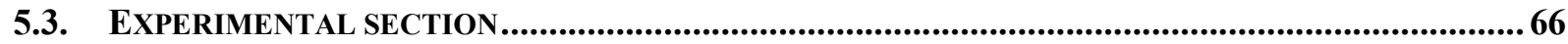

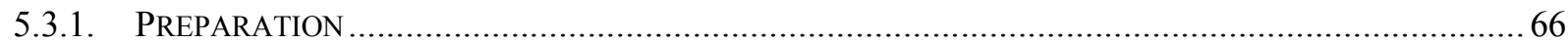

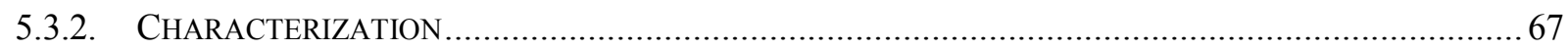

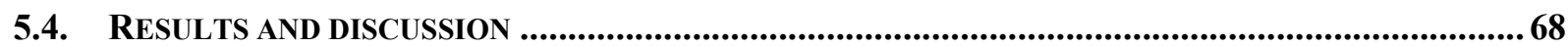

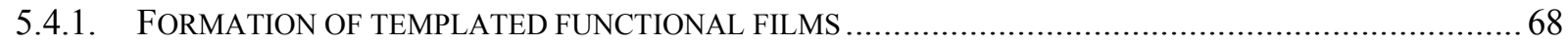

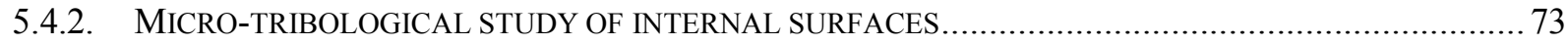

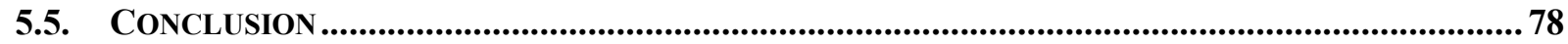

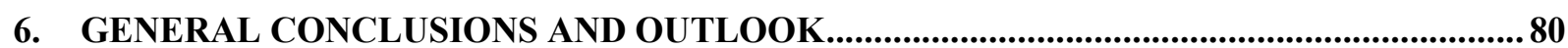

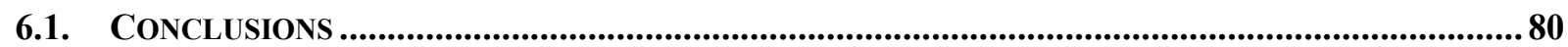

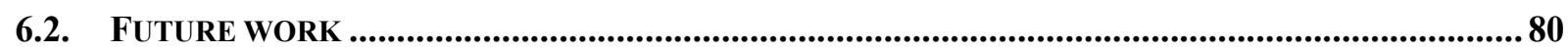

6.2.1. ENHANCING MECHANICAL PROPERTIES THROUGH MATRIX REINFORCEMENT ............................. 80

6.2.2. EFFECT OF SOL AGING ON CHEMICAL AND MECHANICAL PROPERTIES ……............................... 81

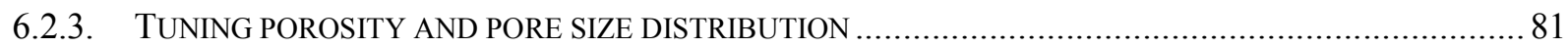

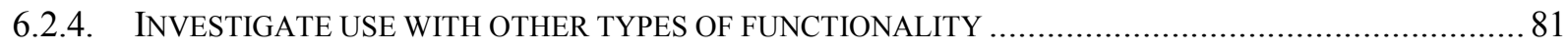

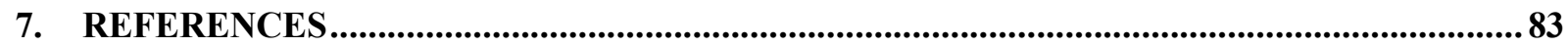

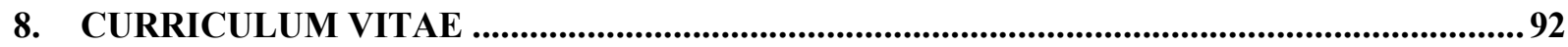




\section{LIST OF FIGURES}

Figure 1. Cellular mesostructure preserves functionality of worn surface .................................. 1

Figure 2. Contact angle of liquid drop on solid surface........................................................... 4

Figure 3. Superhydrophobic surfaces. Left, Cassie-Baxter state of drop suspended over vapor pockets; right, Wenzel state of drop entrapped by surface asperities.......................... 5

Figure 4. Artificial super hydrophobic coatings (a) inspired by lily leaves (b) (from [17]) .......... 5

Figure 5. Chemical structure of tetraethoxysilane (TEOS)..................................................... 7

Figure 6. Schematic of steady state sol-gel dip coating, from [27] ......................................... 8

Figure 7. Proposed structures of SiO2-PDMS hybrids for low (A) and high (B) PDMS content

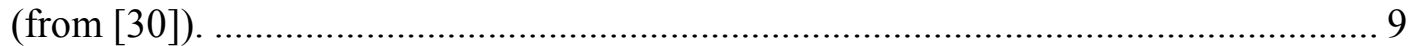

Figure 8. Structure of Solvay Fluorolink S10. $m / n=1.5-2.5,2<n<5$, and $5<m<9$, from [32] ... 10

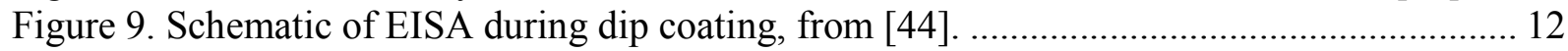

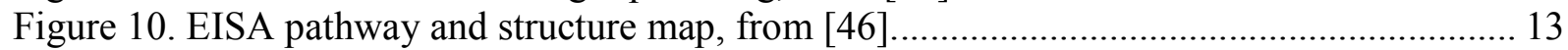

Figure 11. Ternary phase diagram for representative EISA systems, from [47] ...................... 14

Figure 12. Temporal structural evolution of EISA film, from [47] ....................................... 15

Figure 13. Synthesis pathways for functional mesoporous thin films, from [38] ..................... 16

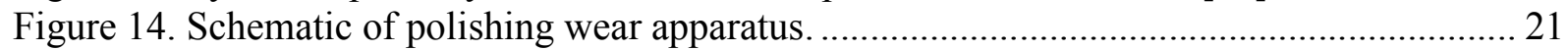

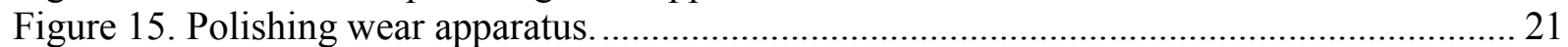

Figure 16. Unworn coating on glass slide (top) and worn coating (bottom). The bracket shows

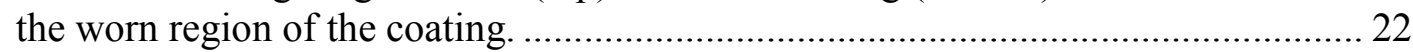

Figure 17. Chemical structure of Fluorolink S10, $m / n=1.5-2.5,2<n<5$, and $5<m<9$ [32] ......... 29

Figure 18. (a) Isothermal TGA at $200{ }^{\circ} \mathrm{C}$ of Pluronic F127, gelled FPES, and gelled functional sols of $x_{f}=0.04$ without F127 and with 10\% F127. Inset shows first few minutes of F127 scan. (b) TGA temperature scans of the same materials in (a) ........................ 33

Figure 19. (a) XPS depth profile of film with composition $x_{f}=0.04, x_{s}=0.08$. Inset shows sample C1s spectra from film surface (blue) and from bulk (red). Atomic concentration ratios, (b) F/Si and (c) C/Si, determined by XPS depth profiling for various compositions synthesized.

Figure 20. (a) Nitrogen adsorption-desorption isotherms on calcined films synthesized with different fluorosilane and surfactant concentrations. (b) BJH pore size distributions of calcined films synthesized with different fluorosilane and surfactant concentrations.

Figure 21. (a) Porosity fraction and average pore diameter of calcined films synthesized with $x_{f}$ $=0.04$ and various surfactant concentrations. (b) Porosity fraction and average pore diameter of calcined films synthesized with $x_{f}=0.02$ and various surfactant concentrations.

Figure 22. TEM micrographs of films with composition $x_{f}=4 / x_{s}=10 \%$. (a) shows film cured at $200{ }^{\circ} \mathrm{C}$ for 3 hours, and (b) a film cured at $400^{\circ} \mathrm{C}$ for 24 hours. Both scale bars $=20$ nm.

Figure 23. (a) Contact angle of water as a function of normalized penetration depth into coating after abrasion for films synthesized with different surfactant concentrations (shown in legend) and $x_{f}=0.04$. (b) Average contact angle of water and $n$-hexadecane measured 
on worn subsurface areas for compositions with various FPES and surfactant concentrations.

Figure 24. (a) Total surface energy of pristine top surface and worn and exposed subsurface areas for compositions with various FPES and surfactant concentrations. (a) Polar and dispersive components of surface energies shown in (a).

Figure 25. Average contact angle of water measured on subsurface areas of coatings that have been exposed by abrasion. Data are shown for films with various fluorosilane concentrations both with and without surfactant template.

Figure 26. Optical transmission of templated and non-templated coatings on glass synthesized with fluorosilane concentrations: (a) 0.02 , (b) 0.03 , (c) 0.04 , and (d) 0.05 .

Figure 27. (a) Nitrogen adsorption-desorption isotherms and (b) BJH pore size distributions of calcined films synthesized with different fluorosilane concentrations both with and without surfactant template. (c) Porosity fraction and (d) average pore diameter of calcined films synthesized with different fluorosilane concentrations both with and without surfactant template.

Figure 28. Nanoindentation (a) hardness and (b) elastic modulus of films synthesized with different fluorosilane concentrations both with and without surfactant template....... 53

Figure 29. Optical micrographs (a) of film with composition F4S8 worn for $100 \mathrm{~m}$, and (b) film with composition F5S8 worn for $20 \mathrm{~m}$. Sliding direction of wear for both micrographs is from bottom left to top right. Scale bars are $100 \mu \mathrm{m}$.

Figure 30. Wear rate of films synthesized with different fluorosilane concentrations both with and without surfactant template. .

Figure 31. Relative friction coefficients of subsurface areas of coatings that have been exposed by abrasion. Friction was measured using AFM with a Si tip scanning at a speed of 10 $\mu \mathrm{m} / \mathrm{s}$.

Figure 32. Topographic and friction force micrographs captured by AFM of partially worn films. Sliding direction of wear for all micrographs is from top left to bottom right, and all films were worn for $20 \mathrm{~m}$ sliding distance. (a) Topography of film with composition F2S0, scan size: $8 \mu \mathrm{m} \times 8 \mu \mathrm{m}$, vertical topography range: $50 \mathrm{~nm}$. (b) Simultaneous friction force map of film in (a), vertical range $=0.20 \mathrm{~V}$. (c) Topography of film with composition F2S0, scan size: $2 \mu \mathrm{m}$ x $2 \mu \mathrm{m}$, vertical topography range: $35 \mathrm{~nm}$. (d) Simultaneous friction force map of film in (c), vertical range $=0.18 \mathrm{~V}$. 57

Figure 33. Topographic and friction force micrographs of captured by AFM of partially worn film. Sliding direction of wear for both micrographs is from top left to bottom right, and films were worn for $20 \mathrm{~m}$ sliding distance. (a) Topography of film with composition F3S0, scan size: $2 \mu \mathrm{m}$ x $2 \mu \mathrm{m}$, vertical topography range: $25 \mathrm{~nm}$. (b) Simultaneous friction force map of film in (a), vertical range $=0.12 \mathrm{~V}$.

Figure 34. Topographic and friction force micrographs captured by AFM of partially worn films. Sliding direction of wear for all micrographs is from top left to bottom right, and all films were worn for $20 \mathrm{~m}$ sliding distance. (a) Topography of film with composition F4S0, scan size: $2 \mu \mathrm{m}$ x $2 \mu \mathrm{m}$, vertical topography range: $30 \mathrm{~nm}$. (b) Simultaneous friction force map of film in (a), vertical range $=0.15 \mathrm{~V}$. (c) Topography of film with composition F4S8, scan size: $2 \mu \mathrm{m}$ x $2 \mu \mathrm{m}$, vertical topography range: $5 \mathrm{~nm}$. (d) Simultaneous friction force map of film in (a), vertical range $=0.04 \mathrm{~V}$.

Figure 35. Topographic and friction force micrographs of captured by AFM of partially worn film. Sliding direction of wear for both micrographs is from top left to bottom right, 
and films were worn for $20 \mathrm{~m}$ sliding distance. (a) Topography of film with composition F4S8, scan size: $0.5 \mu \mathrm{m} \times 0.5 \mu \mathrm{m}$, vertical topography range: $4 \mathrm{~nm}$. (b) Simultaneous friction force map of film in (c), vertical range $=0.03 \mathrm{~V}$.

Figure 36. a) Compilation of bulk contact angle of water versus $\mathrm{F} / \mathrm{Si}$ atomic ratio for all compositions synthesized. Line is linear best fit to the data. (b) Compilation of wear rate versus $\mathrm{F} / \mathrm{Si}$ atomic ratio for all compositions synthesized.

Figure 37. Contact angle of water on virgin and abraded films and film thickness versus concentration of surfactant template added.

Figure 38. (a)-(d) Topographic and friction force micrographs captured by AFM of partially worn film with composition $x_{s}=8 \%$. (a) and (b) are scans of topography and friction, respectively (scan size: $2 \mu \mathrm{m} \times 2 \mu \mathrm{m}$; scan speed: $10 \mu \mathrm{m} / \mathrm{s}$; applied load: $20 \mathrm{nN}$; vertical topography range: $7 \mathrm{~nm}$ ). (c) and (d) are scans of topography and friction, respectively, of the same film shown (a) and (b) (scan size: $0.5 \mu \mathrm{m} \times 0.5 \mu \mathrm{m}$; scan speed: $10 \mu \mathrm{m} / \mathrm{s}$; applied load: $20 \mathrm{nN}$ ). (e) and (f) show topographic and friction force micrographs of a virgin monolayer (scan size: $0.5 \mu \mathrm{m} \times 0.5 \mu \mathrm{m}$; scan speed: $10 \mu \mathrm{m} / \mathrm{s}$; applied load: $20 \mathrm{nN}$; vertical topography range: $0.35 \mathrm{~nm}$ ).................................. 70

Figure 39. Roughness (rms) of functional films after abrasion by $0.3 \mu \mathrm{m}$ alumina slurry........... 71

Figure 40. XPS spectra of F1s levels taken from top surface and sputtered, subsurface samples from films with (a) $x_{s}=0 \%$ and (b) $x_{s}=8 \%$.

Figure 41. A schematic view of a template and internally functional film with intact top surface layer and after removal of the top layer.

Figure 42. (a) Nitrogen adsorption-desorption isotherms on calcined films synthesized with different surfactant concentrations. (b) BJH pore size distributions of the same films.

Figure 43. (a) Approach and retract force-distance curves, normal load $=5 \mathrm{nN}$. (b) Adhesive forces between an AFM tip and surfaces of glass, FPES monolayer, and abraded surfaces of mesostructured fluorinated and non-fluorinated silica films at $45 \% \mathrm{RH}$, normal load $=5 \mathrm{nN}$.

Figure 44. Friction force microscopy data from $500 \mathrm{~nm} \times 500 \mathrm{~nm}$ scans at a speed of $10 \mu \mathrm{m} / \mathrm{s}$. Specimens were bare glass, subsurfaces of mesostructures fluorinated films, a FPES monolayer, and a templated non-functional film. (a) Friction signal versus normal load curves, and (b) relative friction coefficients normalized to the friction coefficient of bare glass.

Figure 45. Friction force versus tip velocity for subsurface regions of a non-templated film, a templated film, the FPES monolayer on top of a virgin templated film, and a calcined surface re-functionalized with a FPES monolayer. Applied load $=20 \mathrm{nN}$. 


\section{General introduction}

In this project, I developed a sol-gel derived silica film with hydrophobic-oleophobic functional cellular mesostructure that provides needed durability through sustained functionality. Currently, no techniques have been established which adequately address the need for substantially durable functional coating materials. Sustained functionality is accomplished by creating an internally functionalized cellular mesostructure within a hard ceramic film. The mesostructure, in the form of pores with diameters of several nanometers, allows exposed surfaces to be sacrificially worn away while maintaining a high degree of the original functionality. To illustrate the concept, Figure 1 shows a schematic of a hydrophobic film maintaining its functionality even though it has been partially worn.
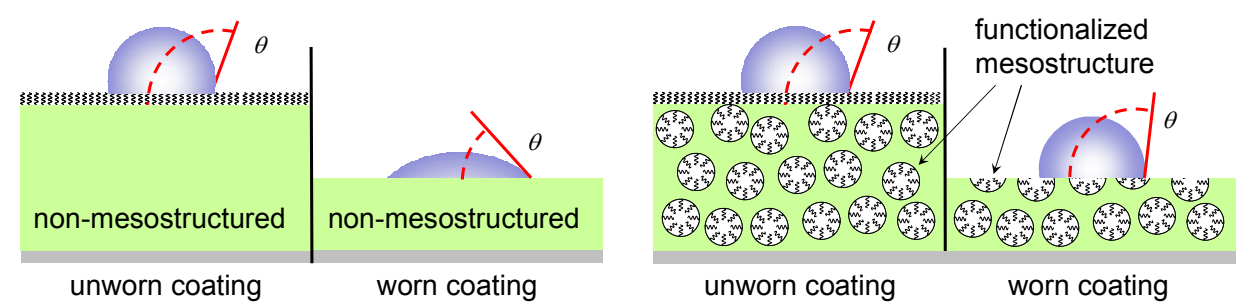

Figure 1. Cellular mesostructure preserves functionality of worn surface.

The film matrix material was a silica organic-inorganic hybrid formed by hydrolysis and condensation of tetraethoxysilane in alcohol, water, and hydrochloric acid. This matrix material has good mechanical properties, thermal stability, and optical transparency, which enables multiple potential applications. Sol-gel synthesis provides for flexible processing and tailoring for specific applications, such as for deposition on metallic, polymeric, or ceramic substrates. A surfactant template was used to fabricate the specific cellular mesostructure. Templating was accomplished by the technique of evaporation induced self assembly and co-condensation of fluorinated functional silanes around micellar pores. This technique has been demonstrated to yield predictable, reliable results for functionalization of internal surfaces. The concentrations of fluorinated silane and templating surfactant were the primary variables in this investigation. Various analytical techniques were used to determine the mechanisms behind functional durability and how it relates to the composition, processing, and structure of the material. 
Ultimately, the composition of the fabricated material is nearly identical to current state of the art. The issue was one of manipulating the processing to achieve a unique, tailored structure that greatly improves material performance. In addition to non-wetting, other applications may benefit from sustained functionality, such as anti-corrosive, anti-icing, and anti-microbial coatings - all of which depend on specific interactions between an exposed solid surface and the environment. 


\section{General background}

As outlined in the introduction, the goal of this research activity was to develop a durable hydrophobic-oleophobic coating. This is possibly by using a sol-gel silica hybrid material, templated to produce pores, which are functionalized internally using a fluorinated organosilane. This general background section introduces these various fields and provides a review of literature that relates to the proposed research.

\subsection{Hydrophobic-oleophobic materials}

Hydrophobicity and oleophobicity are terms used to describe the resistance of a solid material to wetting by, respectively, water/polar molecules and oil/non-polar molecules. There are many reasons why these might be desirable properties, since this non-wetting influences how the solid interacts with other solids as well in terms of friction and adhesion forces, which are generally low in both cases. There are a wide variety of applications for materials with hydrophobic or oleophobic properties, or both. Furthermore, it is of great interest to be able to apply a thin film of such materials as coatings on larger bulk substrates. The thin film is then said to afford a specific functionality to the substrate. Non-wetting, easily-cleaned coating materials are beneficial for a wide range of applications, including solar panels [1-3]; architectural structures [4]; optical displays and touch panels; textiles [5]; and industrial/anti-fouling [6], automotive, and household applications [5,7]. Non-wetting is a form of chemical repellency that prevents build-up of contaminants that impede the ability of the substrate to function and may even damage it.

Relative wetting behavior is a function of interacting intermolecular forces of adhesion and cohesion between molecules in a solid, liquid, and vapor triphase system. The Young equation relates these forces as:

$$
\gamma_{S V}=\gamma_{S L}+\gamma_{L V} \cdot \cos \theta
$$


Where:

$\gamma=$ surface free energies at the interface of the three solid-liquid-vapor interfaces

$\theta=$ contact angle (CA) formed at the intersection of the three phases [8]

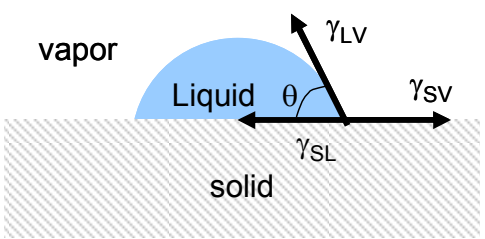

Figure 2. Contact angle of liquid drop on solid surface.

Figure 2 shows a schematic of this system. The contact angle (CA) is easily measured macroscopically. A CA of $0^{\circ}$ corresponds to complete wetting and $180^{\circ}$ to perfect non-wetting. The terms hydrophobicity and oleophobicity do not refer to specific contact angles, but rather are relative terms with which specific contact angles may be compared [9]. That is, one surface may be more hydrophobic than another, but the term hydrophobic does not specify a specific contact angle. Nonetheless, hydrophobicity is popularly accepted as $\mathrm{CA}>90^{\circ}$ for water. Oleophobicity is even more loosely defined, and there is no generally accepted minimum CA. The most common oils for measuring oleophobicity are n-hexadecane and oleic acid [10-13]. CAs for these oils are usually substantially lower than those of water since these fluids have lower surface energies and thus wet more easily.

Regarding the materials used to impart non-wetting properties, hydrophobicity is a relatively easy state to achieve, since many nonpolar materials may be used, including many common polymers such as polyethylene, polydimethylsiloxane, and the like [14]. However, oleophobicity is more difficult, owing to the inherently lower surface energies of organics. Consequently, fluorinated materials are the only ones commonly available that exhibit sufficient oil-repellency. Polytetrafluoroethylene (PTFE) is the most widely used fluoropolymer, although there are many others as well [7].

Superhydrophobicity refers to an apparent CA $>150^{\circ}$ for water [14]; although high apparent CAs for oils are achievable, they are much less common [15] (collectively they are known as 
ultraphobic materials). The CA is called "apparent" because it does not represent the true CA for a corresponding flat surface material. Extremely high apparent CAs are only possibly by making a micro- or meso-scale textured or composite surface that either creates entrapped air pockets for liquid drops to sit on instead of wetting the entire surface or entraps drops to confined areas [16]. These states are referred to as Cassie-Baxter and Wenzel states, respectively, and are shown schematically in Figure 3.
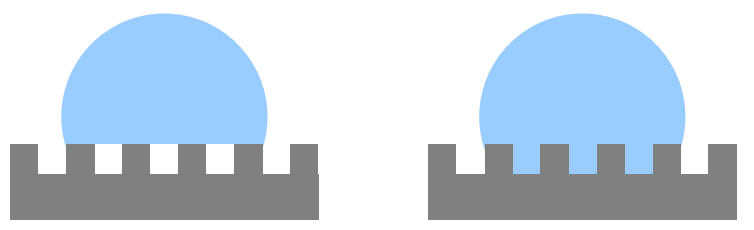

Figure 3. Superhydrophobic surfaces. Left, Cassie-Baxter state of drop suspended over vapor pockets; right, Wenzel state of drop entrapped by surface asperities.

The study of super-repellent surfaces is more a matter of engineering surface morphology and topography than it is a matter of engineering specific surface chemistry [14]. Figure 4 shows an example of such surface engineering and how it is biomimetic, having been inspired by the surface microstructure of lotus and lily leaves [17]. The pillars shown in Figure 4(a) were fabricated by soft lithography of sol-gel silica followed by functionalization with fluorinated silanes. In general, such features may be formed by a variety of additive or subtractive processes, either by lithography or self-assembly $[14,16]$.

a)
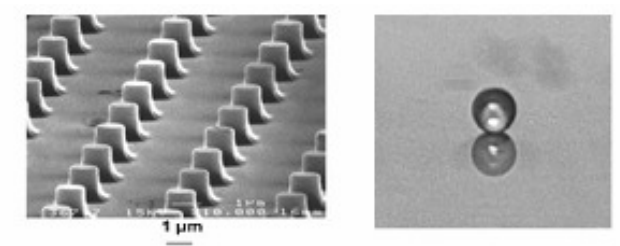

b)
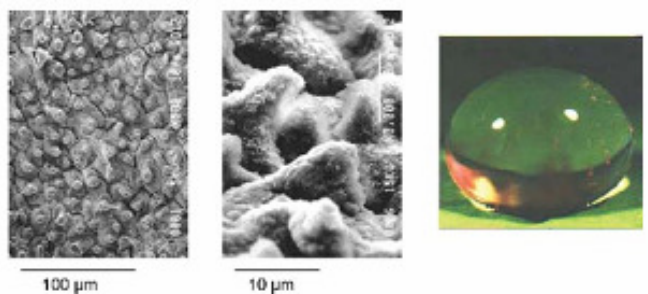

Figure 4. Artificial super hydrophobic coatings (a) inspired by lily leaves (b) (from [17]). 
However, conventional hydrophobic-oleophobic and ultraphobic materials and surfaces suffer from low mechanical strength and low abrasion resistance. The weakness of PTFE, the most widely used hydrophobic-oleophobic material, is compounded by its low adhesive strength to substrates [18]. Engineered microstructured surfaces such as those shown in Figure 4 are notoriously fragile and lack adequate durability. To compound the problem, the damaged surfaces are often rendered even worse (more hydrophilic and easily wetted or soiled) than they were before functionalization [19].

To overcome these deficiencies, many researchers have turned to using sol-gel methods to apply a fluorinated organic monolayer to solid substrates or as monolayers atop hardened films, such as those reported by Yoneda [20] and Giessler [21]. These can perform better than bulk fluoropolymers owing to the strong Si-O film-substrate bond accomplished by sol-gel chemistry. Sol-gel furthermore allows for high thermal stability and optical transparency [22]. During film deposition the fluorinated organosilane moieties, which impart the low-energy surface, align at the solid-air interface because of their chemical nature - it is this very repellency that makes them useful [23]. This surface stratification makes it difficult to incorporate the functional moieties into the bulk, so they reside in a molecularly-thin region at the air interface. Although the chemical bond to the substrate is strong, the material as a functional coating still lacks functional durability because the surface monolayer is easily worn.

Some interesting methods have been employed by other researchers to combat this inherent difficulty, such as by Hong et al. and Cui et al. [24,25] where a textured surface was used to create mountains that protect functionalized valley areas from abrasive wear. Nonetheless, surface alignment and stratification is inevitable and abrasive wear still had a large and immediate impact on surface functionality. Furthermore, the materials developed by Hong and Cui are not inherently more durable since their functional durability depends on substrate pretreatment, not on the coating composition or microstructure. It would be advantageous to develop a coating formulation that would work independently of the substrate condition since it is not always possible or desired to texture the substrate surface. 


\subsection{Sol-gel silica and hybrids}

As mentioned in section 2.1, films based on silica sol-gel synthesis are widely used as matrix materials for hydrophobic-oleophobic films owing to their strong mechanical properties, thermal stability, flexible chemistry, and optical transparency [22]. As summarized in the handbook by Wright and Sommerdijk [26], sol-gel synthesis is also popular for its relatively mild processing conditions (near room temperature and pressure), low ionic strength acidity/basicity, and especially in the case of silicon-based chemistry, convenient operating times. Furthermore, composition and structure may be controlled precisely, enabling high-purity products, and application to large three-dimensional objects is easily achieved by conventional low-cost coating methods such as spinning, dipping, and spraying. Some disadvantages of sol-gel processing are the potentially high cost of raw materials and the difficulty of casting large monoliths - sol-gel is generally used only for thin films and colloidal powders. [26]

The fundamental chemical reactions for sol-gel synthesis are (reverse reactions in parenthesis):

$$
\begin{array}{lll}
\text { Hydrolysis (reesterification): } & \equiv \mathrm{Si}-\mathrm{OR}+\mathrm{HOH} \rightleftharpoons \equiv \mathrm{Si}-\mathrm{OH}+\mathrm{ROH} & \text { Equation 2 } \\
\text { Water condensation (hydrolysis): } & \equiv \mathrm{Si}-\mathrm{OH}+\mathrm{Si}-\mathrm{OH} \rightleftharpoons \equiv \mathrm{Si}-\mathrm{O}-\mathrm{Si} \equiv+\mathrm{HOH} & \text { Equation 3 } \\
\text { Alcohol condensation (alcholosis): } & \equiv \mathrm{Si}-\mathrm{OH}+\equiv \mathrm{Si}-\mathrm{OR} \rightleftharpoons \equiv \mathrm{Si}-\mathrm{O}-\mathrm{Si} \equiv+\mathrm{ROH} & \text { Equation } 4
\end{array}
$$

The Si-OR molecule is termed the alkoxide precursor, and the $R$ group is an organic component, usually a short alkane of 1-4 carbon molecules in length. One common alkoxide precursor is tetraethoxysilane (TEOS), having the structure

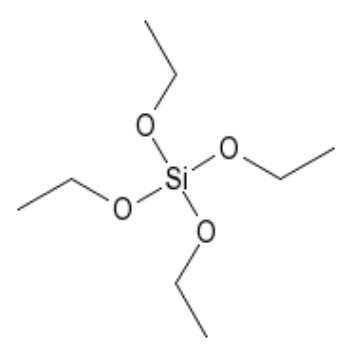

Figure 5. Chemical structure of tetraethoxysilane (TEOS). 
The reactions are catalyzed by either acidic or basic conditions, which result in products of films or powders, respectively, based on the particular reaction mechanisms. In the case of acidic conditions, the rate of condensation is rapid, so the monovalent silicic acid product of Equation 2 rapidly reacts with another like molecule in Equation 3 to form long polymeric chains. Under basic conditions, the rate of hydrolysis is rapid, forming a tetravalent silicic acid product in Equation 2. Subsequent condensation yields dense clusters which grow to form colloidal particles. Once the reaction proceeds over a large volume, the system gels. Residual solvent can then be removed, and the solid may be further densified by calcination and thermal decomposition of organics. When dip coating using acidic conditions to form films, the reacting molecules are driven into close proximity by solvent evaporation, and gelation proceeds at the liquid-substrate meniscus to form a xerogel film. Figure 6 shows a schematic of the steady state sol-gel dip coating process. The structure develops through draining, solvent evaporation, and continuous condensation reactions that are accelerated by solvent losses. [27]

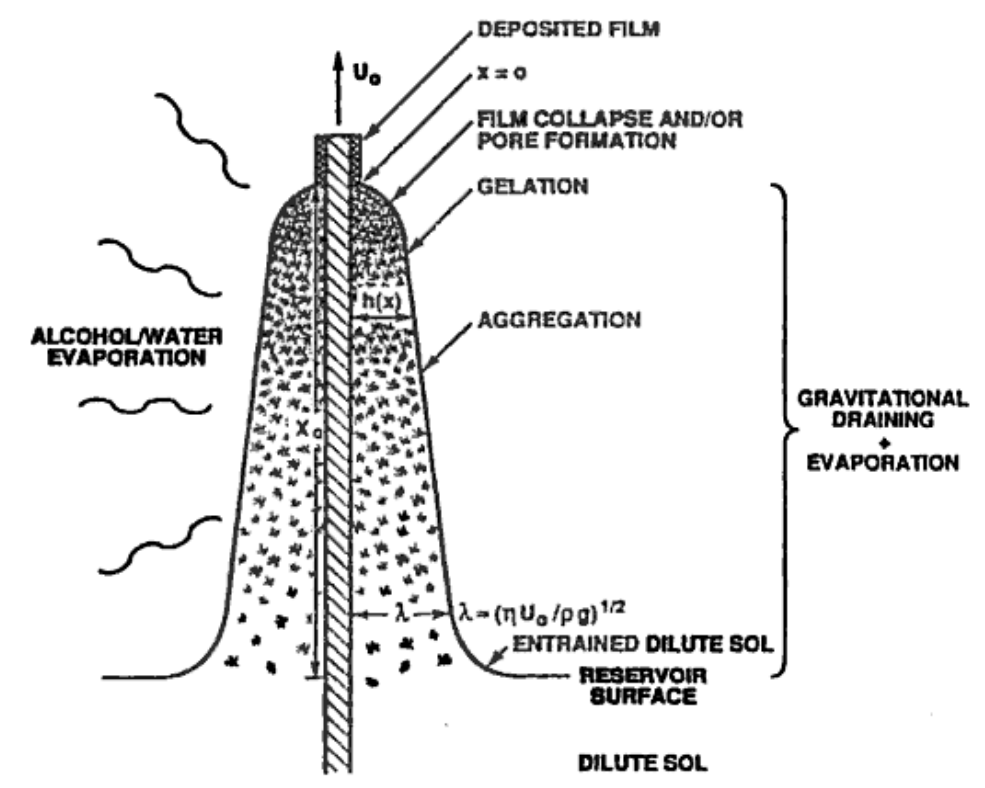

Figure 6. Schematic of steady state sol-gel dip coating, from [27].

The final product of a sol-gel derived silica film is an amorphous network of stoichiometric $\mathrm{SiO}_{2}$. The microstucture is porous owing to the spaces originally filled by unreacted alkoxides and solvent, and therefore the mechanical properties of hardness and elastic modulus are not as high as they are for fully densified silica glass. Thermal processing in the range of $200-800^{\circ} \mathrm{C}$ 
collapses the porous network to provide a material with density approaching that of conventional silica glass.

In the mid 1980s, sol-gel derived inorganic-organic silica-organic polymer hybrids were first combined to form composites with properties intermediate to those of conventional ceramics and polymers $[28,29]$. Essentially this amounts to manipulation of one or more of the side groups on the tetravalent alkoxide precursor in Equation 2. The -OR alkoxy groups participates in hydrolysis, but when the same $R$ is bound to the Si without the esteric oxygen, it does not undergo hydrolysis. If $R$ is a long polymer chain terminated on both ends with silanol groups, then the polymer can become chemically bound to the surrounding and encapsulating silica matrix and thus form a meso-scale composite.

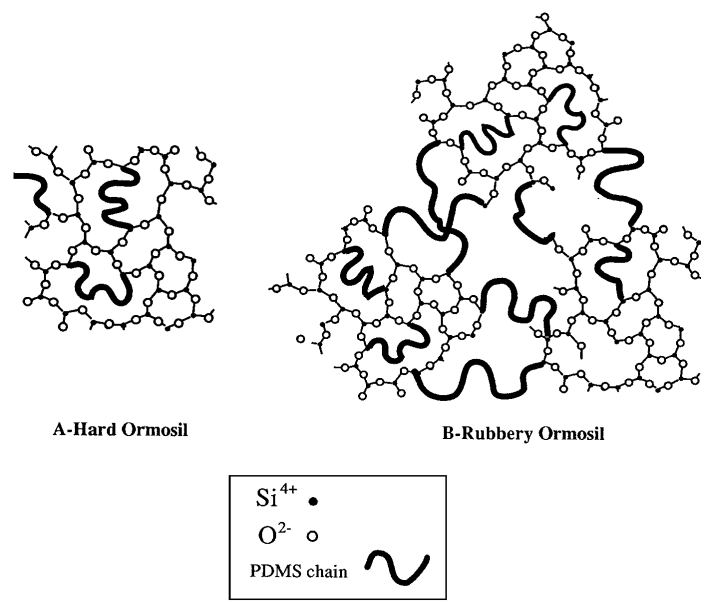

Figure 7. Proposed structures of SiO2-PDMS hybrids for low (A) and high (B) PDMS content (from [30]).

Figure 7 shows a schematic example of such a composite on the molecular scale [30]. In terms of mechanical properties, the bulk material becomes more polymer-like as the concentration and length of the polymer chains are increased. This approach is attractive because the properties are easily tunable by adjusting relative concentrations.

Alternatively, if the $R$ groups are silanol-terminated only on one end and are unreactive at the other, they act as silica network terminators. This function imparts flexibility to the otherwise rigid silica network and is a useful means of preventing excessive build-up of destructive internal 
film stresses which can cause cracking. The incorporation of organics into the otherwise ceramic material can enhance functionality, but it does limit the type of environmental exposure that the materials can experience before degrading. Particularly, organic components degrade at higher temperatures, so sol-gel silica hybrids are usually processed well below $400^{\circ} \mathrm{C}$ [31].

\subsection{Surface functionalization of sol-gel silica}

Functionalization is an extension of the sol-gel silica hybrid class of materials described in the previous sections. Functionalization entails using an organic $R$ group with a specific function, such as hydrophobicity or oleophobicity. The general structure for functional silanes is $\mathrm{R}_{x} \mathrm{Si}(\mathrm{OR})_{3-x}$ where $R$ is the functional moiety and $O R^{\prime}$ participates in hydrolysis and condensation. The product Fluorolink S10, which was used in this study, has the structure shown in Figure 8 and an average molecular weight of $1850 \mathrm{~g} / \mathrm{mol}$.

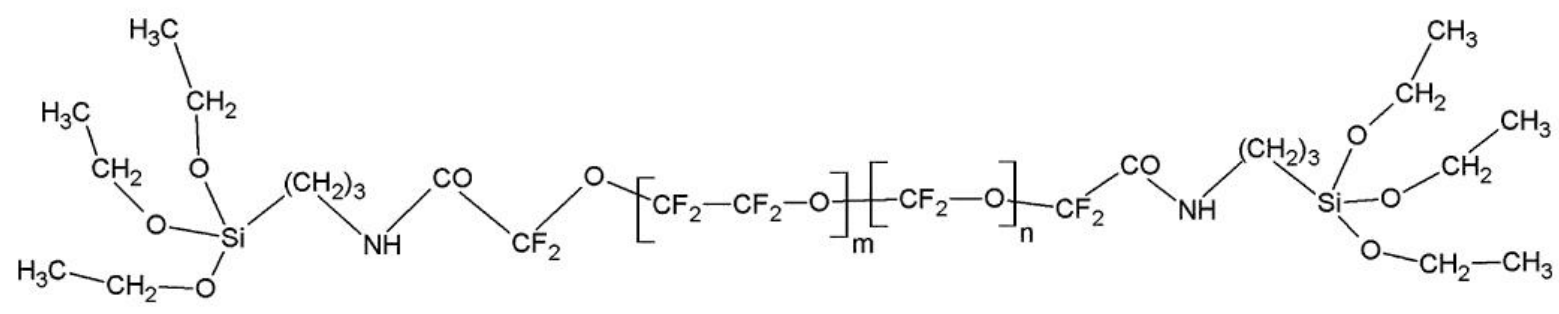

Figure 8. Structure of Solvay Fluorolink S10. $m / n=1.5-2.5,2<n<5$, and $5<m<9$, from [32].

$\mathrm{R}_{x} \mathrm{Si}(\mathrm{OR})_{3-x}$ type molecules may bind to each other or a Si-OH surface via hydrolysis and condensation. When surface-bound they form self-assembled monolayer films [33]. The choice of perfluoropolyether silane was made in order to present the best possible surface for nonwetting properties. Fluorolink S10 has a fairly large molecular weight and two silane grafting end groups. Longer functional molecules have been shown to increase the hydropobic/oleophobic character of films [34,35], and the two grafted ends increases its resistance to mechanical removal from the matrix [32]. Additionally, interchain hydrogen bonding between amide moieties has been found to enhance monolayer stability $[36,37]$.

There are generally two routes towards achieving functionalized silica surfaces by sol-gel processing [38]: 
1. Post-functionalization: Also known as "post-synthesis grafting." First, the silica film is deposited, followed by high temperature calcination, which removes organics and densifies the structure. In a second step, the functional silane is reacted to the surface. Postfunctionalization allows for high mechanical strength in the silica film since thermal processing is not limited by organic degradation. However, the silica surface must be in the correct chemical state for functionalization by silanes. This method involves multiple steps and is generally only effective at functionalizing the outer surface as opposed to internal pores. $[39,40]$.

2. Pre-functionalization: The alkoxide precursors, both functional and non-functional, are mixed together in one-pot co-condensation and deposited in a single step. Prefunctionalization (co-condensation) is more streamlined and allows for the functional moieties to be intimately mixed with the matrix and more completely saturate the surface. As mentioned above, the incorporation of organics limits thermal processing, and so mechanical properties may suffer. Nonetheless, the organic nature of these functional moieties allows for a myriad of potential combinations and applications. [40], [41]

\subsection{Supramolecular templating of sol-gel silica}

Silica material synthesized via sol-gel processing is inherently amorphous. Specific mesoscale geometry (features on the order of 2-50 $\mathrm{nm}$ in size) may be imparted by the use of a supramolecular templating technique. Supramolecular templating may be used in either film or particle synthesis. Also known as surfactant or liquid-crystal templating, this technique uses bottom-up self assembly processes to form soft structures which template the growth of hard solgel silica. Amphiphilic molecules or surfactants in aqueous solutions above the critical micelle concentration (CMC) form higher-order multi-molecular structures or phases such as micelles, lamellae, hexagonal cylinders, and reverse micelles depending on temperature, concentration, and the specific chemical species. A silica sol which gels either in or around the surfactant phases will be imparted with a complementary structure. Essentially, the synthesis is dynamic with soft micelles forming a scaffold for densification of hard silica structures. This method was first reported by researchers at Mobil who used it to synthesize highly porous particles that were 
envisioned as molecular sieves for catalysis and separations applications. They reported the formation of close-packed hexagonal arrays of pores $[42,43]$.

\subsubsection{Mesoporous thin films and evaporation induced self assembly}

The extension of this technique to the formation of mesoporous thin films (MTF) is known as evaporation induced self assembly (EISA) since evaporation of the solvent rapidly concentrates the surfactant in situ with the gelation process $[44,45]$. The process is complex and requires an understanding of the thermodynamics and kinetics involved. The following figures illustrate this dynamic process from different perspectives.

Figure 9 is a good starting point, since it provides a graphical interpretation of film deposition by dip coating. At time $=0 \mathrm{~s}$, the substrate is immersed in the liquid, film thickness is at a maximum, and surfactant concentration is $<<\mathrm{CMC}$ so it exists in free form. Withdrawal of the substrate from solution begins the concentration process as solvents (alcohol and water) are evaporated, and the film contracts. At $\mathrm{t} \approx 4 \mathrm{~s}$, the $\mathrm{CMC}$ is reached and surfactant structuring begins, first with isotropic micelles and then with larger cylindrical conformations. At $10 \mathrm{~mm}$ above the reservoir, the film collapses to its minimum thickness and the solids are completely concentrated, resulting in a locking in of the supramolecular structure.

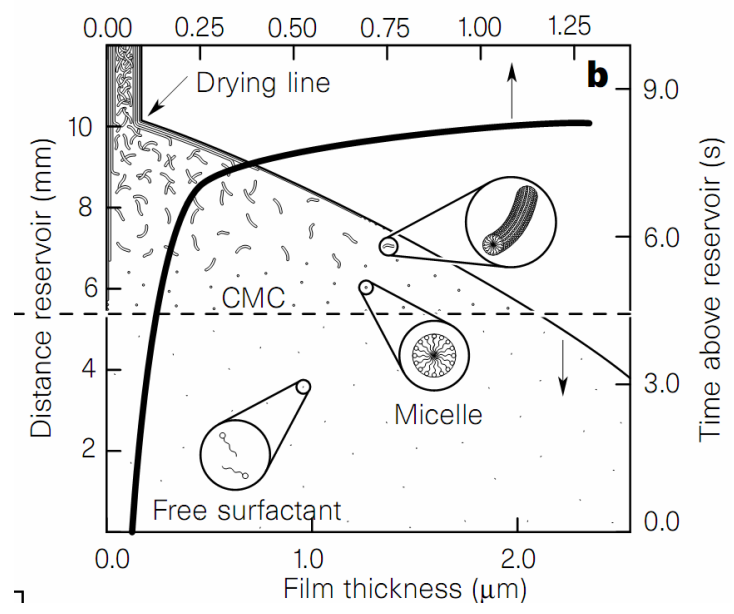

Figure 9. Schematic of EISA during dip coating, from [44]. 
Figure 10 shows two phase diagrams that describe the dynamic sequence shown in Figure 9 [46]. The quarternary diagram (a) includes all of the four components commonly found in such systems: water, ethanol, condensing silica, and the surfactant cetyltrimethylammonium bromide (CTAB). The dashed line indicates schematically the pathway likely taken from the starting point of wet film deposition to the end point of condensed film. There is an initial rapid loss of ethanol via evaporation, then a slower loss of water, also through evaporation. The loss of both these solvents concentrates the solids (silica and surfactant) towards the formation of supramolecular structures. The lower portion of the figure (b) illustrates a projection onto the ternary phase diagram, and shows in greater detail how the concentration of surfactant and water content affect the mesostructures obtainable.

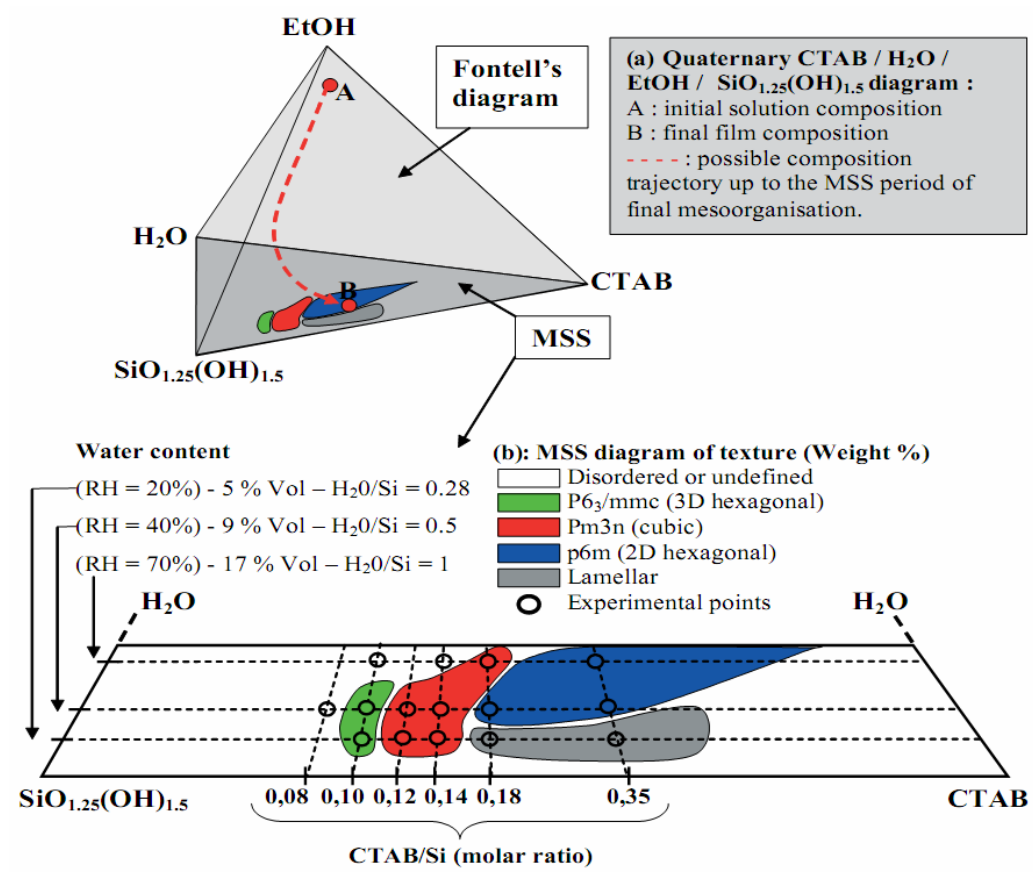

Figure 10. EISA pathway and structure map, from [46].

Figure 11 and Figure 12 show results of a set of experiments in which structure and composition of films were monitored in situ with the EISA process [47]. Grazing incidence small-angle X-ray scattering (GISAXS) combined with gravimetric analysis were used to obtain a quantitative description of the process. Figure 11 shows in detail the results of an experiment which observed in situ the EISA process. The pathway of Figure 10(a) is shown explicitly, and the system moves sequentially from being non-structured/non-ordered at $\mathrm{c}_{\mathrm{CTAB}}<\mathrm{CMC}$, to structured/non-ordered in 
the isotropic region, and finally to structured/ordered in the hexagonal region. Various starting concentrations of CTAB (molar ratio to Si precursor) were investigated, as well as the samples labeled "WS" meaning "without silica."

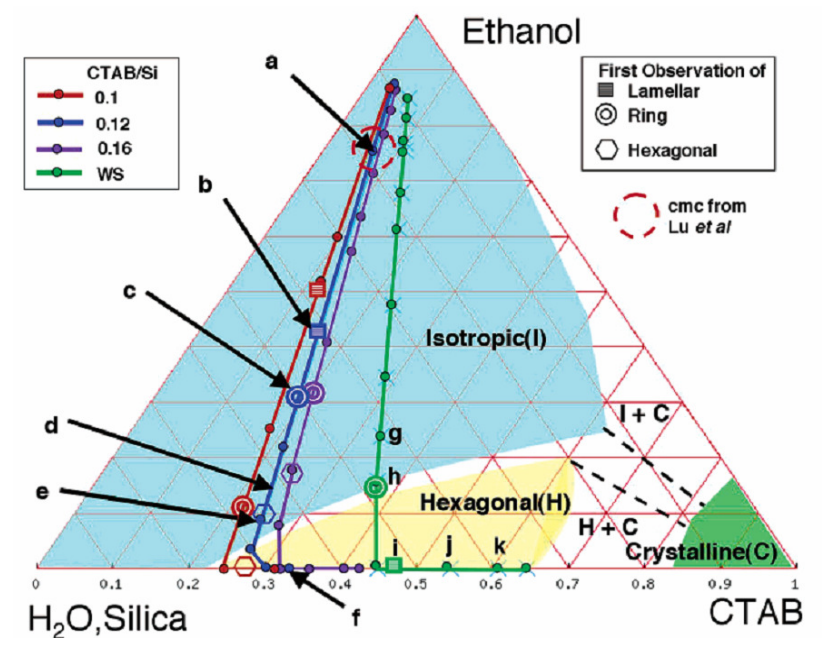

Figure 11. Ternary phase diagram for representative EISA systems, from [47].

Finally, Figure 12 shows in detail the structural evolution over time of one of the samples $(\mathrm{CTAB} / \mathrm{Si}=0.12)$, with the spacing of the ordered structures being detected by GISAXS [47]. Again, there is an initial rapid concentration from solvent evaporation, and then the structures progress through various stages, beginning with non-structured/non-ordered, structured/nonordered (isotropic, no order spacing detectable through GISAXS), and then three structured/ordered phases with structures quantified by GISAXS. 


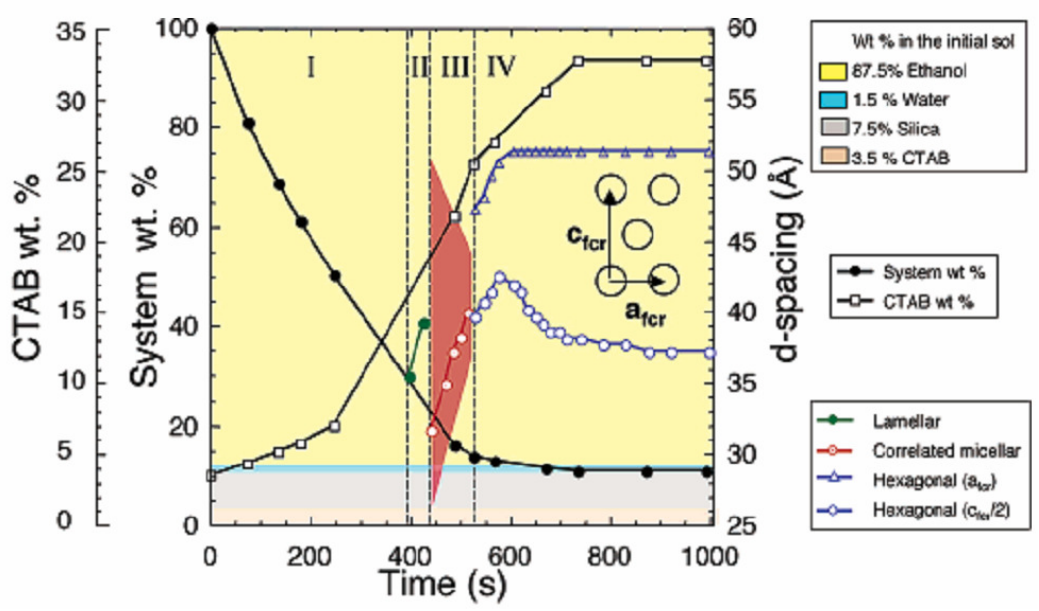

Figure 12. Temporal structural evolution of EISA film, from [47].

The kinetics of EISA has been described as a "race towards order" $[38,48]$. Organization via phase separation of amphiphillic molecules competes with viscous stiffening caused by alkoxide condensation during sol-gel film formation. If organization dominates, the result is highly structured, well ordered, and tightly packed pores; if the solution becomes too viscous before complete phase separation, then the intermediate structure becomes frozen in place and a disordered material is produced. Ordered mesopore structures usually occur at high surfactant concentrations [49] and low functional silane concentrations [50].

\subsubsection{Functionalized mesoporous thin films}

Supramolecular templating has been used in conjunction with surface functionalization to yield materials with internal functionality: functional mesoporous thin films (FMTFs). Applications for such materials are generally those in which high functional surface area are beneficial, namely in catalysis and separations. As in regular (outer solid-air interface) functionalization described in Section 2.3, functional moieties have been grafted by either grafting/postfunctionalization or pre-functionalization/co-condensation. Figure 13 shows a schematic of these synthesis pathways applied towards FMTFs. 


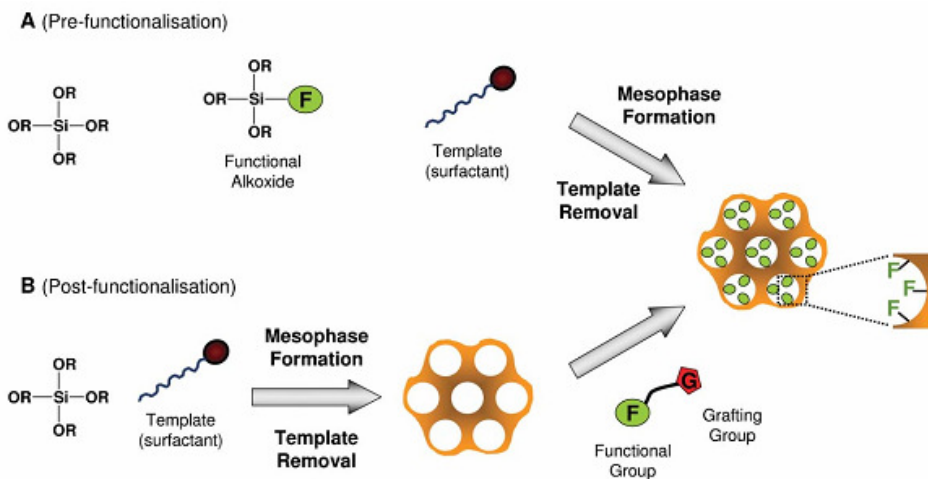

Figure 13. Synthesis pathways for functional mesoporous thin films, from [38].

Grafting has the advantage of allowing for high thermal treatment of the mesoporous material without fear of damage to organo-functional groups, which allows for a denser and stronger matrix. However, grafting suffers from being a multi-stage process, often leading to low loading, and concentration of functional groups around the outer edges of the xerogel (low permeation into interior). Co-condensation is in some ways complicated by the different reaction rates of the functional silanes to tetravalent precurors, possible interactions with the other amphiphilic molecules, and the limitation of thermal exposure posed by the organic components. Nonetheless, it has been recognized as the generally preferable approach towards fabrication of FMTFs because it generally leads to much more uniform entrapment of functionality in the interior surfaces, higher loading - up to around $25 \%$ of functional silanes, and its single-step deposition. $[38,48]$

\subsubsection{Fluorinated mesoporous thin films}

There is a small number of reports on the fluorine functionalization of mesoporous silica $[35,51$ 54]. Of these, some were concerned with synthesis of mesoporous particles only [51,52], which follows an entirely different templating mechanism (basic) than does synthesis of mesoporous films (acidic) [55]. Some of the works reporting synthesis of functionalized mesoporous materials achieved functionalization through vapor-phase grafting [51,54]. The two works by Bae, Jung, et al. $[35,53]$ are the only ones in which the synthesis of FMTFs via co-condensation with fluorinated silanes has been studied in detail. Bae, Jung, et al. have been concerned primarily with engineering low-dielectric constant materials, and to this end have focused on 
maximizing porosity. Consequently, they report the formation of highly porous, structured, and ordered materials. Since the proposed application for such materials is in integrated circuits and electronics packaging, the films need not be exceptionally robust. However, a functionalized surface coating exposed to more mechanical harsh environments needs to be examined more rigorously in terms of its mechanical properties and sustained tribological performance. Furthermore, it would be preferable to optimize the material to enhance its durability even at the cost of some functionality. This has not yet been investigated.

\subsubsection{Structure-Processing-Property Considerations}

As implied by the phase diagrams in section 2.4.1, the chemical composition of the sol-gel formulation has a profound effect on the resulting mesostructure. The major factor here is the surfactant concentration, often expressed as a molar ratio to the silane precursor. Although the relative concentrations of water and alcohol in the formulation affect structuring as well, this ratio is usually varied between approximately $0.1-0.3$ surfactant/Si. We should expect the same concentration-dependent structuring from non-ionic surfactants, and this is indeed the case [49,56-59]. However, the disordered phase structure seen at low concentrations of ionic surfactants like $\mathrm{CTAB}$ is generally seen to extend into higher concentrations of surfactant when using non-ionics. Non-ionic surfactants are available in a wide variety of configurations with essentially customizable chain lengths of hydrophobic and hydrophilic moieties, so their use introduces additional options and parameters for tailoring material properties. Two appealing aspects of templating with block copolymers (Pluronic types) are the variability of pore size as well as wall thickness, both of which may be expected to affect bulk film mechanical properties [49].

In addition to the type and concentration of surfactant, the effect of the $\mathrm{R}_{x} \mathrm{Si}(\mathrm{OR})_{3-x}$ functional silane cannot be overlooked [60]. Cagnol et al. introduced various types of functional silanes and found a general trend that as the functionality moves away from hydrophobicity towards hydrophilicity, pore size increased due to complex interactions between the organic moieties and surfactant [61]. Shimojimam et al. used alkyl-silanes of varying organic chain length (i.e., functionally equivalent) and found that feature size increased linearly with chain length [62]. 
This type of behavior was even seen when the functional silane is methyltriethoxysilane (MTES) which has only a single carbon atom as its functionality and is otherwise so structurally and functionally similar to TEOS. Jung et al. observed that porosity increased with MTES concentration and that higher concentrations of MTES ( $>25 \%)$ disturbed pore ordering [50]. Zhang et al. used an amino-functionalized silane and found that pore size and overall volume decreased with increasing functional content [63]. These results, which are, at first glance, opposite to those of [50], were explained as resulting from interactions between the basic aminosilanes and acid used to catalyze the sol-gel reactions.

The amphiphilic nature of many functional silanes has also been shown to affect structuring in ways complementary to the primary surfactant. Jung et al. reported that the presence of fluorinated silanes, which are extremely amphiphilic, enabled the formation of highly structured and ordered FMTFs at extremely low concentrations of surfactant - down to around 1/25 of the usual surfactant content needed for structuring [35]. Structuring has even been observed when no surfactants have been used at all, depending on the type of silane precursors being employed [64].

EISA process kinetics and the locking in of relative order or disorder are affected by other factors as well. Because the self assembly process is evaporation-induced, it may be expected that the evaporation rate of solvents affects structuring. The ambient water content (relative humidity) is of particular importance and has been shown to affect mesophase structuring [46].

Another factor that has been shown to affect structuring is the degree of aging of the silica sol. The sol-gel hydrolysis and condensation reactions result in nascent chains and clusters of silica that grow into nanoparticles. As the reactions proceed, the viscosity of the solution increases. If viscosity is very high, micelles may form but be unable to rearrange into a close packed formation and have only short-range order $[50,62,65]$. At the other extreme, if the sol is not sufficiently aged, there may be insufficient silica to form a continuous gel [62,65-68]. As indicated above in section 2.4.1, the stiffening effect of this viscosity increase is one of the key players in the "race towards order" of EISA. In the literature, the effect of sol particle size is often referred to as "aging." However, even aging is sometimes not explicit. Some researches 
instead investigate the effect of acid and/or solvent concentrations, both of which affect the rates of hydrolysis and condensation, and consequently, viscosity [62,63]. In any event, there exists an optimum aging time for structuring of surfactant-templated sol-gel FMTFs.

In addition to composition, film processing conditions can affect structuring. Processing can take the form of thermal calcinations, solvent washing, and ultraviolet light exposure. Processing is usually done to remove residual organics within the material - if a truly porous material is desired, the surfactant molecules must be removed [60]. These types of processing can profoundly affect the composition and mesostructure. In the range of temperature from room temperature to several hundreds of degrees Celsius, the organics (surfactants as well as organosilanes) can decompose, the silica matrix can densify and become harder, and the overall porosity can increase $[53,60,66,69]$. Although in this study actual free-space porosity is not critical, the mechanical properties are of critical importance.

Mechanical properties, most importantly the hardness, are affected by densification due to thermal processing as well as the effect of mesoporosity itself. Thermal processing increases hardness [69]. As porosity increased, hardness decreases [70,71]. Porosity itself, as well as supporting wall thickness and resulting mechanical properties, can depend on the type of surfactant being used for templating [72]. In addition, disordered structures have been found to be harder than ordered structures $[50,57]$.

\subsection{Experimental methods}

Various analytical techniques were used to determine the compositional, structural, chemical, and physical properties of synthesized materials.

\subsubsection{Reciprocating polishing testing}

In order to characterize the material functional properties as a function of abrasion through the coating depth, it is necessary to repeatedly remove a small amount of coating material and continually measure the surface properties. Mechanical polishing is one way of providing mild 
and gradual abrasion that does not immediately or abruptly penetrate through to the substrate like more severe testing (i.e., as through Taber abrasion) [73]. Measuring film thickness and liquid CAs on the film surface can then be used to monitor properties throughout the coating depth. Other experimental techniques provide information on other aspects of material properties and composition.

Polishing was done using a lab-built device. This device uses a vertically-loaded, conformal polishing surface to gradually wear through the surface of a film of thickness on the order of 1 $\mu \mathrm{m}$. The key experimental parameters for tribology, such as reciprocating speed, stroke length, and normal force, may be varied by changing motor and hardware settings. The values described here are conditions which roughly simulate the type of stresses experienced by optoelectronic devices during manual handling and cleaning.

The reciprocating polishing device (Figure 14 and Figure 15) is composed of a stepper motor (NM34A200, Zaber) controlling a reciprocating end effector with stroke length of $50.8 \mathrm{~mm}$ and speed of $0.1 \mathrm{~Hz}$. The end effector is a $25 \mathrm{~mm}$ wide section of aluminum rod of $76 \mathrm{~mm}$ diameter, has a total mass of $480 \mathrm{~g}$, and is allowed to float freely in the vertical direction. A cloth pad with nap thickness of approximately $0.8 \mathrm{~mm}$ (90-150-285, Allied) the same width as the end effector is adhered around the aluminum surface. The alumina particles in the polishing slurry becomes entrapped in the cloth, and the weight of the end effector, combined with its reciprocation action, provides the wearing action on a coating sample affixed in a pan below the end effector. This configuration results in a nominal contact area of $1.75 \mathrm{~cm}^{2}$ and $4.70 \mathrm{~N}$ normal force. The pan contains a pool or polishing slurry used for the duration of the test. The thick nap of the cloth conforms to any unevenness in the coating or substrate to generate a uniform wear pattern (Figure 16), which can be determined by mass loss or film thickness measurements. The circular design of the end effector allows it to be easily indexed slightly between each experiment to provide a fresh polishing cloth area. This can be done to minimize the effect of a worn counterface.

The polishing slurry is may be made with $50 \mathrm{~g}$ of either $50 \mathrm{~nm}$ or $300 \mathrm{~nm}$ de-agglomerated alumina (90-187015 and 90-187120, Allied) and $750 \mathrm{ml}$ of deionized water, stirred vigorously 
for $30 \mathrm{~min}$. This composition incorporates sufficient excess water to keep the alumina adequately wet for the duration of the polishing process.

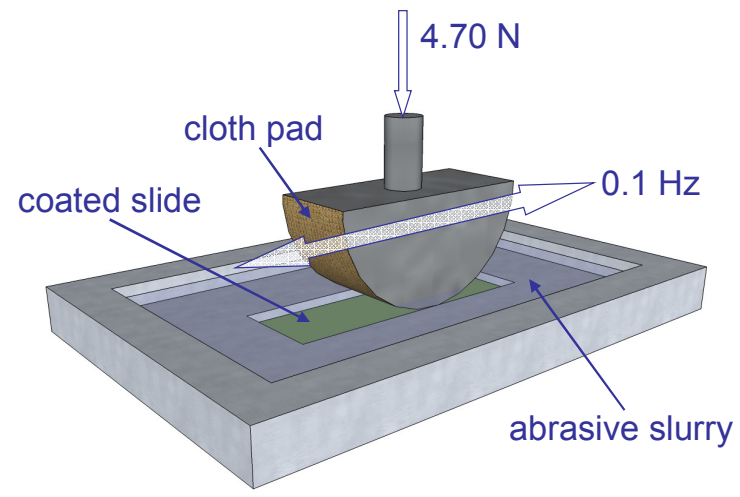

Figure 14. Schematic of polishing wear apparatus.

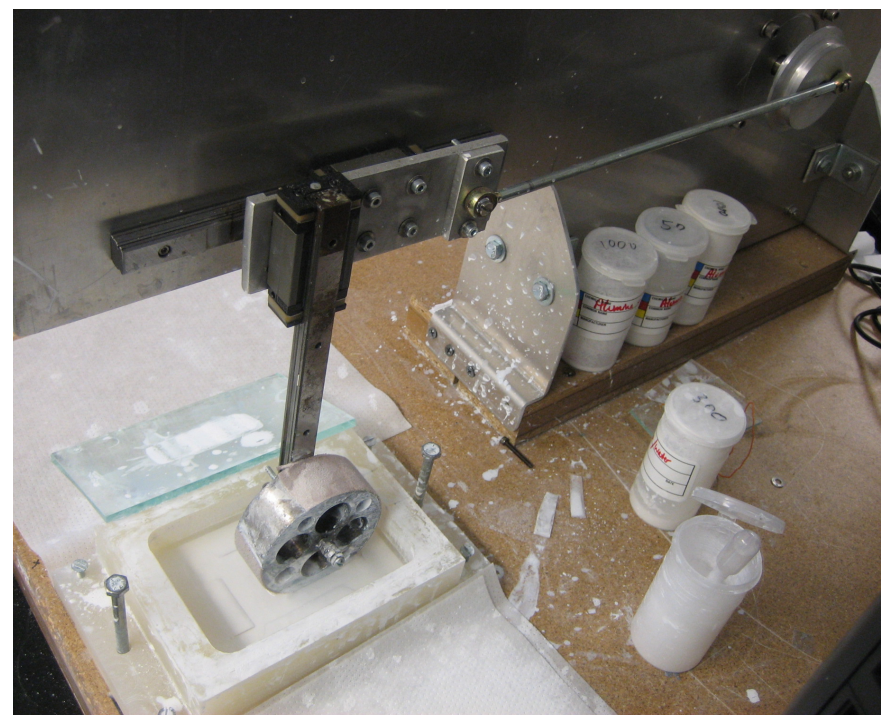

Figure 15. Polishing wear apparatus. 


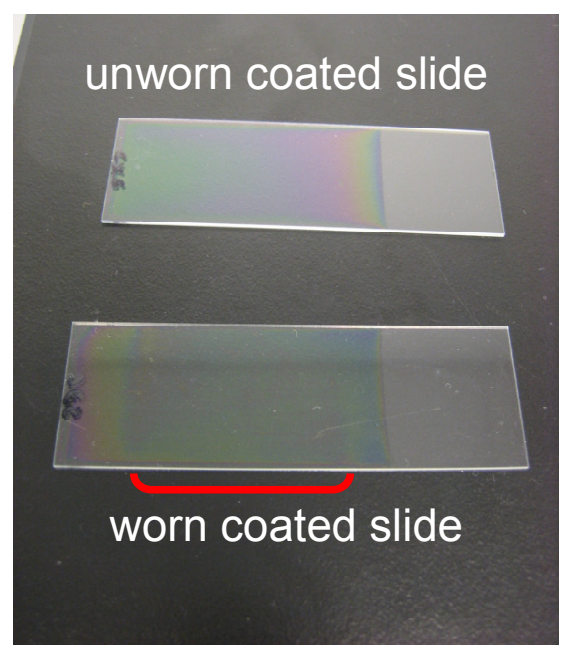

Figure 16. Unworn coating on glass slide (top) and worn coating (bottom). The bracket shows the worn region of the coating.

\subsubsection{Contact angle goniometry}

The hydrophobicity and oleophobicity of the coatings may be measured using a lab-built sessile drop CA goniometer. The test fluids are deionized water and n-hexadecane. A 1-2 $\mu$ l drop of fluid is used so that, when viewed horizontally, the drop shape may be approximated as an arc of a circle [74]. The CA between fluid and surface can then be calculated as the angle between the arc and coated slide surface. CA measurement are performed by digital image analysis using the LB-ADSA method in the "Drop Analysis" plugin [75] for ImageJ (NIH, USA).

\subsubsection{X-ray photoelectron spectroscopy}

X-ray photoelectron spectroscopy (XPS) was used to analyze chemical composition through depth profiling. XPS was conducted on an Physical Electronics PHI 5000 VersaProbe system. The X-ray beam was $100 \mu \mathrm{m}, 25 \mathrm{~W}$, and $15 \mathrm{kV}$, from an $\mathrm{Al} \mathrm{K \alpha}$ source with a photon energy of $1486.6 \mathrm{eV}$. Depth profiling was conducted by Ar sputtering a $2 \mathrm{~mm}$ square area at $4 \mathrm{kV}$ and 10 $\mu \mathrm{A}$. Samples were highly insulating, so charge neutralization was used was a $20 \mu \mathrm{A}$ emission, 1.30 V bias, and 30.0 V extractor voltage. Spectra were collected from F1s, C1s, and Si2p levels, with pass energy of $93 \mathrm{eV}$, energy step of $0.2 \mathrm{eV}$, and time/step of $50 \mathrm{~ms}$. Spectra were collected with multiple repeats and the data averaged. 


\subsubsection{X-ray diffraction}

X-ray diffraction (XRD) was used to quantify the degree of ordering of mesopores and the packing geometry. XRD was conducted on a Bruker D8 Discover diffractometer with $\mathrm{Cu}-$ $\mathrm{K} \alpha \lambda=0.15417 \mathrm{~nm}$. Emission was set at $40 \mathrm{~mA}$ and $40 \mathrm{kV}$, and a $2 \theta$ step size of $0.01^{\circ}$ and time/step of $1 \mathrm{~s}$ were used.

\subsubsection{Atomic force microscopy}

Atomic force microscopy (AFM)was conducted on a Molecular Imaging PicoScan 3000 system in contact mode with Si tips on cantilevers of nominal $k=2.5 \mathrm{~N} / \mathrm{m}$ and radius $<10 \mathrm{~nm}$.

Deflection and force were calibrated by using the slope of the force curve on the approach and the nominal cantilever spring constant. The adhesive force between the tip and film surface was taken as the cantilever pull-off force adjusted by the cantilever resting position using a $5 \mathrm{nN}$ applied load [76]. Three approach-retract curves per location were averaged with sweep time set to $1 \mathrm{~s}$ each, and five of these measurements were taken over random sample spots on the specimens. Relative friction measurements were made by applying forces in the range of 0-50 $\mathrm{nN}$ to the tip scanning over $500 \mathrm{~nm}$, generally at a speed of $10 \mu \mathrm{m} / \mathrm{s}$. All measurements were conducted at $21 \pm 2{ }^{\circ} \mathrm{C}$ and $45 \pm 5 \%$. The tip was cleaned between samples by immersion in acetone for $1 \mathrm{~min}$ followed by air-drying.

\subsubsection{Stylus profilometry}

Film thickness and roughness were measured on a Veeco Dektak 150 stylus profilometer. Roughness was measured over a $1000 \mu \mathrm{m}$ scan length. Film wear rates were calculated from a weighted linear least squares regression fit of film thickness versus total sliding distance of the reciprocating wear device and expressed as film thickness lost per meter sliding distance, $\mathrm{nm} / \mathrm{m}$. 


\subsubsection{Nitrogen adsorption porosimetry}

Porosity and pore size distribution were determined by $\mathrm{N}_{2}$ adsorption at $77 \mathrm{~K}$ using a Micromeritics ASAP 2020 analyzer. Samples for porosimetry were taken from freestanding films cast by evaporation of coating solutions and then calcined at $400^{\circ}$ for 24 hours. This treatment was done to remove residual organics while minimizing film densification through collapse of pores [77,78]. These samples were then degassed under vacuum at $120^{\circ} \mathrm{C}$ for 1 hour prior to the adsorption. The Barrett-Joyner-Halenda $(\mathrm{BJH})$ method was applied to the adsorption isotherm for the analysis of pore-size distribution. The porosity of the films was determined from the ratio of pore volume to sample volume, assuming a silica density of $2.2 \mathrm{~g} / \mathrm{cm}^{3}[56,79]$.

\subsubsection{Nanoindentation}

Hardness was measured by nanoindentation (NHT CSM Instruments) of a $10 \mu \mathrm{m}$ radius spherical diamond indenter. The penetration depth was set to $10 \%$ of the coating thickness to minimize substrate effects.

\subsubsection{Thermogravimetric analysis (TGA)}

Thermogravimetric analysis (TGA) was conducted on a PerkinElmer Pyris 1 TGA. Temperature scans were conducted using a heating rate of $10{ }^{\circ} \mathrm{C} / \mathrm{min}$.

\subsubsection{Transmission electron microscopy}

Transmission electron microscopy (TEM) was conducted using a JEOL JEM-2100F instrument operating at $200 \mathrm{kV}$. 


\section{Template-assisted encapsulation of fluorinated silanes in silica films for sustained hydrophobic-oleophobic functionality}

This chapter describes the synthesis, chemical, surface, and structural properties of fluorinated silica films which have been templated using a block copolymer surfactant. The effect of surfactant concentration on sustained hydrophobic-oleophobic functionality was investigated. The work presented in this chapter has been published in the Journal of Colloid and Interface Science, doi:10.1016/j.jcis.2011.05.026.

\subsection{Overview}

This chapter explores the use of templated silica films as scaffolds for encapsulating surfacesegregating functional organic moieties as a mesoscopically dispersed phase with the goal of imparting sustained functionality. Block copolymer surfactant templated hydrophobicoleophobic fluorinated silica films were synthesized via sol-gel co-condensation and coated on glass substrates. Fluorosilane and surfactant template concentrations were varied, and coating surface properties measured before and after abrasion of the top surface. Surface physical and chemical properties were investigated using XPS and contact angle measurements. Nitrogen adsorption porosimetry and TEM were used to examine the effect of templating and fluorosilane encapsulation on the surrounding silica framework. The results show that surfactant template concentration may be used to tune the dispersion of the fluorosilane-rich phase within the silica film in order to allow exposed surfaces to maintain much of the original functionality of the pristine top surface.

\subsection{Introduction}

Non-wetting anti-fouling coatings are most often based on one of three systems (1) soft polymeric materials like polytetrafluoroethylene (PTFE), (2) highly textured surfaces with high 
aspect ratio surface features, (3) surface active monolayers. All of these systems suffer from inherent mechanical weakness which results in significant loss of functionality when subjected to wear. One common approach to attempt to mitigate such a loss of functionality due to mechanical damage is to apply hydrophobic-oleophobic layers by co-condensation of fluorosilanes with silicon alkoxides, but this approach usually results in a solid-air interface layer that is enriched in fluorinated moieties due to the thermodynamic drive of these components to migrate to low-surface energy interfaces [23,80-82]. Once this surface-enriched layer is removed, such as by mechanical abrasion, these coatings are also much less functional. To overcome this problem we propose to use surfactant template-assisted encapsulation of fluorosilanes as a mesoscopically dispersed phase within the silicon alkoxide coating framework. This approach enables the sustained non-wetting functionality of the coatings even after removal of the top surface.

Functional organic coatings are broadly applicable to a range of protective applications including anti-fouling, anti-microbial [5,83-85], anti-icing [86], and anti-corrosive coatings [87]. However, organic films are inherently weak and can be easily damaged and their functional properties degraded by wear. To enable the development of coatings with sustained functionality, we investigate the use of templated silica films as scaffolds for encapsulating surface-segregating functional organic moieties along interior surfaces. Non-wetting hydrophobic-oleophobic functionality was used as a probe to investigate this area, since it is easily and macroscopically tested by measuring the contact angle of liquid drops on the surface; other types of functionality such as anti-microbial or anti-corrosive require more elaborate analytical techniques. Furthermore, the fluorine chemistry required for hydrophobicity and oleophobicity presents a challenging system, since these molecules will be more surface-segregating than other organics.

Non-wetting coating materials are in their own right beneficial for a wide range of applications, including solar panels [1-3]; architectural structures [4]; optical displays and touch panels; and industrial/anti-fouling [6], automotive, textile, and household applications [5,7]. There are many reasons why hydrophobic and oleophobic functionality might be a desirable property, since nonwetting is a form of chemical repellency that prevents build-up of contaminants that impede the ability of the substrate to function and may even destroy it. Furthermore, the fluorocarbon 
chemistry that produces hydro- and oleo-phobicity influences how the solid interacts with other solids as well in terms of friction and adhesion forces, which are generally low in both cases [88]. It is of great interest to be able to apply a thin film of such materials as a protective coating on larger bulk substrates. However, conventional hydrophobic-oleophobic materials and surfaces suffer from low mechanical strength and low abrasion resistance. The weakness of polytetrafluoroethylene (PTFE), the most widely used hydrophobic-oleophobic material, is compounded by its low adhesive strength to substrates [18]. To overcome these deficiencies, many researchers have turned to using sol-gel methods to apply a fluorinated organic-silane monolayer to solid substrates or as monolayers atop hardened films such as through cocondensation $[20,21,80]$. These can perform better as thin films than bulk fluoropolymers owing to the strong Si-O film-substrate bond accomplished by sol-gel grafting. Sol-gel, furthermore, allows for high thermal stability and optical transparency [22]. When fluorinated organosilanes are combined by co-condensation with an alkoxide matrix, the functional moieties migrate to and align at the solid-vapor interface during film deposition [80,82]. They do so because of their phase-segregating nature and thermodynamic drive to minimize surface energy - it is this very repellency that makes them useful $[23,81]$. This surface segregation and stratification make it difficult to incorporate the functional moieties into the bulk, so they tend to concentrate in a molecularly-thin region at the air interface. Although the chemical bond to the substrate is strong, the material as a functional coating still lacks durability because the concentrated surface layer is easily worn [4].

Some methods employed by other researchers to combat this inherent difficulty include using textured surfaces to create mountains that protect functionalized valley areas from abrasive wear $[20,24,25]$. Nonetheless, surface alignment and stratification are inevitable and abrasive wear still has a large impact on surface functionality, eventually destroying the coating functionality by destruction or removal of the functional monolayer. Furthermore, it would be advantageous to develop a coating formulation that would work independently of the substrate condition since it is not always possible or desirable to texture the substrate surface.

The focus of the work presented here is to investigate the use of surfactant templated films as a sacrificial scaffold for fluorinated silanes that provide sustained hydrophobic-oleophobic 
functionality even after exposure to abrasive wear. Surfactant templating has been used to fabricate mesoporous films that are popular for applications like catalysis and separations and so are generally engineered for high porosity and surface area. There are some reports on the fluorine functionalization of mesoporous silica [35,51-54]. Of these, only the works by Bae, Jung, et al. [35,53] involve synthesis of mesoporous films via co-condensation with functional moeties, which, unlike the post-synthesis grafting approach, is the only templating route that fully incorporates the functional groups in the bulk, in addition to being a single step process. Bae, Jung, et al. have been concerned primarily with engineering low-dielectric constant materials, and to this end have also focused on maximizing porosity. Consequently, they report the formation of highly mesoporous and ordered materials. However, for many applications, a functionalized surface coating exposed to mechanically harsh environments needs to be examined more rigorously in terms of its sustained functional performance. Generally, studies of templated mesoporous films have sought to form highly porous and ordered networks. Ordered networks usually require a relatively large concentration of the templating surfactant. In our case, we have sought to minimize the surfactant concentration since increased porosity tends to degrade the mechanical properties. The chemical properties of functional mesoporous films with have not been examined as much in terms of subsurface functionality and functional durability, and that area is the subject of our research.

\subsection{Experimental section}

\subsubsection{Preparation}

Fluorinated silica films were synthesized at room temperature via co-condensation of fluorinated silane with an alkoxide silica precursor in the presence of a surfactant. Tetraethoxysilane (TEOS, Acros Organics) was used as the alkoxide. A perfluoropolyether silane (FPES, Fluorolink S10, Solvay Solexis) was used for functionalization in order to present the best possible surface for non-wetting properties. Fluorolink S10, which has the structure shown in Figure 17, was selected for this study because it has a fairly large molecular weight (average $=1850 \mathrm{~g} / \mathrm{mol}$ ) compared to perfluoroalkylsilanes and two silane grafting end groups. Longer functional molecules have been shown to increase the hydropobic/oleophobic character of films [34,35], and two grafted ends increases resistance to mechanical removal from the matrix [32]. Additionally, interchain 
hydrogen bonding between amide moieties has been found to enhance intermolecular stability $[36,37,89]$. Pluronic F127 (MW $=12600, \mathrm{PEO}_{106} \mathrm{PPO}_{70} \mathrm{PEO}_{106}$, a gift from BASF) was used as the surfactant template.

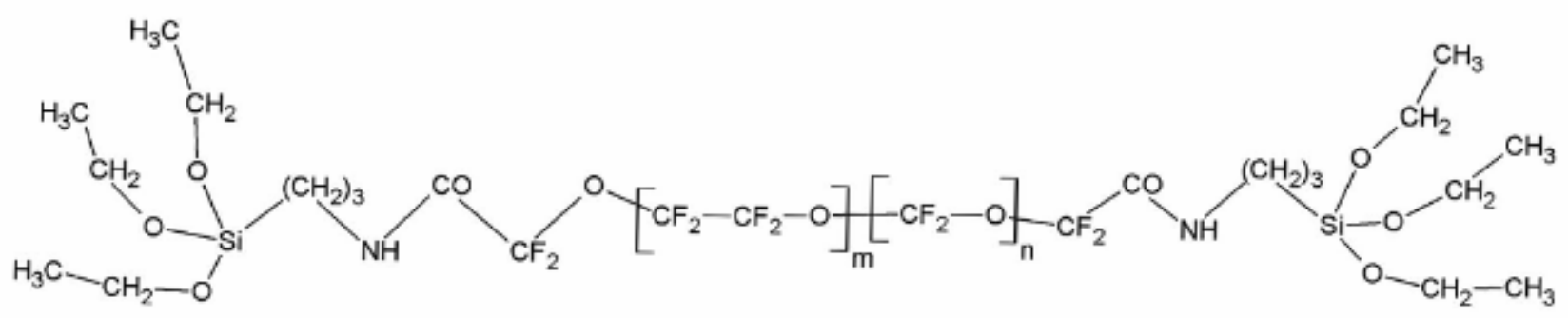

Figure 17. Chemical structure of Fluorolink S10, $m / n=1.5-2.5,2<n<5$, and $5<m<9$ [32].

Coating solutions were synthesized in $35 \mathrm{~g}$ batches as follows. First, TEOS was hydrolyzed with water and a small amount of $\mathrm{HCl}$ in the molar ratio 1- $x_{f} \mathrm{TEOS}: 4 \mathrm{H}_{2} \mathrm{O}: 0.001 \mathrm{HCl}$. After 60 minutes of stirring, FPES was added and the sol stirred for 5 minutes to allow FPES hydrolysis. The sol was then diluted with ethanol to achieve a final molar ratio of 1-

$x_{f}$ TEOS: $x_{f}$ FPES: $4 \mathrm{H}_{2} 0: 0.01 \mathrm{HCl}: 20 \mathrm{EtOH}$. The sol was stirred for an additional 24 hours and filtered through a $0.47 \mu \mathrm{m}$ filter. The surfactant template was then added at a concentration $x_{s}$, expressed as a mass percent of F127 to total silanes $=100 \% \times$ F127/(TEOS + FPES + F127). The range of $x_{f}$ was $0.2-0.4$, and the range of $x_{s}$ was $0-10 \%$. After several minutes of mixing to ensure homogeneity, the sols were coated on soda-lime glass microscope slides by dip coating at a withdrawal speed of $200 \mathrm{~mm} / \mathrm{min}$ in ambient air $\left(23 \pm 2{ }^{\circ} \mathrm{C}, 45 \pm 5 \%\right.$ relative humidty). Slides were first cleaned by sonication at $40^{\circ} \mathrm{C}$ for 15 minutes each in an acid-based detergent, multiple washes of deionized water, and finally acetone. Coated films were then dried for 24 hours at ambient conditions before curing at $200^{\circ} \mathrm{C}$ for 3 hours in a box furnace with a ramp rate of 10 ${ }^{\circ} \mathrm{C} / \min$.

\subsubsection{Characterization}

Static contact angles were measured by placing five drops $(\sim 1.0 \mu \mathrm{L}$ each) approximately $1 \mathrm{~mm}$ apart using a manual microsyringe. This was done to cover a macroscopic and representative area, compared to the microscopic size of film structural features, and the results were averaged. 
Deionized water and $n$-hexadecane (Alfa Aesar) were used as test fluids. Images were captured using a digital microscope and analyzed using the LB-ADSA method in the "Drop Analysis" plugin [75] for ImageJ.

Static contact angles were used to determine the surface energy of the various surfaces being investigated. According to the Owens-Wendt method [90], surface energy, $\gamma$, is the sum of two components:

$$
\gamma=\gamma^{d}+\gamma^{p}
$$

where $\gamma^{d}$ is the dispersive component and $\gamma^{p}$ the polar component. The solid, liquid, and vapor interfacial energies are related to liquid contact angle by the Young equation [8]:

$$
\gamma_{S V}-\gamma_{S L}=\gamma_{L V} \cos \theta
$$

Owens and Wendt considered the surface energy of a solid to be a geometric mean of dispersive and polar components, which when combined with the Young equation yields:

$$
\gamma_{L V}(\cos \theta+1)=2 \sqrt{\gamma_{L V}^{d} \gamma_{S V}^{d}}+2 \sqrt{\gamma_{L V}^{p} \gamma_{S V}^{p}}
$$

The two unknowns in equation (3), $\gamma_{S V}^{d}$ and $\gamma_{S V}^{p}$, may then be solved for using measured values of $\cos \theta$ for at least two liquids of known $\gamma_{L V}^{d}$ and $\gamma_{L V}^{p} \cdot \gamma_{S V}$ of the solid surface of interest may then be calculated using equation (1). The test liquids used here had $\gamma_{L V}^{d}$ and $\gamma_{L V}^{p}=21.8$ and 51.0 $\mathrm{mN} / \mathrm{m}$, respectively for water, and 27.6 and $0 \mathrm{mN} / \mathrm{m}$, respectively for $n$-hexadecane [91].

Contact angles were measured on pristine coating surfaces and on coatings abraded to remove the top surface and expose the internal functional surfaces. These were abraded with an aqueous slurry of $0.3 \mu \mathrm{m}$ alumina particles (90-187120, Allied) is trapped in a cloth pad (90-150-285, Allied). The pad was in contact with the surface over a nominal area of $175 \mathrm{~mm}^{2}$, and a $4.70 \mathrm{~N}$ normal force was applied while the pad reciprocated over a stroke length of $35 \mathrm{~mm}$ at $0.1 \mathrm{~Hz}$ [92]. Film thickness and roughness were measured on a Veeco Dektak 150 stylus profilometer. Roughness was measured over a $1000 \mu \mathrm{m}$ scan length.

Thermogravimetric analysis (TGA) was conducted on a PerkinElmer Pyris 1 TGA. Samples for TGA included Pluronic F127 used as provided, FPES gelled by mixing with $0.1 \mathrm{~N}$ hydrochloric 
acid and ethanol, and gelled functional sols cast by evaporation of coating solutions. Temperature scans were conducted using a heating rate of $10^{\circ} \mathrm{C} / \mathrm{min}$.

X-ray photoelectron spectroscopy (XPS) was conducted on a Physical Electronics PHI 5000 VersaProbe system. The X-ray beam was $100 \mu \mathrm{m}, 25 \mathrm{~W}$, and $15 \mathrm{kV}$, from a monochromatic Al $\mathrm{K} \alpha$ source using charge neutralization and pass energy $=93 \mathrm{eV}$. Depth profiling was conducted by Ar sputtering a $2 \mathrm{~mm}$ square area at $4 \mathrm{kV}$ and $10 \mu \mathrm{A}$. Spectra were collected from F1s, C1s, and Si2p levels. X-ray diffraction (XRD) was conducted on a Bruker D8 Discover diffractometer with $\mathrm{Cu}-\mathrm{K} \alpha$ radiation $(\lambda=0.15417 \mathrm{~nm}, 40 \mathrm{~mA}, 40 \mathrm{kV})$, a $2 \theta$ step width of $0.01^{\circ}$, and a step size of $1 \mathrm{~s}$.

Porosity and pore size distribution were determined by $\mathrm{N}_{2}$ adsorption at $77 \mathrm{~K}$ using a Micromeritics ASAP 2020 analyzer. Samples for porosimetry were taken from freestanding films cast by evaporation of coating solutions and then calcined at $400^{\circ}$ for 24 hours. This treatment was done to remove residual organics while minimizing film densification through collapse of pores $[77,78]$. These samples were then degassed under vacuum at $120^{\circ} \mathrm{C}$ for 1 hour prior to the adsorption. The Barrett-Joyner-Halenda $(\mathrm{BJH})$ method was applied to the adsorption isotherm for the analysis of pore-size distribution. The porosity of the films was determined from the ratio of pore volume to sample volume, assuming a silica density of $2.2 \mathrm{~g} / \mathrm{cm}^{3}[56,79]$.

Transmission electron microscopy (TEM) was conducted using a JEOL JEM-2100F instrument operating at $200 \mathrm{kV}$.

\subsection{Results and discussion}

\subsubsection{Chemical and structural properties}

Coating thickness was measured by stylus profilometry and ranged from 300-700 nm. Thickness increased linearly with both concentration of FPES and surfactant, since these organic species add bulk to the alkoxide matrix. 
XRD measurements showed no discernable diffraction peak in the range of 0-52 2 , indicating a completely disordered mesoporous structure of the silica framework. Pore ordering depends on many factors, perhaps most importantly on the concentration of surfactants used $[68,71,78,93]$. In the case of the films synthesized here the $10 \%$ concentration of F127 surfactant, which was the maximum used, is still substantially less than that normally used to obtain ordered structures. The contact angle and XPS results indicate that the accumulation of residual surfactant decomposition products decreases bulk hydrophobicity and oleophobicity for compositions with great than $8 \%$ surfactant. Therefore, there is no advantage in obtaining ordered structures in terms of the non-wetting properties. Furthermore, the higher surfactant concentrations normally required to generate ordered structures also result in higher porosity, which degrades the mechanical properties of films.

Films were cured at $200^{\circ} \mathrm{C}$ for 3 hours to remove as much surfactant as possible while still maintaining organic functionality. Isothermal TGA scans at $200{ }^{\circ} \mathrm{C}$ showed the near-complete decomposition of F127 surfactant after 10 minutes, as shown in Figure 18 (a), although $1.3 \%$ remained after 3 hours. Conversely, approximately $98.6 \%$ of gelled FPES remained even after 5 hours at $200{ }^{\circ} \mathrm{C}$, and most of this lost weight is likely from residual water and alcohol evaporation during the initial temperature ramp. Temperature scans showed the onset of decomposition of F127 at $193{ }^{\circ} \mathrm{C}$ and of gelled FPES at $257^{\circ} \mathrm{C}$, as shown in Figure 18 (b). However, functional films cured at $200{ }^{\circ} \mathrm{C}$ for longer than 3 hours or for shorter periods of time at temperatures slightly above $200{ }^{\circ} \mathrm{C}$ showed diminished contact angles even though there is minimal apparent weight loss from the FPES in those ranges. Therefore, the films analyzed in this study were cured at $200^{\circ} \mathrm{C}$ for 3 hours, even though F127 decomposition was not $100 \%$ complete. This is in agreement with previously published research showing that the thermal decomposition of PEO-PPO-PEO block copolymers such as Pluronic F127 in SBA-15 mesoporous silica begins at temperatures as low as $160^{\circ} \mathrm{C}[94,95]$, but decomposition byproducts remain until much higher temperatures owing to stabilization by interaction with the inorganic matrix and diffusion effects $[95,96]$.

TGA analysis of functional films revealed that, without F127 the functional films lose approximately $5 \%$ weight by $200{ }^{\circ} \mathrm{C}$, as shown in both isothermal and temperature scans in 
Figure 18. The temperature scan profile for the non-templated and templated functional films are nearly identical up to approximately $220^{\circ} \mathrm{C}$, and the isothermal scan of the non-templated functional film shows that this weight loss is rapid. Taken together, these results indicate that the $5 \%$ weight loss is likely due to loss of water and solvents, which may be more entrapped in a gelled sol than the FPES alone. Compared to the non-templated film, the film with $10 \%$ F127 shows a weight loss of an additional $17.7 \%$ after 3 hours of isothermal curing at $200{ }^{\circ} \mathrm{C}$. This weight loss occurs more slowly than the loss of water and solvents. We also observe from the temperature scans that the onset of this weight loss in the functional film occurs at a higher temperature than pure F127 surfactant. Together with the isothermal TGA results, this suggests that there are still some residual surfactant and/or decomposition products remaining in the films cured at $200{ }^{\circ} \mathrm{C}$ for 3 hours.
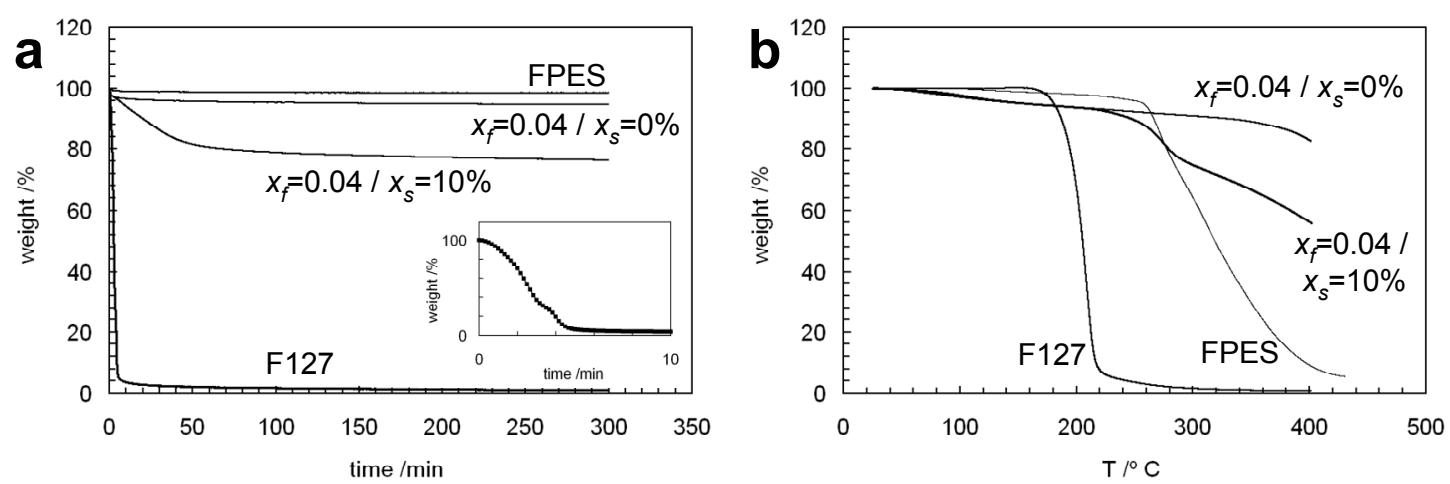

Figure 18. (a) Isothermal TGA at $200^{\circ} \mathrm{C}$ of Pluronic F127, gelled FPES, and gelled functional sols of $x_{f}=0.04$ without F127 and with 10\% F127. Inset shows first few minutes of F127 scan. (b) TGA temperature scans of the same materials in (a).

Films were analyzed by XPS depth profiling, showing somewhat different characteristics at the top surface and eventually stabilizing around an average composition. Figure 19 (a) shows a sample depth profile ( $x_{f}=0.04 / x_{s}=8 \%$ ) showing film composition before the crossover point at the film-substrate interface. Data were averaged from after film sputtering began to before the crossover point, and these averages were used to compute atomic concentration ratios representing the bulk film composition, which are represented in Figure 19 (b) and Figure 19 (c). As illustrated by Figure 19 (a), and is typical of all the films measured, the composition is not perfectly homogeneous throughout the thickness. This variability is expressed in the error bars of 
Figure 19 (a) and Figure 19(b), which represent $1 \sigma$ of the atomic ratios, and is also observed macroscopically as contributing to the variability of the CA measurements. Also observable in Figure 19 (a) is the relatively high concentration of fluorine at the top surface (sputtering time $=$ $0 \mathrm{~min})$.

The trends shown in Figure 19 (b) and Figure 19 (c) indicate a moderate increase in the F/Si ratio with increasing surfactant concentration. This indicates that templating encapsulates the fluorosilanes, which would otherwise be more concentrated at the top surface due to their thermodynamic drive to phase separate. Compared to the $\mathrm{F} / \mathrm{Si}$ ratio, the $\mathrm{C} / \mathrm{Si}$ ratio increases at a significantly higher rate. Although the integration of the $\mathrm{C} 1 \mathrm{~s}$ core level spectra to compute concentration includes some contribution from the C-F bonding present in the FPES, the increased slope of the $\mathrm{C} / \mathrm{Si}$ trend compared to $\mathrm{F} / \mathrm{Si}$ indicates an accumulation of other carboncontaining species. We also observed this directly from the $\mathrm{C} 1 \mathrm{~s}$ spectra (example shown in inset to Figure 19 (a)) that show an increase versus surfactant concentration in peaks centered in the range of 284-288 eV, which represent various C-C and C-O type bonding, and a much smaller increase in intensity of peaks in the range of 292-295 eV, which represent C-F bonds. Taken together, these results confirm the incomplete decomposition and removal by thermal treatment of the F127 surfactant, and an accumulation of the surfactant molecule and/or its decomposition byproducts trapped within the pores and silica matrix. 

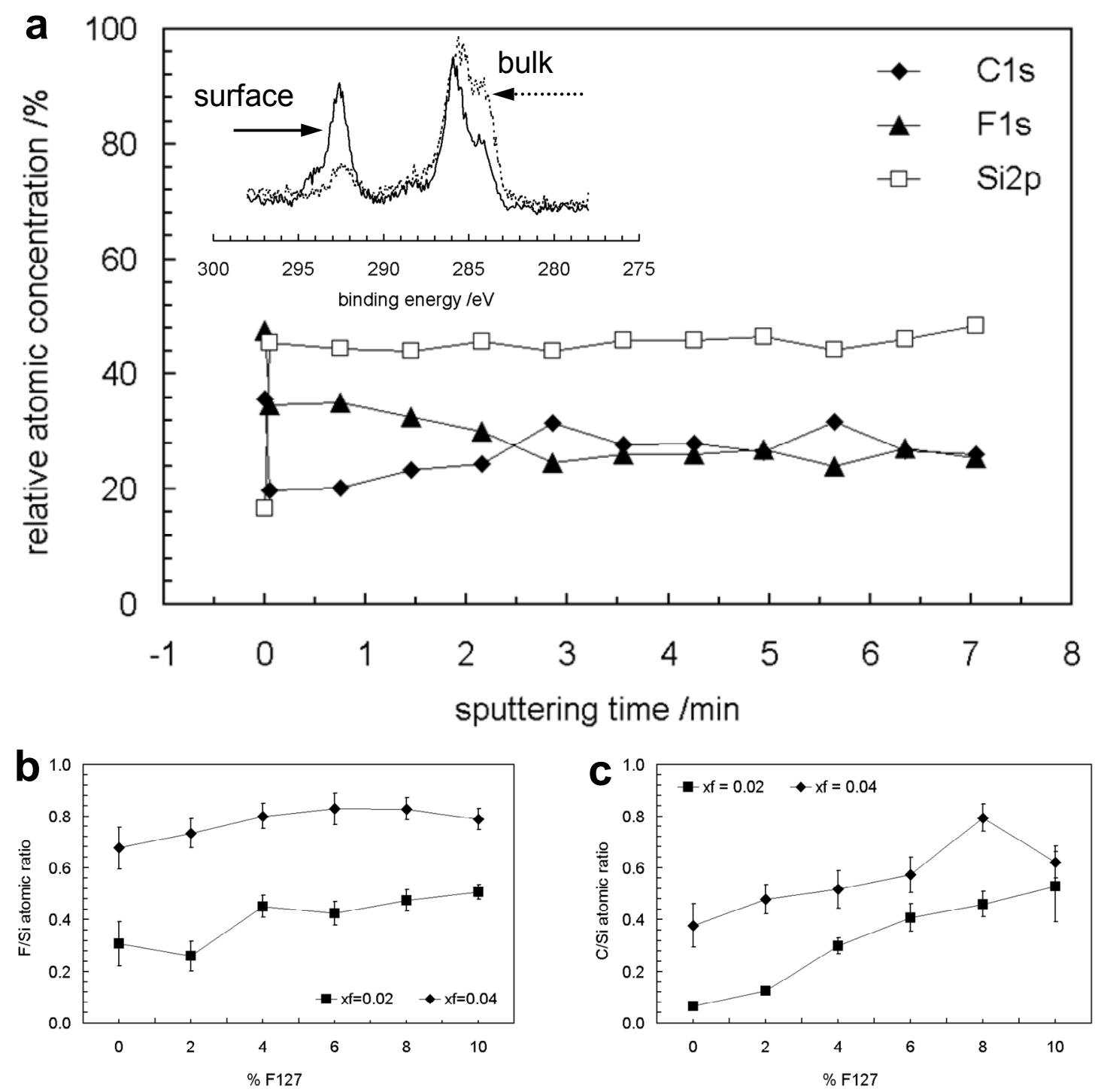

Figure 19. (a) XPS depth profile of film with composition $x_{f}=0.04, x_{s}=0.08$. Inset shows sample C1s spectra from film surface (blue) and from bulk (red). Atomic concentration ratios, (b) F/Si and (c) C/Si, determined by XPS depth profiling for various compositions synthesized.

Films cured at $200{ }^{\circ} \mathrm{C}$ for 3 hours showed no significant internal surface area when analyzed by nitrogen adsorption porosimetry. An extended high-temperature treatment at $400{ }^{\circ} \mathrm{C}$ for 24 hours was necessary in order to sufficiently decompose surfactant and FPES molecules within the matrix and obtain a true porous structure. This treatment revealed a mesoporous silica framework with pore size and pore volume dependent on concentrations of FPES and F127 surfactant. Consequently, the functional films contain a mesoscopically dispersed flurosilane-rich phase 
while technically not being mesoporous. Nonetheless, porosimetry provides a measure of the void space in the silica framework left by removal of the dispersed functional phase, which is useful in characterizing the mechanical properties of the coatings [79]. While the pores are filled in the functional material, the organic FPES and surfactants are soft and contribute little to the overall mechanical properties of the film. Furthermore, the high-temperature treatment should densify the material through the condensation of the silica matrix, contracting it around the pores and shrinking them $[60,97,98]$. Therefore, the porosity and pore diameters reported here should be understood as somewhat relative measurements that are proportional but not identical to the true properties of the films that were not exposed to the high thermal treatment. The BJH method, furthermore, is based on an assumption of cylindrical pore geometry [99], which the TEM micrographs that follow indicate is not the case in this study. Pore size distributions obtained by the BJH model applied to non-ideal pore geometry tend to underestimate pore size [100]. Nonetheless, as TEM micrographs below indicate, the porosimetry calculations are quite close to what we observe in the micrographs.
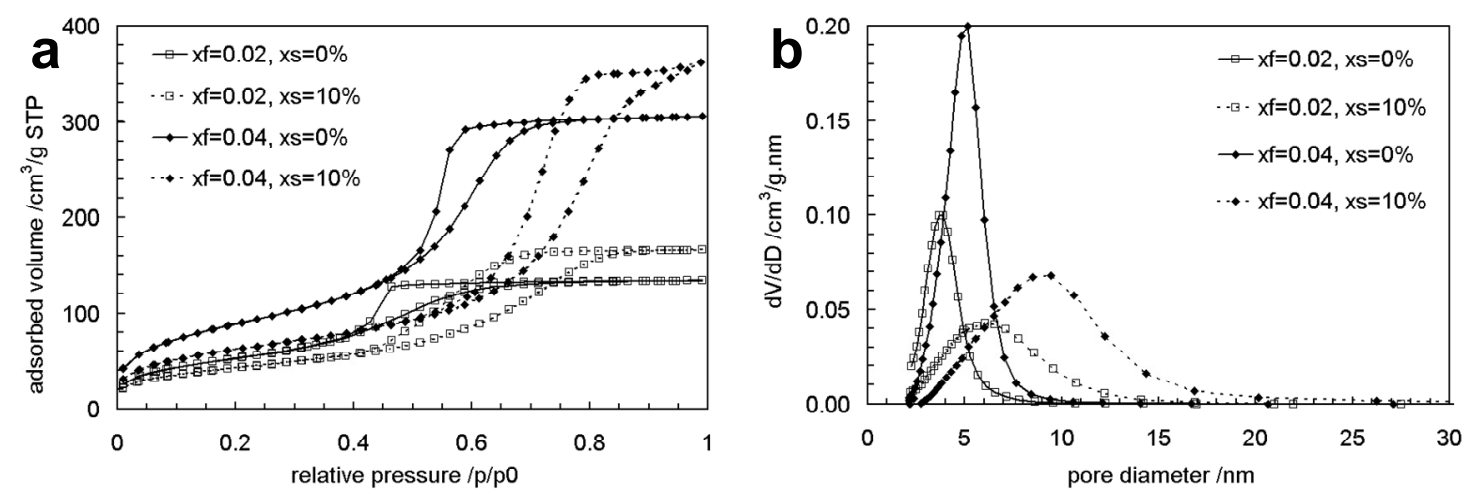

Figure 20. (a) Nitrogen adsorption-desorption isotherms on calcined films synthesized with different fluorosilane and surfactant concentrations. (b) BJH pore size distributions of calcined films synthesized with different fluorosilane and surfactant concentrations.

Some sample nitrogen adsorption-desorption isotherms are shown in Figure 20 (a). For clarity, some isotherms have been omitted, and the figure shows isotherms from films synthesized with the entire range of FPES concentrations studied and at the two extreme concentrations of surfactant, $x_{s}=0$ and $10 \%$. All samples analyzed showed IUPAC type IV isotherms, which are characteristic of mesoporous materials. The trend is that both FPES and surfactant concentration 
increase the total adsorbed volume and shift the mesopore size to longer dimensions. Without surfactant addition we observe that the calcined material is still mesoporous, owing to the strongly amphiphilic nature of fluorosilanes, which have been shown to act as mesoporous templates synergistically with extremely small quantities of surfactants [53].

In all cases, addition of surfactant drops the adsorbed volume in the range of micropore filling, while increasing it at higher pressures which represent the capillary condensation in the mesopore size range. This transition is confirmed by the $\mathrm{BJH}$ pore size distributions of the same samples, shown in Figure 20 (b), which were calculated from the adsorption isotherms. The pore sizes distributions shift to larger dimensions and spread out considerably once the surfactant is introduced. This seems to imply that without a pore template, FPES molecules in the bulk of the film reside as small molecular aggregates, which are evenly distributed throughout. Upon calcination the FPES is removed and leaves behind small pores with narrow size distribution, which is common when organosilanes are co-condensed with TEOS [101]. In our case the size of those pores, around $4 \mathrm{~nm}$ in diameter, are somewhat larger than the IUPAC classification of micropores $(<2 \mathrm{~nm})$ which reflects the relatively large size of each individual FPES molecule $(\mathrm{MW}=1850)$ compared to smaller organosilanes. When the surfactant template is added, it allows the FPES to arrange at higher concentrations at the pore surfaces than in the bulk, and this is most likely due to the FPES acting as a cosurfactant together with the F127 as has been described by Bae, et al. [53].
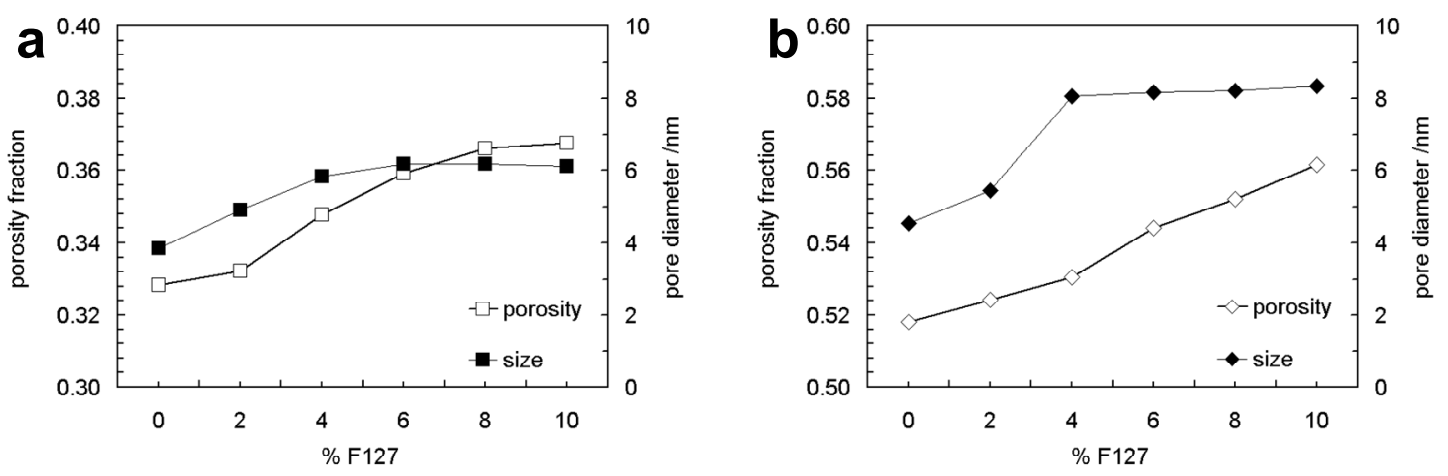

Figure 21. (a) Porosity fraction and average pore diameter of calcined films synthesized with $x_{f}=0.04$ and various surfactant concentrations. (b) Porosity fraction and average pore diameter of calcined films synthesized with $x_{f}=$ 0.02 and various surfactant concentrations. 
We observe a moderate monotonic increase in porosity across the range of surfactant concentrations studied, as shown in the plots of porosity fraction versus surfactant concentration summarized in Figure 21 (a) and (b). Average pore size based on BJH analysis increased at low surfactant concentration, but then was approximately constant at moderate to higher surfactant concentrations, as is shown by the plots of pore diameter in Figure 21 (a) and (b). This is due to the competing factors of pore volume and pore size: since pore volume must increase with addition of surfactant mass, we may expect pore size to become limited [102]. Overall, these values of porosity and pore size are consistent with those observed by Fan et al. when using a pore swelling agent of molecular weight similar to that of our FPES [70].
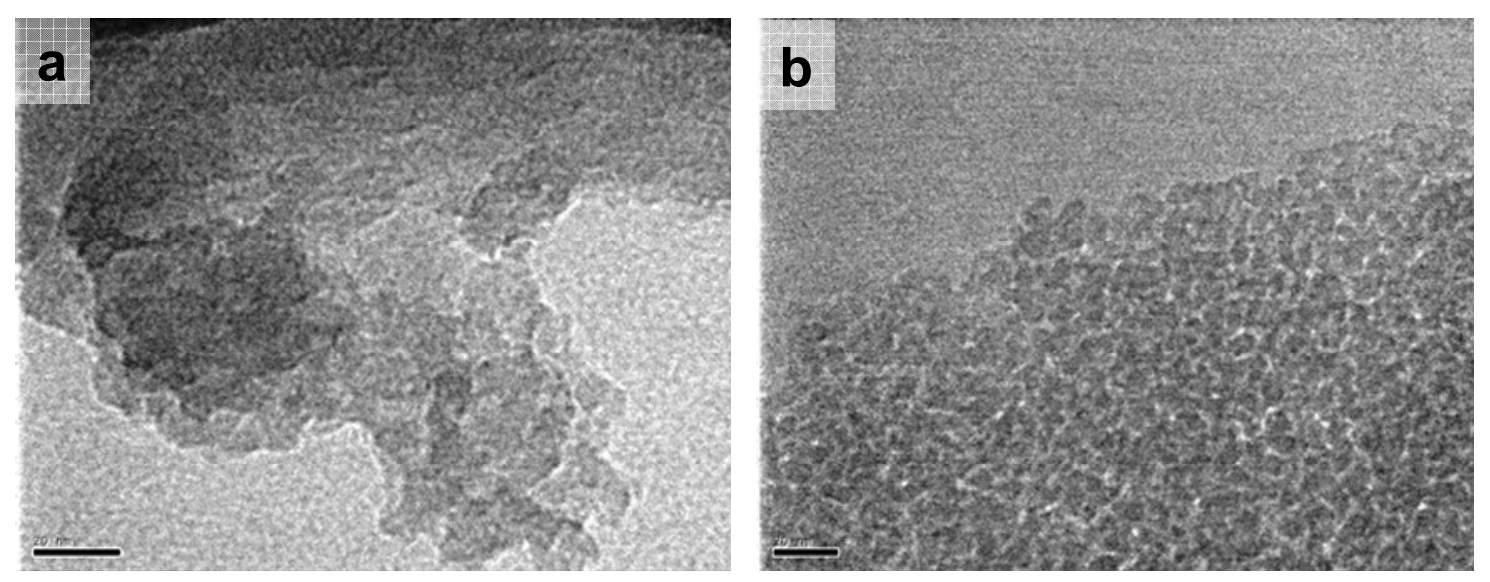

Figure 22. TEM micrographs of films with composition $x_{f}=4 / x_{s}=10 \%$. (a) shows film cured at $200{ }^{\circ} \mathrm{C}$ for 3 hours, and (b) a film cured at $400{ }^{\circ} \mathrm{C}$ for 24 hours. Both scale bars $=20 \mathrm{~nm}$.

TEM microscopy was used to verify the structural characteristics of films, particularly regarding pore morphology, distributon and ordering, and any structural differences between films cured at $200{ }^{\circ} \mathrm{C}$ for 3 hours and $400{ }^{\circ} \mathrm{C}$ for 24 hours. Sample TEM micrographs are shown in Figure 22, which are the same film cured at (a) low temperature and (b) high temperature. The film in (a) shows a low contrast between the pores and matrix, owing to the encapsulation of a large quantity of organics. The film in (b) shows higher contrast due to their calcination. In both micrographs we observe the non-circular and asymmetrical pore morphology and the lack of any long-range pore order. We also note that the sizes of the pores are quite variable, but are overall consistent between the two micrographs. This indicates that the BJH model still provides a useful 
measure of pore size for this material with an accuracy of within $\sim 10 \%$ as determined by digital image analysis.

\subsection{Surface physicochemical properties}

As deposited, all films were smooth with roughness $\mathrm{R}_{\mathrm{a}}<5 \mathrm{~nm}$. All unworn films had contact angles in the range of $105-110^{\circ}$ for water and $63-67^{\circ}$ for $n$-hexadecane, with standard deviations of $<2^{\circ}$. The contact angles on unworn surface were independent of FPES concentration, which is often the case provided that the concentration of the hydrophobic moiety exceeds a minimum threshold $[81,82]$. After abrasion, the thickness of the films decreased. Contact angles of water and $n$-hexadecane were measured intermittently after multiple abrasion cycles done in order to remove the top surface and expose the internal functional surfaces. After several abrasion cycles the contact angles (CA) decreased, eventually fluctuating around some average value, reported here as the bulk contact angle. After abrasion the roughness of the film surfaces increased to between 15 and $20 \mathrm{~nm}$ and remained in that range during all subsequent abrasion cycles, so the contact angle measurements can be considered unaffected by surface roughness effects.

Figure 23 (a) shows a sample plot of CA versus normalized penetration depth by abrasion for films synthesized with $x_{f}=0.04$ and different surfactant concentrations. As surfactant concentration is increased, we observe a gradual increase in the CA of water as measured on the film bulk, as opposed to the unworn top surface. Bulk contact angle for water and oil versus composition data are summarized in Figure 23 (b). Although all surfaces are strongly hydrophobic when unworn, the CA measured after abrasion depends substantially on the overall concentrations of FPES and surfactant added during film synthesis. For example, although addition of surfactant can increase the CA of water from $47^{\circ}$ to $64^{\circ}$ when $x_{f}=0.02$, the CA can not be increased beyond this point due to conservation of mass - there must be sufficient fluorinated moieties to provide a non-wetting surface. Clearly, at $x_{f}=0.02$ the available surface area for functionalization is not saturated, since increasing $x_{f}$ positively influences the maximum attainable CA. Ultimately, the bulk CA of water may be increased substantially from $<50^{\circ}$ to $>$ $90^{\circ}$, depending on how FPES and surfactant concentrations are balanced. 

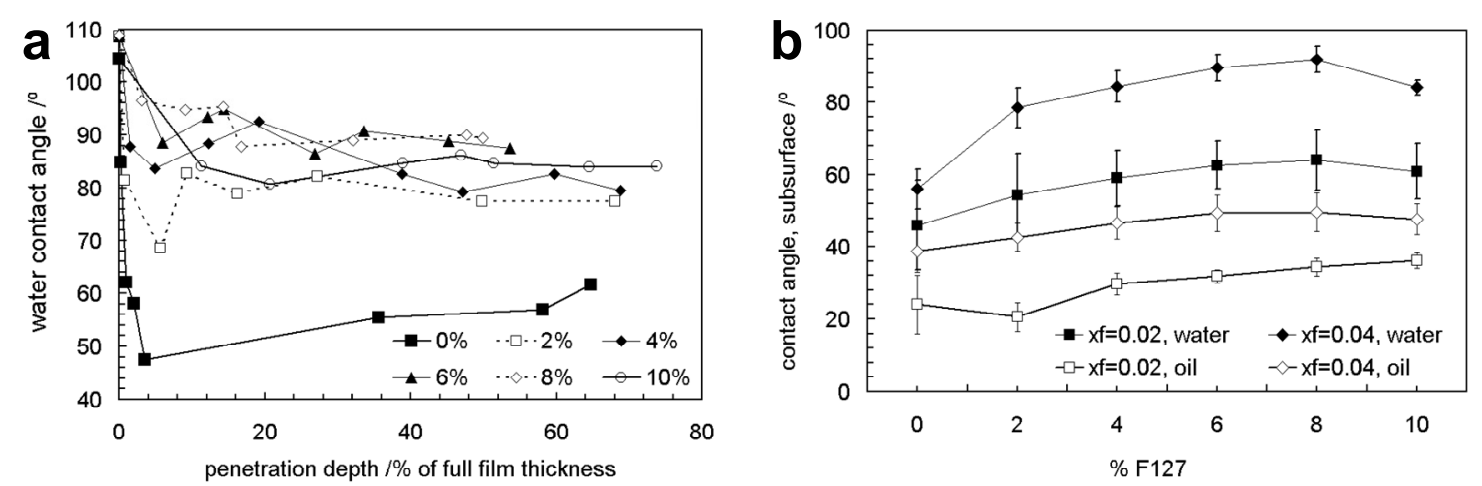

Figure 23. (a) Contact angle of water as a function of normalized penetration depth into coating after abrasion for films synthesized with different surfactant concentrations (shown in legend) and $x_{f}=0.04$. (b) Average contact angle of water and $n$-hexadecane measured on worn subsurface areas for compositions with various FPES and surfactant concentrations.

At higher surfactant concentrations the water CAs decrease slightly. We attribute this phenomenon to the accumulation of the surfactant template and its decomposition products in the film bulk. These hydrophilic species may not be completely removed by the relatively mild thermal treatment used here, which has been minimal in order to protect the FPES from decomposition as discussed above in discussion of TGA results. We believe that these products are not completely removed, and that they mitigate the hydrophobic effect of the fluorinecontaining moieties, which is reflected in the XPS analysis that shows accumulation of carbonaceous species.
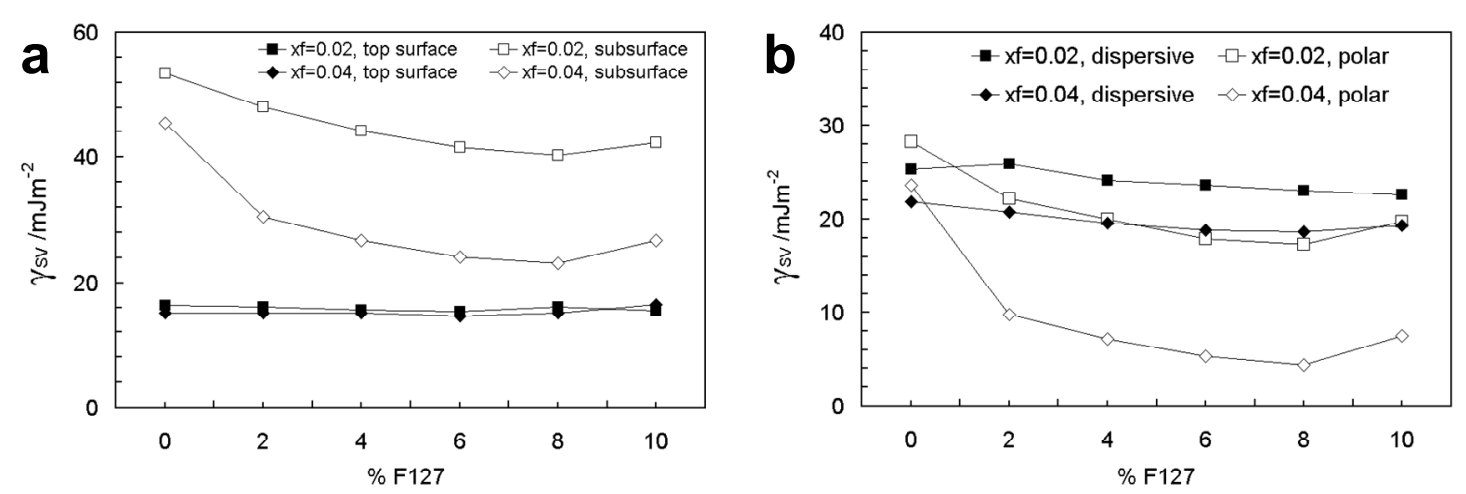

Figure 24. (a) Total surface energy of pristine top surface and worn and exposed subsurface areas for compositions with various FPES and surfactant concentrations. (a) Polar and dispersive components of surface energies shown in

(a). 
Calculation of surface energy and the contribution from polar and dispersive components provides further insight into the composition and properties of the films. We observe that the pristine top surface had low surface energy $=15.5 \pm 0.6 \mathrm{~mJ} / \mathrm{m}^{2}$ that was invariant of film composition as shown in Figure 24 (a) and is consistent with previously reported values for a surface covered with the same FPES molecules [81]. The polar and dispersive contributions to this were $1.1 \pm 0.3 \mathrm{~mJ} / \mathrm{m}^{2}$ and $14.4 \pm 0.4 \mathrm{~mJ} / \mathrm{m}^{2}$, respectively. These values are characteristic of fluorinated organics like PTFE that have only minimal polar contribution to an overall low surface energy. Meanwhile, the surface energy of worn and exposed subsurface areas of films was dependent on both FPES and surfactant concentrations. Total surface energy decreased with increasing FPES concentration, decreased with low to moderate surfactant concentrations, and increased slightly at higher surfactant concentrations, as shown in Figure 24 (a). These results are consistent with the CA and XPS analyses that showed a fluorine-enriched top surface compared to the various subsurface compositions. Films synthesized without addition of surfactant template showed subsurface values of $\gamma^{d}$ and $\gamma^{p}$ similar to those reported for a completely nonfunctional film synthesized with TEOS only [81]. In both cases of films templated with $x_{f}=0.02$ and 0.04 , the decrease in surface energy with increasing surfactant concentration was due in larger proportion to the polar component of surface energy, as is shown in Figure 24 (b). This is the results of substitution of silanol groups with fluorinated segments, which act more strongly on the polar component of surface energy [90]. XPS showed a moderate increase in the F/Si ratio with increasing surfactant concentrations. We see here that this increased encapsulation of fluorosilanes is able to lower the polar component surface energy more dramatically than it is the dispersive component, which changes much more subtly.

\subsection{Conclusion}

The conventional model of hydrophobic-oleophobic films synthesized by co-condensation of fluorosilanes with silicon alkoxides is that of a solid-air interface layer that is enriched in fluorinated moieties due to the thermodynamic drive of these components to migrate to lowsurface energy interfaces [23,80-82]. Consequently, these conventional coatings may be strongly non-wetting and have low-surface energy when pristine, but upon wear and exposure of the bulk subsurface regions, the films are much less functional. We hypothesized in this paper that the 
bulk concentration might be increased if a surfactant template is used to encapsulate the fluorosilanes and aid their meso-scale dispersion in the bulk, with the intent of increasing hydrophobicity and oleophobicity when the subsurface regions are exposed after abrasion. We have shown here that the concentrations of Pluronic F127 PEO-PPO-PEO block copolymer surfactant and perfluoropolyether silane may be tuned to achieve a bulk functionality that is significantly greater than that of a conventional, non-templated film. XPS analysis showed that the $\mathrm{F} / \mathrm{Si}$ atomic ratio increased upon addition of surfactant, although only from a minimum of 0.67 to a maximum of 0.83 across the entire range of surfactant concentrations studied.

Meanwhile, porosimetry suggests that the fluorosilane acts as a co-surfactant to increase the size of the mesoscopically dispersed fluorosilane-rich phase. Consequently, we believe that the observed increase in bulk non-wetting behavior originates from a synergistic effect of chemical encapsulation and physical arrangement in mesoscopic volumes of specific size. The results of this work suggest that it may be possible to tune the encapsulation of other types of organic functionalities such as corrosion resistance and anti-fouling. The combination of smaller surfactants and additional swelling agents could provide a new route to synthesis of these materials. 


\section{Structural, mechanical, and tribological properties of silica films with encapsulated hydrophobic functionality: effect of functional moiety and surfactant template concentrations}

This chapter describes the effect of composition on the structural, mechanical, and tribological properties of the mesostructured films. Porosity was related to the hardness of films, and the affect of these properties on wear was investigated in light of the changes in friction coefficient of exposed surfaces due to the encapsulation of the organofunctional groups.

\subsection{Overview}

Thin organo-functional coatings are inherently weak and can be easily damaged and their functional properties degraded by wear. Encapsulating organo-functional moieties into surfactant-templated ceramic coatings has the possibility of extending the functional lifetime of such materials. This study examines the effects of functional silane and surfactant template concentrations on the structural, mechanical, and tribological properties of hydrophobic silica films. Fluorinated silica films were synthesized via sol-gel co-condensation of tetraethoxysilane (TEOS) and a perfluoropolyether silane (FPES) and coated on glass substrates. The range of functional silane concentrations investigated was $x=0.02-0.05$, with $(1-x)$ TEOS: $(x)$ FPES representing the molar ratios of the two species. Pluronic F127 was used as the surfactant template in a concentration of $8 \%$ by mass with respect to total silanes. Contact angle measurements were used to measure the functionality of exposed surfaces. Nitrogen porosimetry was used to quantify mesostructure, nanoindentation was used to measure mechanical properties, and AFM was used to measure coefficient of friction. Films were gently abraded with a fine alumina slurry, and wear rates were determined by film thickness measurements on a stylus profilometer. The results show that the concentrations of fluorinated silane and surfactant template affected functional durability. However, surfactant templating creates void spaces which are detrimental to the mechanical properties of the material. Tribological results suggest 
that the low-friction surface generated by encapsulation of fluorosilane moieties grafted to internal surfaces mitigates to some extent the detrimental effect of film porosity on hardness and wear resistance.

\subsection{Introduction}

Non-wetting transparent coatings are beneficial for a wide range of applications including solar panels [1-3]; architectural structures [4]; optical displays and touch panels; and industrial/antifouling [6], automotive, textile, and household applications [5,7]. Conventional hydrophobic materials and surfaces suffer from low mechanical strength and low abrasion resistance. The weakness of hydrophobic polymers like polytetrafluoroethylene are compounded by low adhesive strength to substrates [18]. Monolayers or thin coatings may be synthesized by sol-gel co-condensation of fluorinated silanes with alkoxide precursors to create hard functional films $[20,21]$. These can perform better as thin films than bulk fluoropolymers owing to the strong SiO film-substrate bond accomplished by sol-gel grafting. However, when fluorinated silanes are combined by co-condensation with an alkoxide matrix, the functional moieties migrate to and align at the solid-vapor interface during film deposition $[23,81]$. This surface stratification makes it difficult to incorporate the functional moieties into the bulk, so they tend to reside more concentrated in a molecularly-thin region at the air interface. Although the chemical bond to the substrate is strong, the material as a functional coating still lacks mechanical durability because the surface layer is easily worn [4].

We have reported previously on the synthesis of coatings in which fluorinated silanes have been encapsulated within the bulk of the film as a mesoscopically dispersed phase formed by evaporation-induced assembly with a surfactant template [103]. Template-assisted encapsulation of the functional moiety allows the bulk of the film to remain substantially more hydrophobic than films that have not been templated. However, encapsulation is linked to an increase in film porosity compared to the non-templated material, and increasing porosity lowers the hardness of mesoporous sol-gel films [70,71]. On one hand, decreasing hardness should yield a higher abrasive wear rate. On the other hand, encapsulation of fluorosilanes yields not only more hydrophobic but also lower-friction internal surfaces. While we might expect softer materials to 
wear easily, low-friction surfaces may resist wear. These relationships are not easily predicted a priori, and this study will seek to elucidate through experiment how composition and structure affect the functional durability of these mesoscopically structured films.

\subsection{Experimental section}

\subsubsection{Preparation}

Fluorinated silica films were synthesized at room temperature via co-condensation of fluorinated silane with an alkoxide silica precursor in the presence of a surfactant. Tetraethoxysilane (TEOS, Acros Organics) was used as the alkoxide, a perfluoropolyether silane (FPES, Fluorolink S10, Solvay Solexis, MW = $1850 \mathrm{~g} / \mathrm{mol}$ ) was used for functionalization, and Pluronic F127 (MW = $12600 \mathrm{~g} / \mathrm{mol}, \mathrm{PEO}_{106} \mathrm{PPO}_{70} \mathrm{PEO}_{106}$, a gift from BASF) was used as the surfactant template.

Coating solutions were synthesized in $35 \mathrm{~g}$ batches as follows. First, TEOS was hydrolyzed with

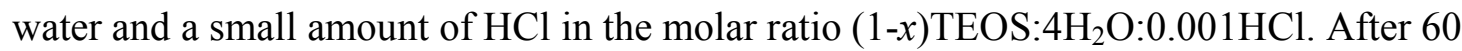
minutes of stirring, FPES was added and the sol stirred for 5 minutes to allow FPES hydrolysis. The sol was then diluted with ethanol to achieve a final molar ratio of (1$x$ )TEOS:( $x$ FPES: $4 \mathrm{H}_{2} 0: 0.001 \mathrm{HCl}: 20 \mathrm{EtOH}$. The range of $x$, the FPES molar concentration, was $0.02-0.05$. The sol was stirred for an additional 24 hours and filtered through a $0.47 \mu \mathrm{m}$ filter. Some coatings were not templated, in which case the concentration of surfactant template was = 0 . For those that were templated, F127 was added at a concentration of 8 mass percent $($ concentration $=100 \% \times$ F127/(TEOS + FPES + F127) $)$. Coating formulations described in this test will use the convention FxSy, where $x$ is the molar concentration of FPES and $y$ is the mass percent surfactant. Table 1 provides a summary of these formulations.

After several minutes of mixing to ensure homogeneity, the sols were coated on soda-lime glass microscope slides by dip coating at a withdrawal speed of $200 \mathrm{~mm} / \mathrm{min}$ in ambient air $\left(23 \pm 2{ }^{\circ} \mathrm{C}\right.$, $45 \pm 5 \%$ relative humidity). Slides were first cleaned by sonication at $40^{\circ} \mathrm{C}$ for 15 minutes each in an acid-based detergent, multiple washes of deionized water, and finally acetone. Coated films 
were then dried for 24 hours at ambient conditions before curing at $200^{\circ} \mathrm{C}$ for 3 hours in a box furnace with a ramp rate of $10^{\circ} \mathrm{C} / \mathrm{min}$.

Table 1. Various starting formulations investigated in this study. All are expressed in molar proportions, with the exception of F127 which represents a mass percent compared to total silanes.

\begin{tabular}{ccccccc}
\hline label & FPES & TEOS & water & HCl & ethanol & F127 \\
\hline F2S0 & 0.02 & 0.98 & 4 & 0.001 & 20 & 0 \\
F2S8 & 0.02 & 0.98 & 4 & 0.001 & 20 & 8 \\
F3S0 & 0.03 & 0.97 & 4 & 0.001 & 20 & 0 \\
F3S8 & 0.03 & 0.97 & 4 & 0.001 & 20 & 8 \\
F4S0 & 0.04 & 0.96 & 4 & 0.001 & 20 & 0 \\
F4S8 & 0.04 & 0.96 & 4 & 0.001 & 20 & 8 \\
F5S0 & 0.05 & 0.95 & 4 & 0.001 & 20 & 0 \\
F5S8 & 0.05 & 0.95 & 4 & 0.001 & 20 & 8
\end{tabular}

\subsubsection{Characterization}

Static contact angles were measured by placing five drops $(\sim 1.0 \mu \mathrm{L}$ each $)$ of deionized water approximately $1 \mathrm{~mm}$ apart using a manual microsyringe. This was done to cover a macroscopic and representative area, compared to the microscopic size of film structural features, and the results were averaged. Images were captured using a digital microscope and analyzed using the LB-ADSA method in the "Drop Analysis" plugin [75] for ImageJ.

Films were abraded using a lab-built reciprocating polishing wear apparatus. The details of the instrument are available elsewhere [92]. Briefly, this instrument uses a vertically-loaded, conformal polishing surface to uniformly and gradually wear through the surface of a film of thickness on the order of several hundred nanometers. The polishing media, composed of an aqueous slurry of $0.3 \mu \mathrm{m}$ alumina particles (90-187120, Allied), is trapped in a cloth pad (90150-285, Allied). The pad is in contact with the surface over a nominal area of $175 \mathrm{~mm}^{2}$, and a $4.70 \mathrm{~N}$ normal force is applied while the pad reciprocates over a stroke length of $35 \mathrm{~mm}$ at 0.1 Hz. These conditions were chosen to represent conditions similar to that of a finger touching an 
electronic sensor or manual cleaning of devices like solar panels. Samples were periodically removed for analysis, before which they were cleaned with water followed by alcohol to remove residue from abrasion.

Film thickness and roughness were measured on a Veeco Dektak 150 stylus profilometer. Roughness was measured over a $1000 \mu \mathrm{m}$ scan length. Coating wear rates were determined from multiple measurements of film thickness at multiple sliding distances until the coatings were completely worn. Wear rates were calculated using the equation

$$
K=\frac{V}{S \cdot F}
$$

where $V$ is the wear volume in $\mathrm{mm}^{3}, S$ the total sliding distance in $\mathrm{m}$ and $F$ is the applied normal load in N.

Optical transmission was measured using a UV-vis spectrometer (Jaz, Ocean Optics) on coatings deposited by dip coating on glass slides. X-ray diffraction (XRD) was conducted on a Bruker D8 Discover diffractometer with $\mathrm{Cu}-\mathrm{K} \alpha$ radiation $(\lambda=0.15417 \mathrm{~nm}, 40 \mathrm{~mA}, 40 \mathrm{kV})$, a $2 \theta$ step with of $0.01^{\circ}$, and step of $1 \mathrm{~s}$.

Porosity and pore size distribution were determined by $\mathrm{N}_{2}$ adsorption at $77 \mathrm{~K}$ using a Micromeritics ASAP 2020 analyzer. Samples for porosimetry were taken from freestanding films cast by evaporation of coating solutions and then calcined at $400^{\circ}$ for 24 hours. These were then degassed under vacuum at $120^{\circ} \mathrm{C}$ for 1 hour prior to the adsorption. The Barrett-JoynerHalenda (BJH) method was applied to the adsorption isotherm for the analysis of pore-size distribution.

Hardness and elastic modulus were measured by nanoindentation (NHT CSM Instruments) of a $10 \mu \mathrm{m}$ radius spherical diamond indenter. Values reported here were obtained from a penetration depth of $10 \%$ of the coating thickness to minimize substrate effects. 
Atomic force microscopy was conducted on a Molecular Imaging PicoScan 3000 system in contact mode with Si tips on cantilevers of nominal $k=2.5 \mathrm{~N} / \mathrm{m}$ and radius $<10 \mathrm{~nm}$.

Simultaneous imaging and friction measurements were made by applying forces in the range of $0-50 \mathrm{nN}$ to the tip scanning over $500 \mathrm{~nm}$ at a speed of $10 \mu \mathrm{m} / \mathrm{s}$. All measurements were conducted at $21 \pm 2{ }^{\circ} \mathrm{C}$ and $45 \pm 5 \%$. The tip was cleaned between samples by immersion in acetone for $1 \mathrm{~min}$ followed by drying in air.

\subsection{Results and discussion}

\subsubsection{Functional properties}

All unworn films had water contact angles (CA) in the range of $105-110^{\circ}$ with standard deviations of $<2^{\circ}$, and these were independent of FPES concentration. After a small number of wear cycles (sliding distance $<20 \mathrm{~m}$ ), the contact angles decreased, eventually fluctuating around some average value, reported here as the bulk contact angle. The coatings were all relatively smooth $\left(\mathrm{R}_{\mathrm{a}}<20 \mathrm{~nm}\right)$ both before and after polishing wear, and so the contact angle measurements can be considered unaffected by surface roughness effects. Bulk CA versus composition data are summarized in Figure 25. We observe that the CA of surfactant templated coatings is higher than that of the non-templated coatings at each FPES composition except for that with FPES $=0.05$, in which case the CA for templated and non-templated films are similar. As reported previously, the observed increase in hydrophobicity of exposed internal surfaces with increased surfactant concentration is due to encapsulation of FPES into the coating bulk [103]. The composition of F5S0 shows a large increase in bulk CA compared to F4S0. At this high concentration of FPES, the CA remains close to $90^{\circ}$ independent of surfactant concentration, indicating that a different mechanism is dominating the formation of these films. As discussed later in the section on tribological properties, these films were worn in a discontinuous manner, with areas of the coating delaminating from the substrate even at a low number of abrasion cycles. This film discontinuity limits the measurable CA of $\sim 1 \mu$ drops even though the concentration of FPES is very high. 


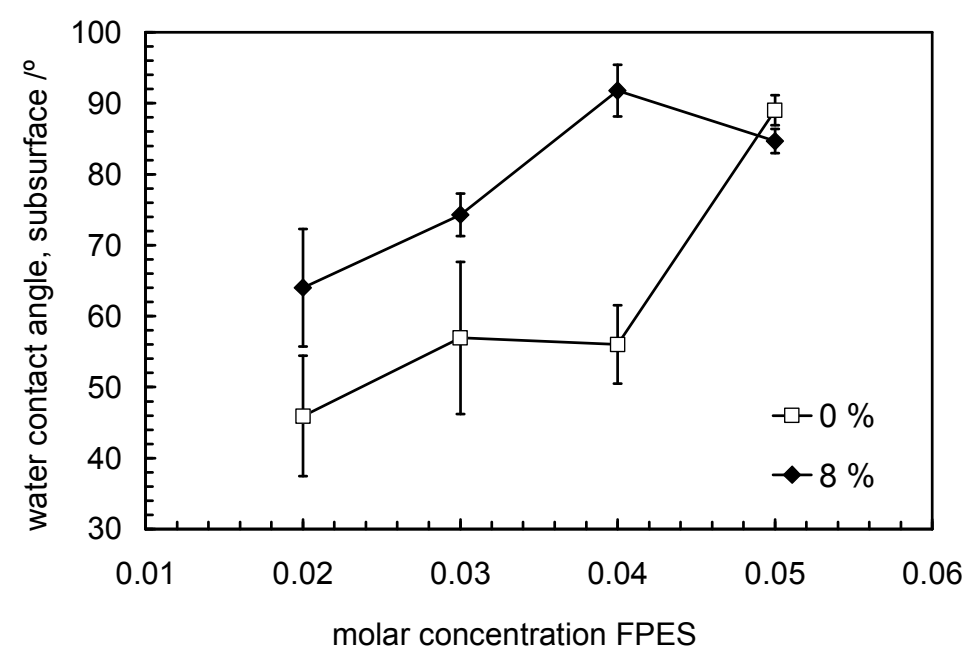

Figure 25. Average contact angle of water measured on subsurface areas of coatings that have been exposed by abrasion. Data are shown for films with various fluorosilane concentrations both with and without surfactant template.

Optical transmission measurements showed that all films were highly transparent in the visible range. Compared to the transmission of the soda-lime glass slides, which was $91.5 \%$ across the visible range, the average transmission of all coatings were higher and exhibited interference fringes, as can be seen from Figure 26. These properties are indicative of coatings that have a lower refractive index than the glass substrate, which has been shown to result from incorporation of fluorinated organics and mesoporosity effects [53,104-106]. Differences arise between the coatings due to their different composition and structure. 


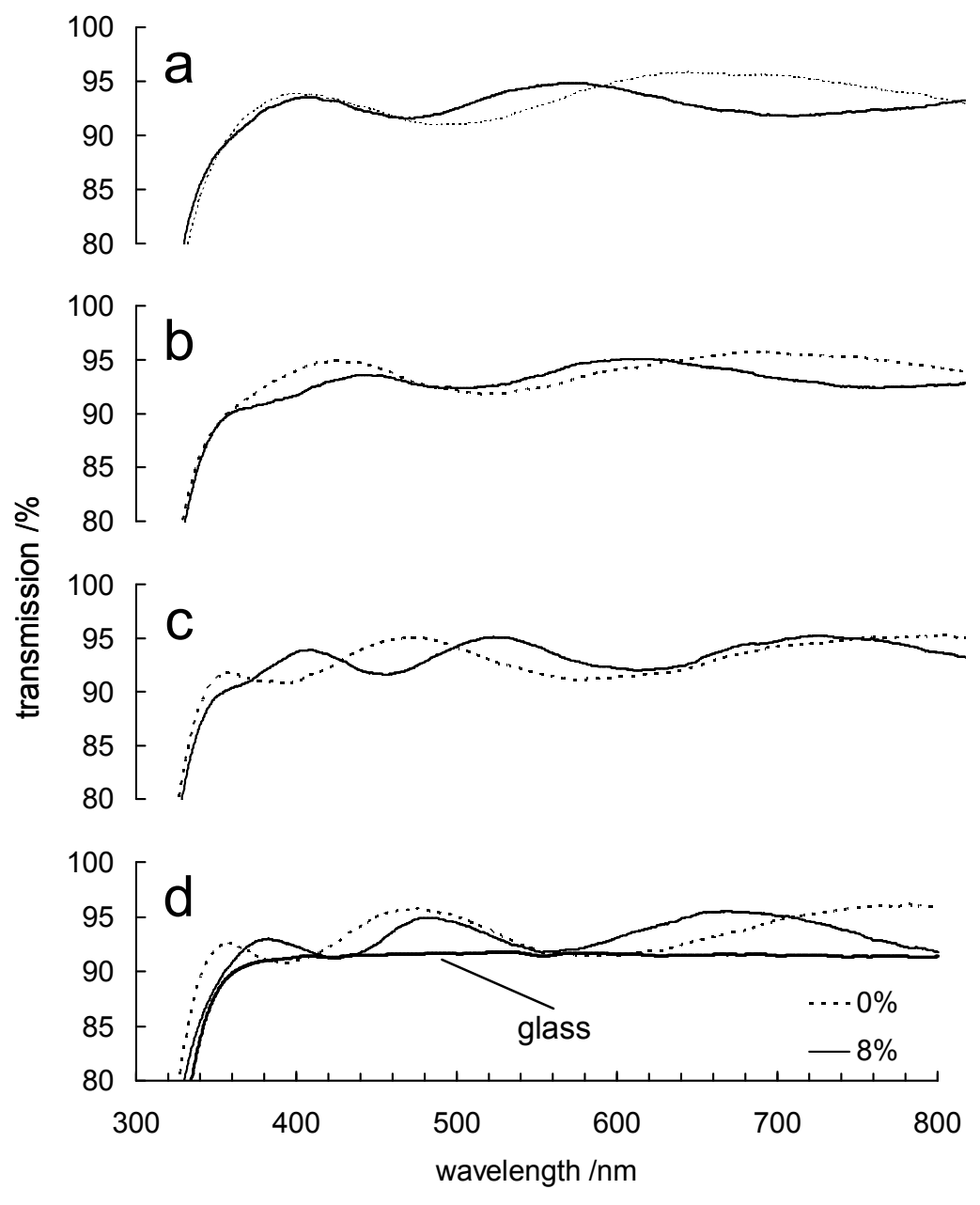

Figure 26. Optical transmission of templated and non-templated coatings on glass synthesized with fluorosilane concentrations: (a) 0.02, (b) 0.03, (c) 0.04, and (d) 0.05 .

\subsubsection{Structural and mechanical properties}

Coating thickness was measured by stylus profilometry and ranged from 300-700 nm. Thickness increased linearly with both concentration of FPES and surfactant, since these organic species add bulk to the alkoxide matrix. XRD measurements showed no discernable diffraction peak in the range of $0-52 \theta$, indicating a completely disordered mesoporous structure of the silica framework. In terms of mechanical properties, this may be advantageous, since disordered structures have been found to be harder than ordered structures [50,57]. 
Nitrogen adsorption-desorption isotherms are shown in Figure 27(a). All samples analyzed showed IUPAC type IV isotherms, which are characteristic of mesoporous materials. Without surfactant addition we observe that the calcined material is still mesoporous, owing to the strongly amphiphilic nature of fluorosilanes, which have been shown to act as mesoporous templates synergistically with extremely small quantities of surfactants [53]. As FPES concentration is increased from $0.02-0.05$, the total adsorbed volume increases, indicating an increase in porosity. Figure 27(b) shows BJH pore size distributions for these same films. Pore size generally increases with FPES concentration, although we observe that for the film with composition F5S0, the pore size distribution has become somewhat broader than the nontemplated films with lower FPES concentration. Even more pronounced is the effect of surfactant templating, which shows that the pore size distribution of F5S8 has shifted considerably to larger sizes and has become very broad, which contributes to the lower porosity of this material. At this extreme the structure of the framework may begin to be compromised by the high concentration of FPES compared to TEOS. At this point the FPES may physically interfere with gelation of the silica framework during film deposition, possibly resulting in a disordered and even partially lamellar structure. Such a structure could result in a lowering of porosity, an increasing in calculated pore size, and a substantial widening of the size distribution, all of which we observe from the data in Figure 27(a) and (b). 

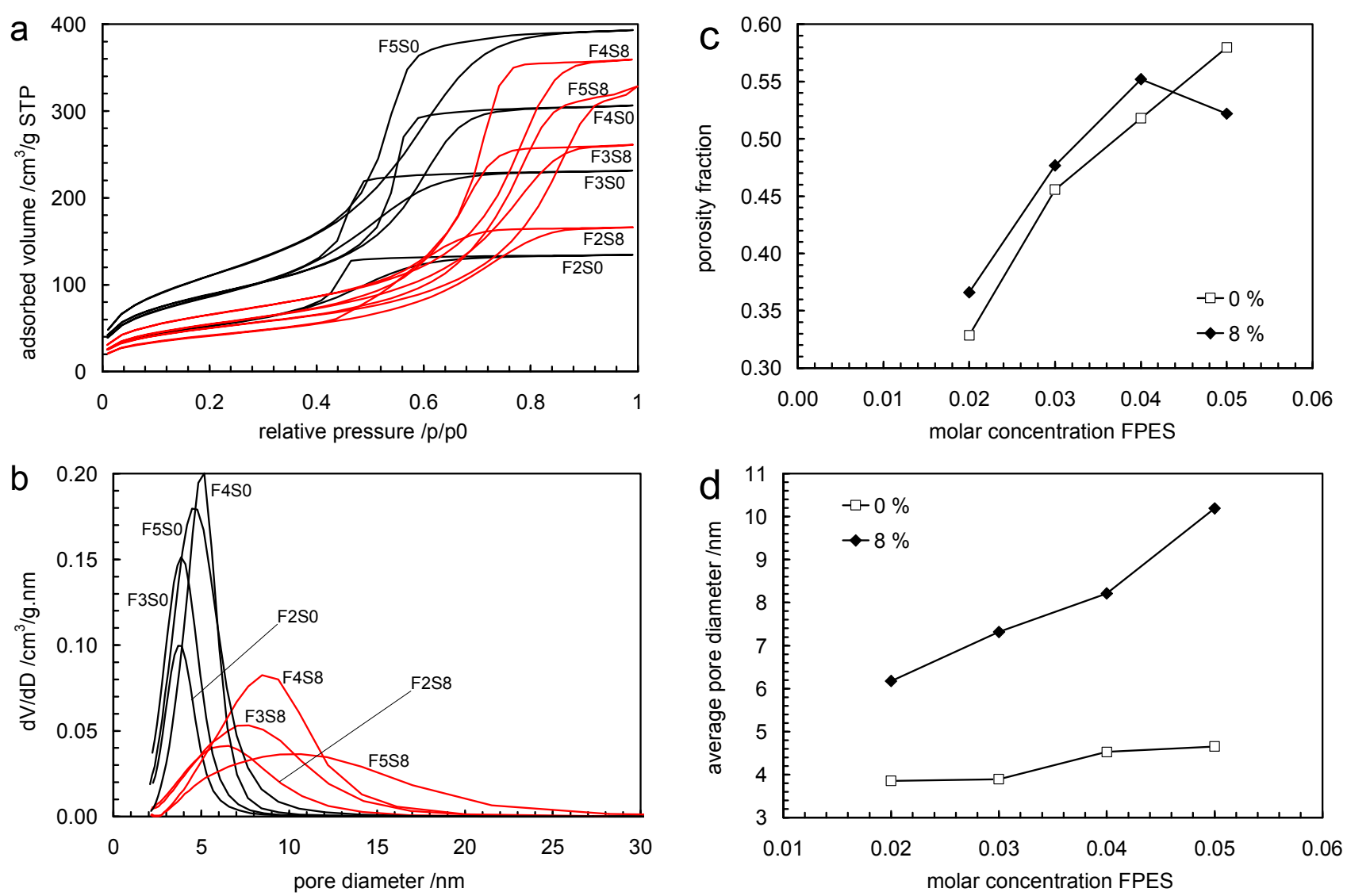

Figure 27. (a) Nitrogen adsorption-desorption isotherms and (b) BJH pore size distributions of calcined films synthesized with different fluorosilane concentrations both with and without surfactant template. (c) Porosity fraction and (d) average pore diameter of calcined films synthesized with different fluorosilane concentrations both with and without surfactant template.

Figure 27 (c) and (d) show a summary of porosimetry data. Porosity increases linearly with FPES concentration when no surfactant is added. There is a small increase in porosity due to the inclusion of $8 \%$ surfactant, except in the case of the composition F5S8. For F5S8, as mentioned above, the structure has changed substantially compared to all the other films, and the BJH model, which assumes cylindrical pores, may no longer be appropriate. Average pore diameter increases monotonically for templated and non-templated films. However, as can be observed from the BJH pre size distributions, the entire shape of the distribution must be considered.

Nanoindentation hardness and elastic modulus are summarized in Figure 4. Both hardness and modulus decrease with surfactant concentration, which is expected based on the increasing 
porosity. Hardness also decreases with addition of fluorosilanes, since these are soft and more compliant than the silica framework. Overall, the hardness values are similar to those reported for similarly porous films using large molecular weight swelling agents [70]. In that study, nanoindentation hardness values were in the range of $0.2-0.7 \mathrm{GPa}$ for a porosity range of $0.45-$ 0.6 .
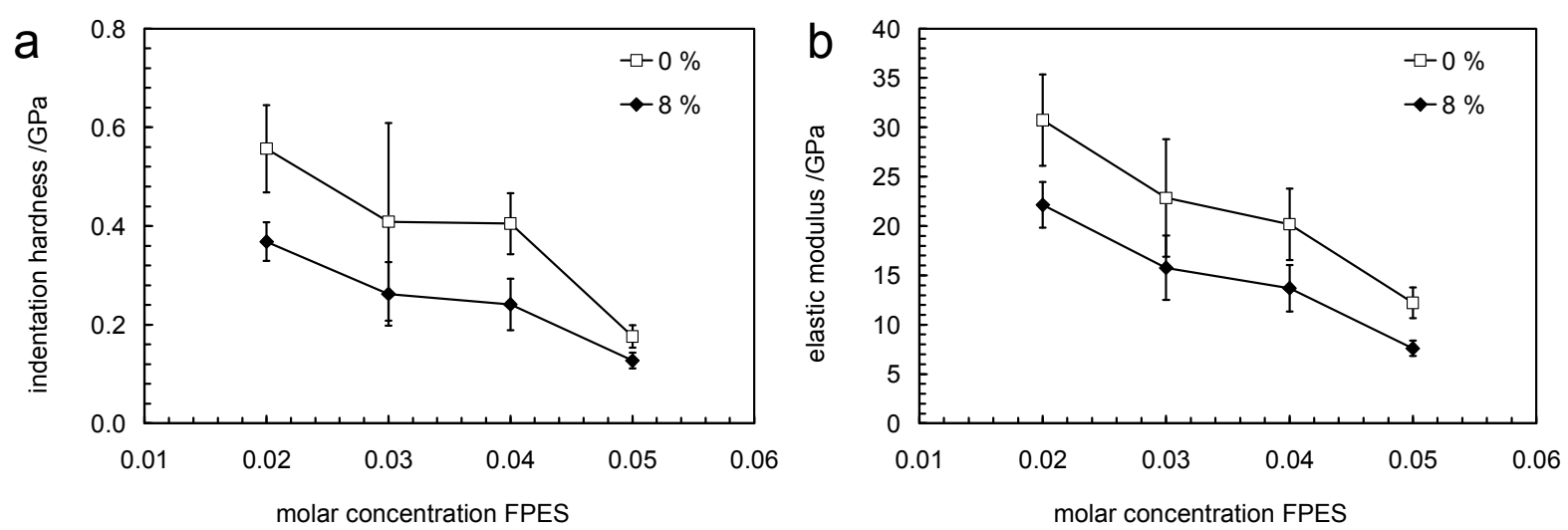

Figure 28. Nanoindentation (a) hardness and (b) elastic modulus of films synthesized with different fluorosilane concentrations both with and without surfactant template.

\subsubsection{Tribological properties}

As deposited, all films were smooth with roughness $\mathrm{R}_{\mathrm{a}}<2 \mathrm{~nm}$ as measured by stylus profilometry over $1000 \mu \mathrm{m}$ scan lengths. During wear, after $10 \mathrm{~m}$ of sliding (90 cycles), the roughness of the film surfaces increased to between 15 and $20 \mathrm{~nm}$ and remained in that range during all subsequent wear cycles. Figure 5(a) shows an optical micrograph of a film with composition F4S8 worn for $100 \mathrm{~m}$. The film surface shows shallow wear tracks parallel to the sliding direction, and wear is caused by cohesive failure of the coated material due to mild abrasion. This behavior was noted for all films with composition of FPES $=0.02-0.04$. However, for films with FPES $=0.05$, the primary wear mechanism was different. Figure $5(\mathrm{~b})$ shows a film with composition F5S 8 worn for only $20 \mathrm{~m}$. In this micrograph we observe shallow wear tracks on the coated portion that are parallel to the sliding direction. The roughness of these parts was $<$ $20 \mathrm{~nm}$. However, large areas of the coating have been removed in a pattern indicative of adhesive failure and delamination of the coating from the glass substrate. This adhesive wear contributes to the high wear rates observed for the films with FPES $=0.05$, as shown below. 

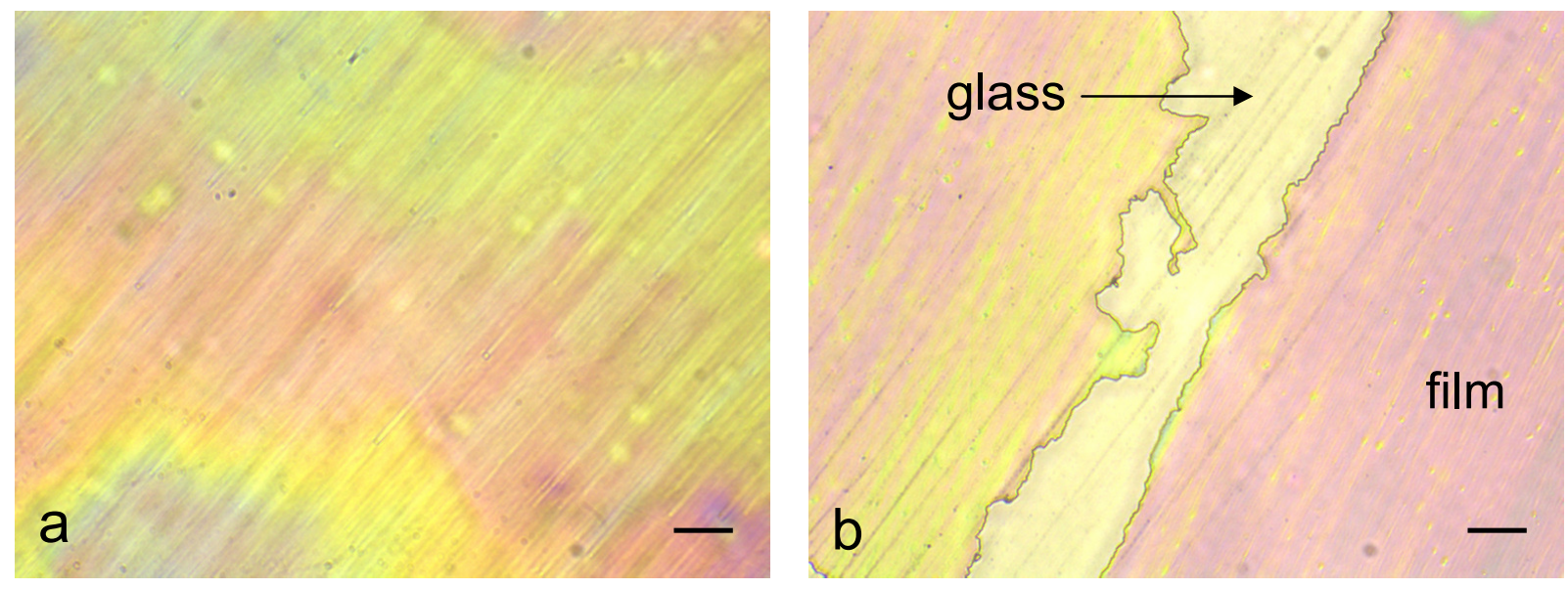

Figure 29. Optical micrographs (a) of film with composition F4S8 worn for $100 \mathrm{~m}$, and (b) film with composition F5S8 worn for $20 \mathrm{~m}$. Sliding direction of wear for both micrographs is from bottom left to top right. Scale bars are $100 \mu \mathrm{m}$.

Figure 30 shows the wear rates of films with the various compositions studied here. The wear rate of non-templated films increases roughly linearly in the range of FPES $=0.02-0.04$, and then nearly doubles at FPES $=0.05$. As described above, this is due to the rapid loss of material by delamination from the substrate. The wear rates of templated films were higher than those of the non-templated films for each corresponding FPES concentration. We attribute this to the increased porosity and lower hardness of the templated materials. Although porosity increases and hardness decreases for templated films in the range of FPES $=0.02-0.04$, the wear rate increases only slightly in this range, and it then increases greatly at FPES $=0.05$. Based on the porosimetry and hardness data alone, which indicate that templating creates a more porous and therefore less mechanically robust structure, these observations are not expected. We might expect that since porosity and hardness both trend linearly with respect to FPES, the wear rate of the templated films should have a linear dependency as well - at least in the range of FPES = $0.02-0.04$, prior to the onset of adhesive wear at F5S8. This would place the wear rate of F4S8 between F3S8 and F5S8. Clearly the observations do not coincide with these predictions. 


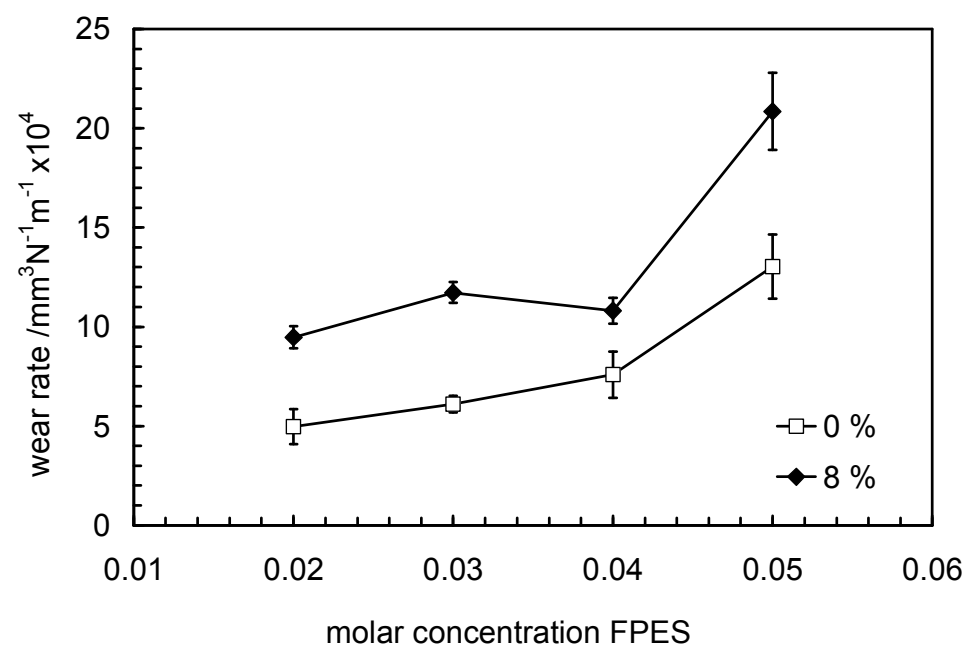

Figure 30. Wear rate of films synthesized with different fluorosilane concentrations both with and without surfactant template.

To help explain this phenomenon, relative friction coefficients were determined. Friction was measured on films that had been partially worn for $20 \mathrm{~m}$ sliding distance (180 cycles) in order to expose the inner surface, which is what was presented to the abrading media for most of the coating lifetime and was always less hydrophobic and less lubricious than the unworn top surface. AFM was selected for tribological characterization in this study since the actual tribological contact using the reciprocating apparatus is between the film and $0.03 \mu \mathrm{m}$ alumina particles, so the contact of an AFM probe tip is more appropriate than a larger scale tribometer even though a macroscopically large area was worn on each film. Areas selected for friction force measurements, summarized in Figure 31, were areas of the subsurface exposed by wear and not just the lightly top surface, as will be detailed below in discussion of the AFM micrographs. The relative friction coefficient is observed to decrease with surfactant and FPES concentration, since the films that are more hydrophobic are also lower friction due to the lubricating nature of fluorocarbon materials. Consequently, there should be a mitigating effect on wear rate of lower friction surfaces, provided that the film material has sufficient cohesive shear strength and substrate adhesion. For films with FPES $=0.05$, the material still wears quickly even though it is lubricious, and this is partially due to the adhesive failure of the coating from the substrate, as well as its low hardness. 


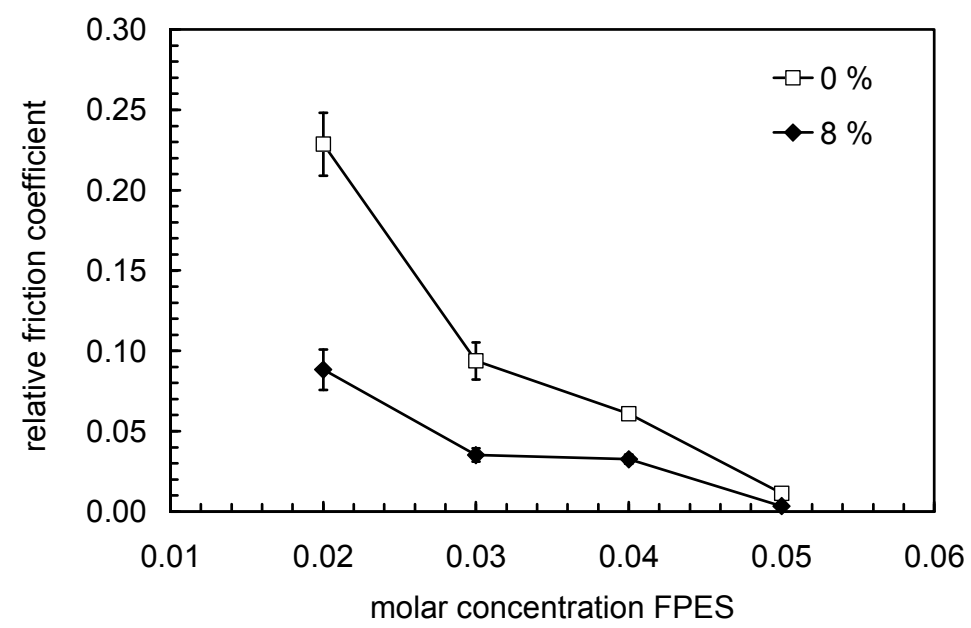

Figure 31. Relative friction coefficients of subsurface areas of coatings that have been exposed by abrasion. Friction was measured using AFM with a Si tip scanning at a speed of $10 \mu \mathrm{m} / \mathrm{s}$.

Topographical and friction force micrographs were also obtained using AFM, and these reveal interesting surface properties of the coatings. The sliding direction of wear for all micrographs was from top left to bottom right, and all films were worn for $20 \mathrm{~m}$ to expose the interior pore surfaces. Topographical micrographs have been scaled automatically by the software, and the vertical range is provided in the figure captions. Friction force micrographs show higher friction areas in brighter shades and lower friction in darker shades, and the vertical range expressed as a raw voltage signal is provided in the figure captions. The micrographs shown below were selected because they show an interesting range of coating compositions, structures, and tribological behaviors.

The film with composition F2S0 in Figure 32 (a) exhibits some shallow wear tracks parallel to the sliding direction. We observe also that the wear is delamination-like: the surface has worn in a step-like manner, with the exposed subsurface regions being approximately $30 \mathrm{~nm}$ below the top surface. This change in thickness is close to the average film thickness measurements obtained by stylus profilometry. The friction force micrograph obtained of the same surface, shown in Figure 32 (b) shows that the higher surface in (a) are lower friction areas and that the exposed subsurface has a higher coefficient of friction. More details of these surfaces are shown in Figure 32 (c) and (d), which show a magnified view of the same F2S0 surface. The worn film 
with composition F3S0 is shown in Figure 33 (a) and (b). The delamination-like pattern of wear of the top surface is similar to that observed for F2S0.
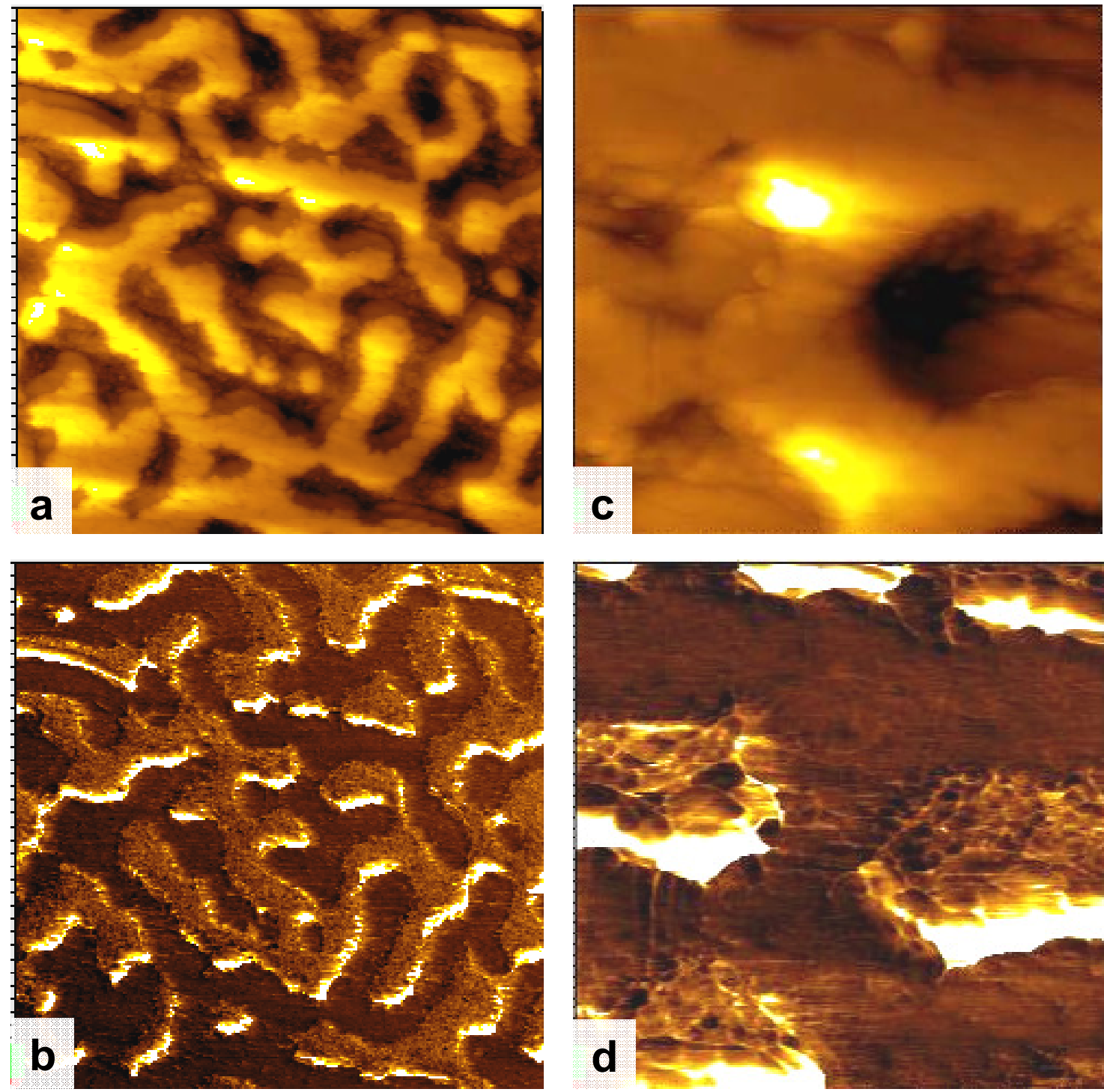

Figure 32. Topographic and friction force micrographs captured by AFM of partially worn films. Sliding direction of wear for all micrographs is from top left to bottom right, and all films were worn for $20 \mathrm{~m}$ sliding distance. (a)

Topography of film with composition F2S0, scan size: $8 \mu \mathrm{m} \times 8 \mu \mathrm{m}$, vertical topography range: $50 \mathrm{~nm}$. (b) Simultaneous friction force map of film in (a), vertical range $=0.20 \mathrm{~V}$. (c) Topography of film with composition F2S0, scan size: $2 \mu \mathrm{m} \times 2 \mu \mathrm{m}$, vertical topography range: $35 \mathrm{~nm}$. (d) Simultaneous friction force map of film in (c), vertical range $=0.18 \mathrm{~V}$. 

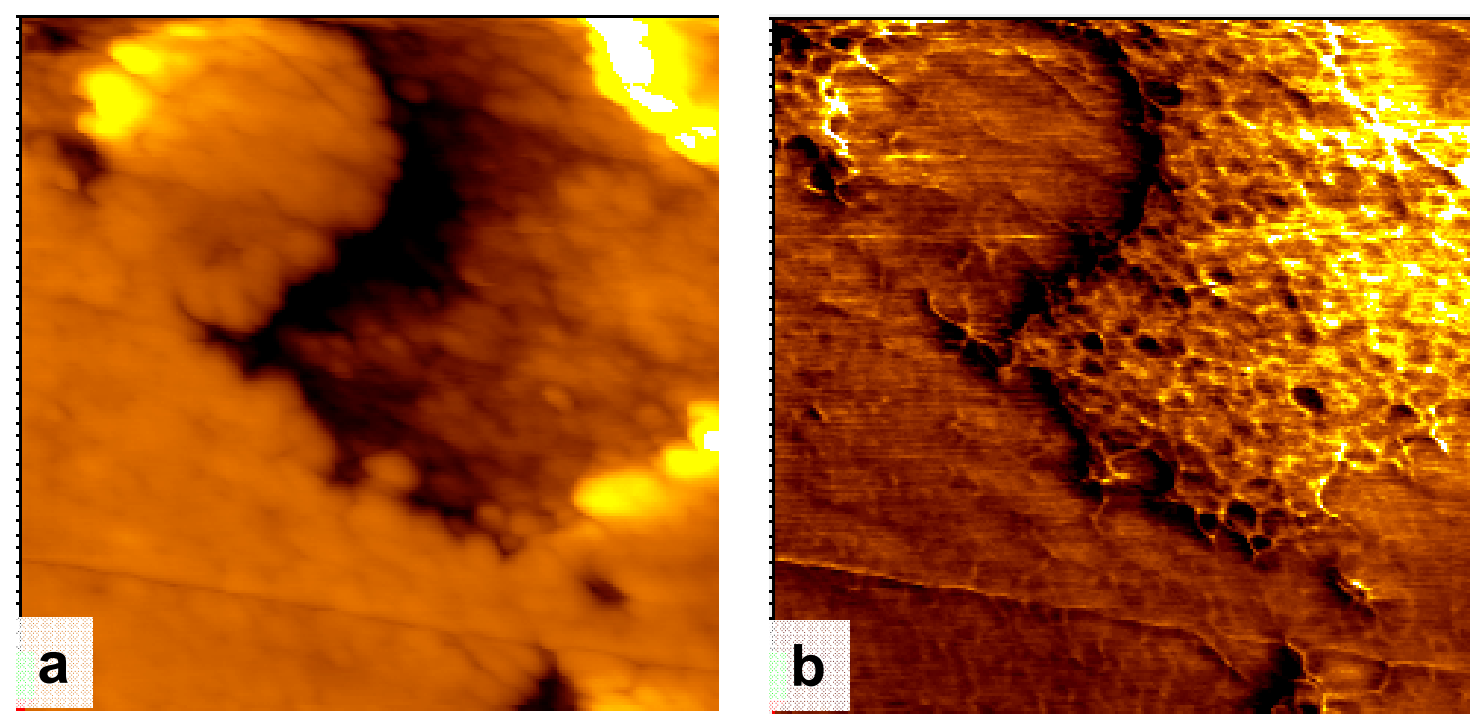

Figure 33. Topographic and friction force micrographs of captured by AFM of partially worn film. Sliding direction of wear for both micrographs is from top left to bottom right, and films were worn for $20 \mathrm{~m}$ sliding distance. (a)

Topography of film with composition F3S0, scan size: $2 \mu \mathrm{m}$ x $2 \mu \mathrm{m}$, vertical topography range: $25 \mathrm{~nm}$. (b) Simultaneous friction force map of film in (a), vertical range $=0.12 \mathrm{~V}$.

Figure 34 (a) and (b) show topographical and friction force micrographs F4S0. The top surface again shows shallow wear tracks parallel to the sliding direction, and in certain areas it has been removed in a step-like manner from the subsurface areas approximately $30 \mathrm{~nm}$ below. The film with composition F4S8 is shown in Figure 34 (c) and (d). Here the top surface has been worn away completely during the initial $20 \mathrm{~m}$ of sliding wear, and only the subsurface remains. Here the wear tracks are apparent, and their maximum depth is $5 \mathrm{~nm}$. A magnified view of this surface is shown in Figure 35 (a) and (b). In these micrographs the mesostructure begins to be visible. 

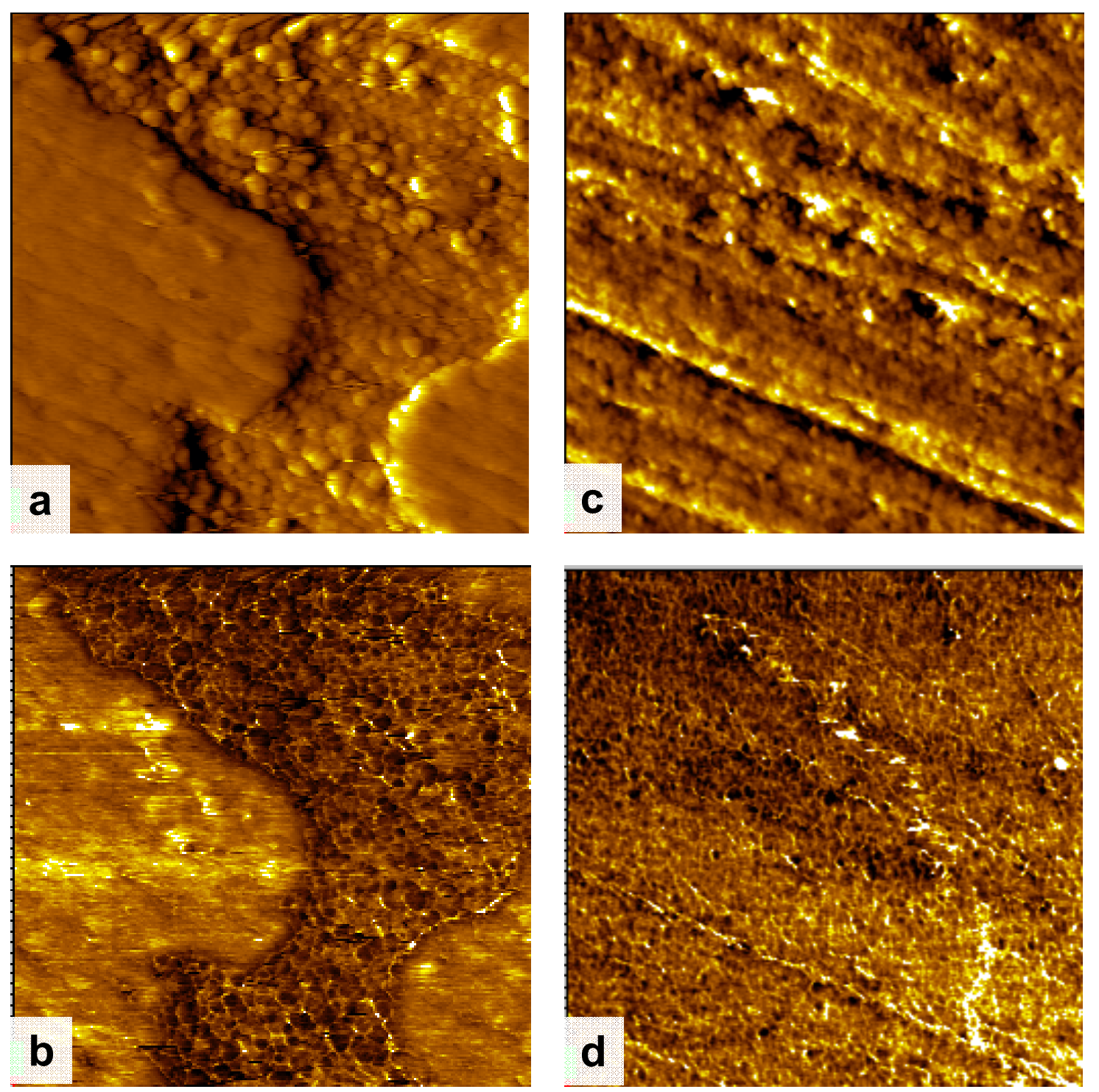

Figure 34. Topographic and friction force micrographs captured by AFM of partially worn films. Sliding direction of wear for all micrographs is from top left to bottom right, and all films were worn for $20 \mathrm{~m}$ sliding distance. (a)

Topography of film with composition F4S0, scan size: $2 \mu \mathrm{m}$ x $2 \mu \mathrm{m}$, vertical topography range: $30 \mathrm{~nm}$. (b) Simultaneous friction force map of film in (a), vertical range $=0.15 \mathrm{~V}$. (c) Topography of film with composition F4S8, scan size: $2 \mu \mathrm{m}$ x $2 \mu \mathrm{m}$, vertical topography range: $5 \mathrm{~nm}$. (d) Simultaneous friction force map of film in (a), vertical range $=0.04 \mathrm{~V}$.

Topographical features such as steps and scratches have been shown to influence adhesion and friction mapping using AFM due to the increasing area of interaction between the textured surface and sharp tip [107-109]. Here we observe that only the deepest of the wear tracks 
detected in Figure 34 (c) are observable as artifacts in the friction force micrograph (d). Likewise, there may be a small contribution of the topography in Figure 35 (a) to the frictionforce distribution in (b). However, it appears that Figure 35 (b) shows that the internal pore surfaces are low-friction areas compared with the matrix material that makes up the pore walls. This is a result of the encapsulation of FPES within these mesoscopic pockets dispersed throughout the film bulk.
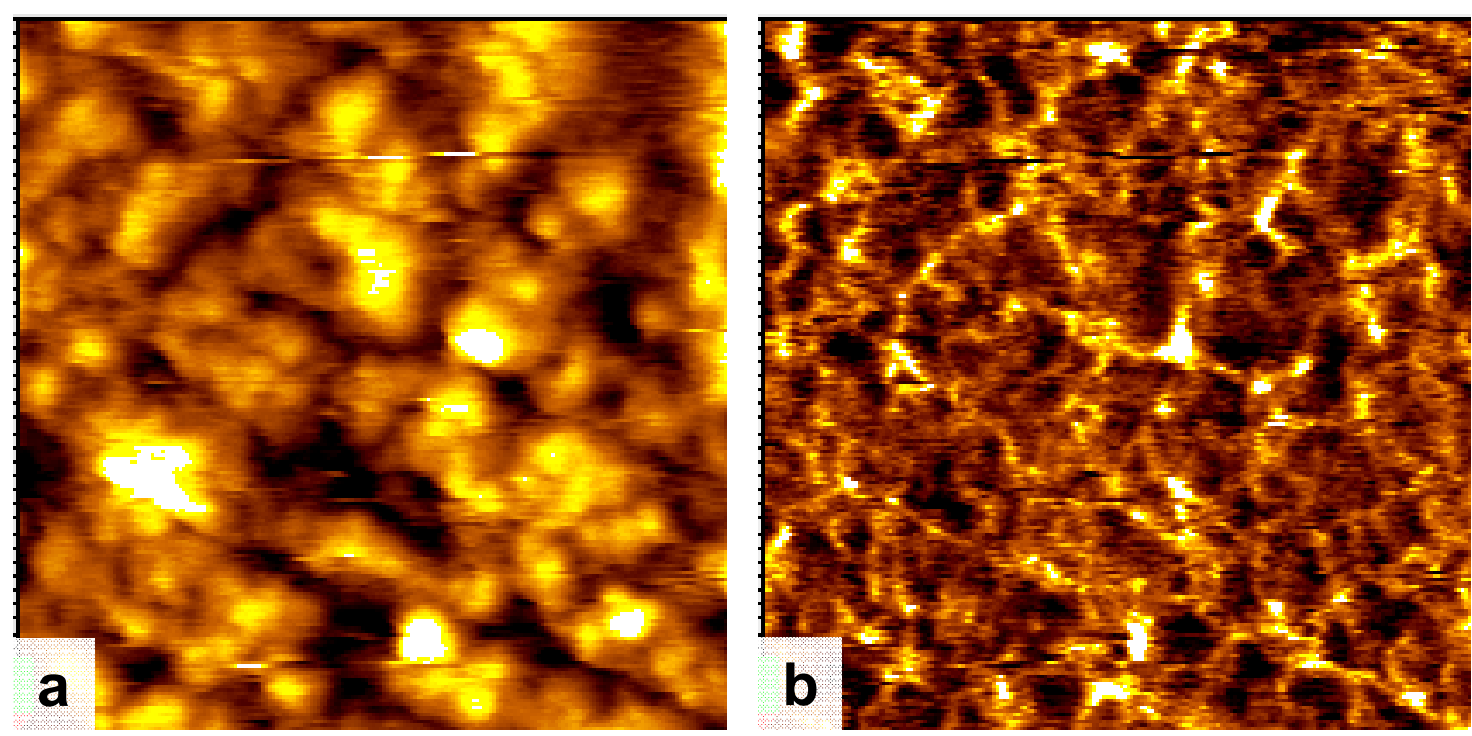

Figure 35. Topographic and friction force micrographs of captured by AFM of partially worn film. Sliding direction of wear for both micrographs is from top left to bottom right, and films were worn for $20 \mathrm{~m}$ sliding distance. (a) Topography of film with composition F4S8, scan size: $0.5 \mu \mathrm{m}$ x $0.5 \mu \mathrm{m}$, vertical topography range: $4 \mathrm{~nm}$. (b) Simultaneous friction force map of film in (c), vertical range $=0.03 \mathrm{~V}$.

In designing hydrophobic-oleophobic films for sustained functionality in tribological environments, several factors must be considered. First, non-wetting properties are determined fundamentally through chemical means, so enhancing functionality must be attained through increasing concentration of fluorinated moieties, as shown in Figure 36 (a). Using surfactants to template the mesostructure enables this encapsulation of surface-segregating moieties, although the surfactant itself tends to accumulate which increases wetting behavior. To create mechanically robust functional materials, consideration must be given to the structural changes induced by varying film composition, such as the changes in the pore size distribution and the need to maintain strong mechanical properties by minimizing void space. Furthermore, the 
behaviour of the film during tribological contact is complicated by the contribution of functional chemistry to creating a low-friction surface, which tends to reduce wear by abrasion. Figure 36 (b) shows a compilation of the wear rate behavior versus encapsulation of fluorine. Unlike the data in Figure 36 (a), there is no clear linear trend here. The films with low F/Si had low to moderate wear rates and the films with very high $\mathrm{F} / \mathrm{Si}$ had high wear rates. However, films with moderate $\mathrm{F} / \mathrm{Si}$ had wear rates relatively unaffected by the $\mathrm{F} / \mathrm{Si}$ ratio. These data indicate that multiple mechanisms contribute to the mechanical robustness of these mesostructured functional materials.
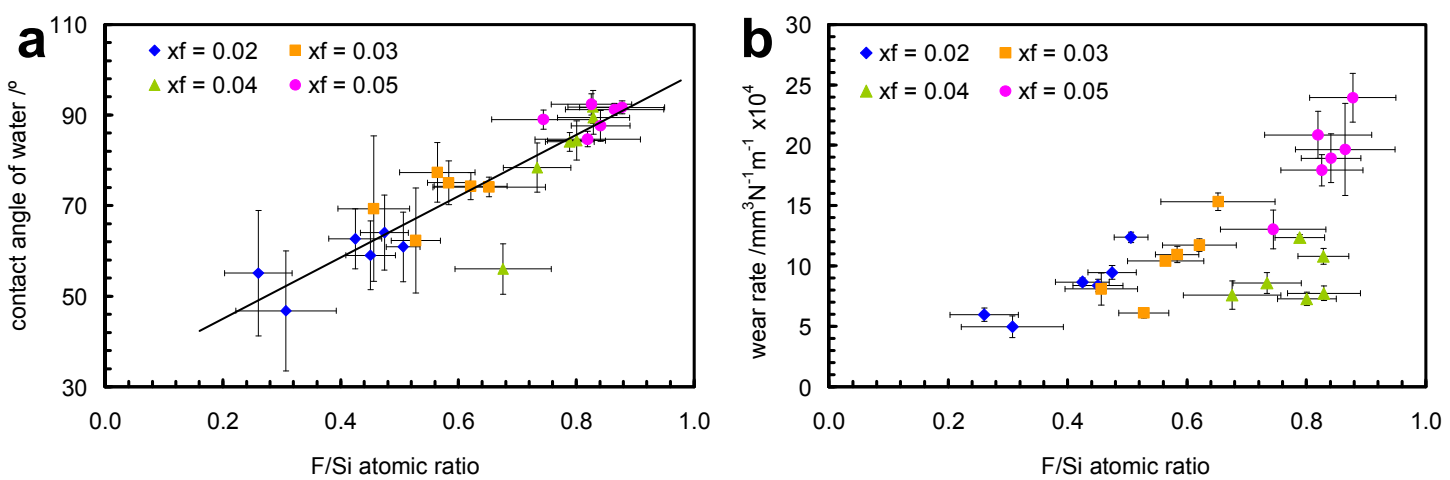

Figure 36. a) Compilation of bulk contact angle of water versus F/Si atomic ratio for all compositions synthesized. Line is linear best fit to the data. (b) Compilation of wear rate versus F/Si atomic ratio for all compositions synthesized.

\subsection{Conclusion}

We investigated the composition-structure-properties relationships of transparent surfactant templated hydrophobic sol-gel silica films. In creating mechanical robust functional materials, consideration must be given to the structural changes induced by varying film composition, such as the changes in the pore size distribution and the need to maintain strong mechanical properties by minimizing void space. Fluorosilane and surfactant template concentrations were varied to elucidate the effect of organic functionality and porosity on surface, structural, mechanical, and tribological properties. We found that surfactant templating allowed worn films to be more hydrophobic than their non-templated counterparts through encapsulation of fluorosilanes. 
Increasing concentrations of fluorosilanes and surfactant template resulted in more porous and therefore softer films. Tribological investigation showed that hydrophobicity correlated to increased lubricity. However, multiple mechanisms were involved in the abrasive wear of the coatings. Hardness, lubricity, and coating-substrate adhesion were all found to influence the wear of these materials. At lower fluorosilane concentrations, coating-substrate adhesion was found to be sufficiently high that the primary cause of coating failure was abrasive wear. However, at high fluorosilane concentrations, although the surfaces were hydrophobic without the aid of a surfactant template, the coating structure became disrupted and rapid adhesive wear became the dominant wear mechanism. 


\section{Microtribological study of internal surfaces of fluorinated mesoporous silica films}

This chapter describes a microtribological investigation of the internal surfaces of fluorinated silica films, comparing the properties of surfactant templated films to those of non-templated films. Tribological properties, including the dependence of friction coefficient on sliding speed, were compared to those of conventional functional monolayers in order to elucidate the difference between these surfaces.

Reproduced with permission from A.J. Kessman, D.R. Cairns, "Microtribological Study of Internal Surfaces of Fluorinated Mesoporous Silica Films,” Langmuir 27 (10) 2011, 5968-5975. Copyright 2011 American Chemical Society. http://dx.doi.org/10.1021/la2000238 [103]

\subsection{Overview}

Fluorinated mesoporous silica films were synthesized via sol-gel co-condensation and coated on glass substrates. Surfactant template concentrations were varied to examine the effect of encapsulated organic functionality on the microtribological properties of films using atomic force microscopy. Films were tested as synthesized and also after being abraded to expose interior mesostructured surfaces. Results indicate that templating allows fluorinated moieties to become encapsulated within the film, which affect the tribological properties of the exposed internal surfaces. Depending on the amount of template added, the interior surfaces were able to achieve a friction level comparable to that of conventional monolayers. The dependence of friction on sliding speed revealed that fluorinated templated films have tribological properties intermediate to those of a non-functional surface and a conventional fluorinated monolayer. 


\subsection{Introduction}

Self-assembled monolayers have been studied extensively in terms of their tribological properties as boundary lubricants [37,76,89,110-119]. Monolayers have been particularly useful for preventing stiction, friction, and wear in microelectromechanical systems (MEMS) devices [120-122]. Chemisorbed monolayers, such as those terminated by silane and thiol groups, have been shown to be more resilient than Langmuir-Blodgett layers owing to their strong chemical bonding to substrates as opposed to the physisorbed Langmuir-Blodgett films $[119,123,124]$. Furthermore, silanes have been shown to be more resistant to removal by wear than thiols, and this has been attributed to the strong $\mathrm{Si}-\mathrm{O}$ bonds of silanes compared to the weaker $\mathrm{Au}-\mathrm{S}$ bonds of thiols $[114,124]$. In general, the use of various monolayer types is interesting, since various factors such as end-group chemistry, molecular packing arrangement, molecular mobility, and conformation may be manipulated to affect microtribological properties.

Sol-gel films, in which functional groups are co-condensed with an alkoxide matrix, have generally not been studied in terms of microtribological properties. In many cases, this may be because these types of films do not offer any advantage over monolayers, since only the top surface tends to be functional. During deposition, the organic functional groups such as alkylsilanes or fluorinated silanes migrate to the liquid-vapor surface where they remain after film solidification [92]. They do so because of their phase-segregating nature and thermodynamic drive to minimize surface energy - it is this very chemical repellency that makes them useful in lowering friction [23,81]. This surface stratification makes it difficult to incorporate the functional moieties into the bulk, so they tend to be concentrated in a molecularly-thin region at the air interface. What remains is an organo-functional monolayer atop a hardened supporting film that has substantial thickness, usually in the hundreds of nanometers, compared to the single nanometer scale thickness of the monolayer alone.

The focus of our study is to investigate the tribological properties of internally functionalized surfactant-templated mesoporous films synthesized by co-condensation of a fluorinated silane with tetraethoxysilane through the process of evaporation induced self assembly [38]. In these films, the silica matrix acts as a scaffold for fluorinated silanes that are able to align at the internal mesopore surfaces. If through surfactant templating the fluorinated moieties are 
encapsulated in the film bulk to a greater extent than in a non-templated film, we may expect that once the top surface layer is removed, the interior functionality will present a low-friction tribological surface. Scanning probe techniques such as atomic force microscopy (AFM) are useful methods by which to probe these functional and partially-functional surfaces and subsurfaces, since they are sensitive to physicochemical properties at small scales and spatial resolutions. Furthermore, other functionalities may be encapsulated for a broad range of applications including anti-fouling, anti-microbial [5,83-85], anti-icing [86], and anti-corrosive materials [87].

Mesoporous films are generally popular for applications like catalysis and separations and so are generally engineered for high porosity and surface area. Other applications include low- $k$ dielectric films for integrated circuits, and these have often been functionalized with fluorosilanes [35,53]. While the mechanical properties of templated films have been studied [70], the tribological properties of functional mesoporous films have not been examined as much. One study examined the wetting and stiction properties of fluorinated sol-gel silica films with a templated surface structure that enabled superhydrophobicity. Those authors used very high concentrations of templates to create a rough surface texture, minimizing contact area and stiction, but the subsurface properties were not probed [125]. Although sol-gel is frequently used to create strongly-grafted chemically functional surfaces, the subsurface functionality has been less examined, and this area is the subject our study. Microtribological investigations of the subsurface are of broad interest because an understanding of the internal functionality provides an indication of the efficacy of encapsulation. Additionally, for some applications, the top surface may degrade over time, thus exposing the internal surfaces, and these should be compared in terms of relative functionality. The ability to distribute surface-segragating functional groups throughout the full thickness of a durable scaffold is of significant scientific interest, since surface enrichment of organic functional groups is common for sol-gel hybrid films [126]. To the best of our knowledge, this is the first time the subsurface properties of functional films have been investigated with a focus towards effective encapsulation of the functional moieties. Furthermore, tribological properties, such as friction-scan velocity dependencies, can reveal information regarding the physical and chemical structure of surfaces. 
In this paper, we investigate the subsurface tribological properties of various fluorinated mesoporous silica films compared to that of a conventional fluorinated monolayer. Film composition and macroscopic functional properties were examined by contact angle measurements and X-ray photoelectron spectroscopy (XPS) of the top surface and of films with the top surface removed by mild abrasion or sputtering to expose the internal functional mesostructure. AFM was used to determine the adhesive forces and microtribological interactions between the $\mathrm{Si} / \mathrm{SiO}_{2}$ tip and the various surfaces examined here. Relative friction coefficients were determined, and the dependence of friction on sliding speed was examined and related to accepted theories of physicochemical tribological interactions.

\subsection{Experimental section}

\subsubsection{Preparation}

Fluorinated silica films were synthesized at room temperature via co-condensation of fluorinated silane with an alkoxide silica precursor in the presence of a surfactant. Tetraethoxysilane (TEOS, Acros Organics) was used as the alkoxide. A perfluoropolyether silane (FPES, Fluorolink S10, Solvay Solexis) was used for functionalization in order to present the best possible surface for non-wetting properties. Fluorolink S10 was selected for this study because it has a fairly large molecular weight (average $=1850 \mathrm{~g} / \mathrm{mol}$ ) compared to perfluoroalkylsilanes and two silane grafting end groups. Longer functional molecules have been shown to increase the lubricity of films [127] and two grafted ends increases resistance to mechanical removal from the matrix [32]. Additionally, interchain hydrogen bonding between amide moieties has been found to enhance intermolecular stability [36,37,89]. Pluronic F127 (MW = 12600, $\mathrm{PEO}_{106} \mathrm{PPO}_{70} \mathrm{PEO}_{106}$, a gift from BASF) was used as the surfactant template.

Coating solutions were synthesized in $35 \mathrm{~g}$ batches as follows. First, TEOS was hydrolyzed with

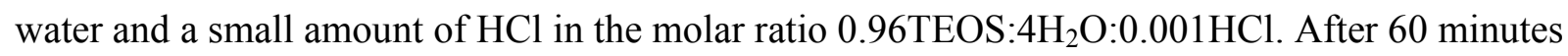
of stirring, FPES was added and the sol stirred for 5 minutes to allow FPES hydrolysis. The sol was then diluted with ethanol to achieve a final molar ratio of 0.96TEOS:0.04FPES:4H $\mathrm{H}_{2} 0: 0.01 \mathrm{HCl}: 20 \mathrm{EtOH}$. The sol was stirred for an additional 24 hours and filtered through a $0.47 \mu \mathrm{m}$ filter. The surfactant template was then added at a concentration $x_{s}$ 
expressed as a mass percent of F127 to total silanes $=100 \% \times$ F127/(TEOS + FPES + F127). The range of $x_{s}$ was $0-8 \%$. For comparison, one coating was synthesized without FPES and with a surfactant concentration of $8 \%$. After several minutes of mixing to ensure homogeneity, the sols were coated on soda-lime glass microscope slides by dip coating at a withdrawal speed of $200 \mathrm{~mm} / \mathrm{min}$ in ambient air $\left(23 \pm 2{ }^{\circ} \mathrm{C}, 45 \pm 5 \%\right.$ relative humidty). Slides were first cleaned by sonication at $40^{\circ} \mathrm{C}$ for 15 minutes each in an acid-based detergent, multiple washes of deionized water, and finally acetone. Coated films were then dried for 24 hours at ambient conditions before curing at $200^{\circ} \mathrm{C}$ for 3 hours in a box furnace with a ramp rate of $10^{\circ} \mathrm{C} / \mathrm{min}$.

\subsubsection{Characterization}

Static contact angles were measured by placing five drops $(\sim 1.0 \mu \mathrm{L}$ each $)$ of deionized water approximately $1 \mathrm{~mm}$ apart on surfaces to cover a macroscopic and representative area, compared to the microscopic size of film structural features, and the results were averaged. Contact angles were measured on virgin coating surfaces and surfaces abraded with an aqueous slurry of $0.3 \mu \mathrm{m}$ alumina particles (90-187120, Allied) [92]. After abrasion, the films were washed with water and isopropanol then dried in air in preparation for contact angle and microscopic analysis. Film thickness and roughness were measured on a Veeco Dektak 150 stylus profilometer. Roughness was measured over a $250 \mu \mathrm{m}$ scan length.

X-ray photoelectron spectroscopy (XPS) was conducted on a Physical Electronics PHI 5000 VersaProbe system. The X-ray beam was $100 \mu \mathrm{m}, 25 \mathrm{~W}$, and $15 \mathrm{kV}$, from a monochromatic Al $\mathrm{K} \alpha$ source using charge neutralization and pass energy $=93 \mathrm{eV}$. Depth profiling was conducted by Ar sputtering a $2 \mathrm{~mm}$ square area at $4 \mathrm{kV}$ and $10 \mu \mathrm{A}$.

Porosity and pore size distribution were determined by $\mathrm{N} 2$ adsorption at $77 \mathrm{~K}$ using a Micromeritics ASAP 2020 analyzer. Samples for porosimetry were taken from freestanding films cast by evaporation of coating solutions and then calcined at $400^{\circ}$ for 24 hours. This treatment was done to remove residual organics while minimizing film densification through collapse of pores $[77,78]$. These samples were then degassed under vacuum at $120^{\circ} \mathrm{C}$ for 1 hour 
prior to the adsorption. The Barrett-Joyner-Halenda (BJH) method was applied to the adsorption isotherm for the analysis of pore-size distribution.

Atomic force microscopy (AFM) and friction force microscopy (FFM) were conducted on a Molecular Imaging PicoScan 3000 system in contact mode with Si tips on cantilevers of nominal $k=3.0 \mathrm{~N} / \mathrm{m}$ and radius $\approx 10 \mathrm{~nm}$. Deflection and force were calibrated by using the slope of the force curve on the approach and the nominal cantilever spring constant. The adhesive force between the tip and film surface was taken as the cantilever pull-off force adjusted by the cantilever resting position using a $5 \mathrm{nN}$ applied load [76]. Three approach-retract curves per location were averaged with sweep time set to $1 \mathrm{~s}$ each, and five of these measurements were taken over random sample spots on the specimens. Relative friction measurements were made by applying forces in the range of $0-50 \mathrm{nN}$ to the tip scanning over $500 \mathrm{~nm}$ at a speed of $10 \mu \mathrm{m} / \mathrm{s}$. The friction force is reported here as a voltage signal, which should be proportional to the real friction force $[128,129]$. Therefore, the results from the different film surfaces are comparable to each other. All measurements were conducted at $21 \pm 2{ }^{\circ} \mathrm{C}$ and $45 \pm 5 \%$ relative humidity (RH). The tip was cleaned between samples by immersion in acetone for $1 \mathrm{~min}$ followed by air-drying.

\subsection{Results and discussion}

\subsubsection{Formation of templated functional films}

As seen from the results shown in Figure 37, all unworn films had contact angles (CA) in the range of $105-110^{\circ}$ with standard deviations of $<2^{\circ}$. The contact angles on unworn surface were independent of FPES concentration, which is often the case provided that the concentration of the hydrophobic moiety exceeds a minimum threshold $[81,82]$. These unworn surfaces sit atop the bulk of the templated films, and they are enriched through the surface segregating nature of the fluorosilanes. What results is effectively a highly hydrophobic monolayer, which is observed in the CA measurements shown in Figure 37. A cleaned and uncoated glass slide surface was completely wetted with water and had no measurable contact angle. Likewise, a templated film synthesized without FPES was wetted completely by water. Thickness increased linearly with concentration of surfactant, since these organic species add bulk to the alkoxide matrix. 


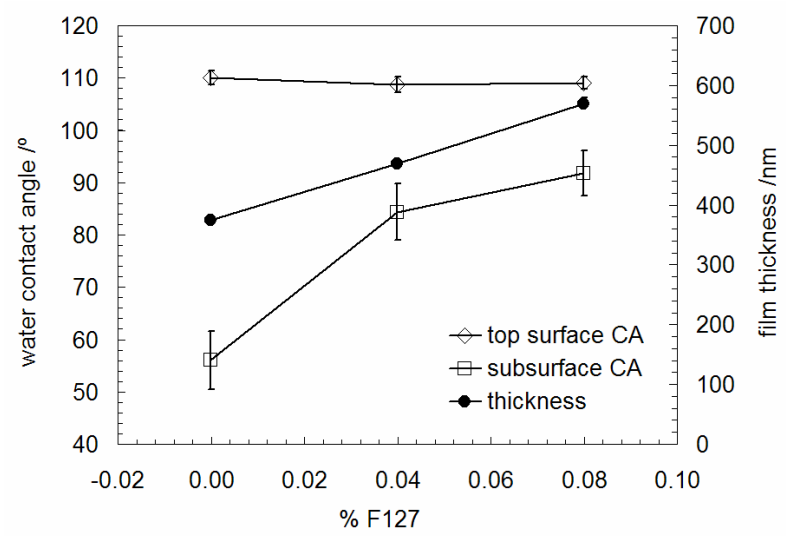

Figure 37. Contact angle of water on virgin and abraded films and film thickness versus concentration of surfactant template added.

Topographical and friction force micrographs were obtained simultaneously using AFM. A sample of these, obtained from a film templated with $x_{s}=8 \%$, are shown in Figure 38. The film was abraded with alumina slurry to expose the interior pore surfaces, and the sliding direction of abrasion for micrographs (a)-(d) was from the top left to bottom right. Figure 38 (a) and (b) show topography and friction, respectively, of a $4 \mu^{2}$ area. (c) and (d) show topography and friction, respectively, of a $0.25 \mu \mathrm{m}^{2}$ area obtained from an area within that of (a) and (b). Wear tracks are observable parallel to the direction of abrasion in both topographical micrographs (a) and (c). In the large area scan (a) we observe some few remaining patches of the top surface that have remained after abrasion. These surfaces appear as regions of lower friction (darker tone) in (b) compared to the exposed internal surfaces which have higher friction (lighter tone). The smaller topographical scan in Figure 38 (c) reveals a disordered mesoporous structure with pores approximately $10 \mathrm{~nm}$ in diameter. The friction force micrograph in (d) indicates lower friction with darker tones and higher friction with lighter tones. The micrograph (d) should be interpreted with consideration that topographical features such as steps and scratches have been shown to influence adhesion and friction mapping using AFM due to the increasing area of interaction between the surface and tip [107-109]. In our case, we observe that in Figure 38 (b) only the deepest of the wear tracks detected in Figure 38 (a) are observable as artifacts in the friction force micrograph (b). Consequently, there may be some contribution of pore topography to the friction-force distribution in Figure 38 (d), so these images should be interpreted in terms of the interaction between tip and surface materials. With that in mind, Figure 38 (d) may be showing 
that the internal pore surfaces are low-friction areas compared with the matrix material that makes up the pore walls. This would happen if, through co-surfactancy, the FPES moieties were more concentrated on the interior pore surfaces than if they were more evenly distributed within the bulk of the matrix silica. This complements the findings of the contact angle measurements that indicate that templating encapsulated hydrophobic/low-friction fluorinated moieties.

Figure 38 (e) and (f) show topography and friction force of an unworn film with an intact virgin monolayer. We observe that the surface is very smooth, as shown in (e), with the vertical topography range an order of magnitude lower than that of the abraded surface shown in (c). Likewise, the variation in the friction force micrograph in (f) is relatively small, since the friction signal range for this micrograph (range $=0.009$ ) is also lower than that of the interior surfaces shown in $(\mathrm{c})($ range $=0.035)$. This indicates that the monolayer surface is more uniform in structure and composition, and that the templated and worn film has a relatively heterogeneous structure and composition.

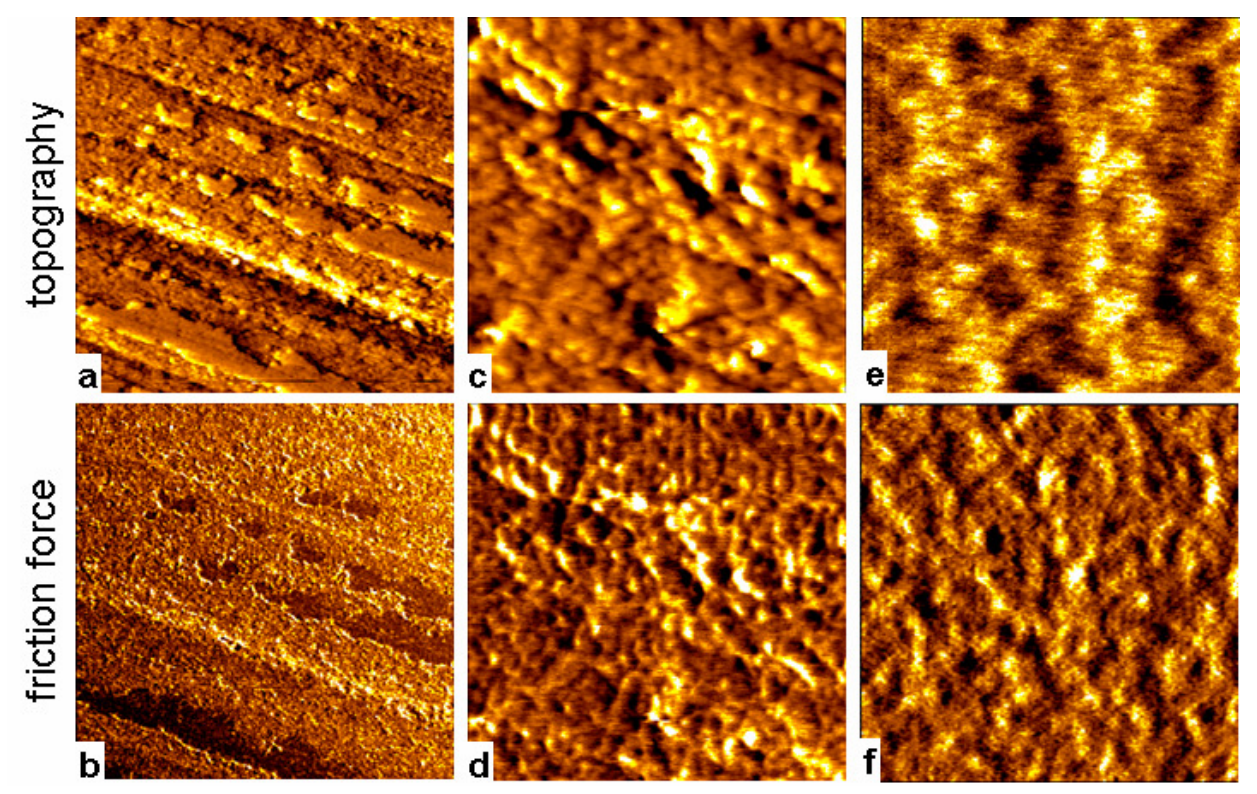

Figure 38. (a)-(d) Topographic and friction force micrographs captured by AFM of partially worn film with composition $x_{s}=8 \%$. (a) and (b) are scans of topography and friction, respectively (scan size: $2 \mu \mathrm{m} \times 2 \mu \mathrm{m}$; scan speed: $10 \mu \mathrm{m} / \mathrm{s}$; applied load: $20 \mathrm{nN}$; vertical topography range: $7 \mathrm{~nm}$ ). (c) and (d) are scans of topography and friction, respectively, of the same film shown (a) and (b) (scan size: $0.5 \mu \mathrm{m} \times 0.5 \mu \mathrm{m}$; scan speed: $10 \mu \mathrm{m} / \mathrm{s}$; applied load: $20 \mathrm{nN}$ ). (e) and (f) show topographic and friction force micrographs of a virgin monolayer (scan size: $0.5 \mu \mathrm{m} \times$ $0.5 \mu \mathrm{m}$; scan speed: $10 \mu \mathrm{m} / \mathrm{s}$; applied load: $20 \mathrm{nN}$; vertical topography range: $0.35 \mathrm{~nm}$ ). 
After abrasion the roughness of the film surfaces increased slightly to between 10 and $20 \mathrm{~nm}$ due to surface damage, so the contact angle measurements can be considered unaffected by surface roughness effects. Figure 39 shows how rms roughness changed after abrasion for the functional films. The roughness ratio (actual area from surface scan / projected nominal area) was calculated to be $=1$ with slight deviations smaller than $2 \times 10^{-4}$. Such small deviations of the roughness ratio from unity are not expected to significantly affect the observed contact angle of liquids on the rough surfaces[130]. The CA values reported as subsurface measurements in Figure 37 were obtained after at least $10 \%$ of the film thickness was removed by abrasion, as determined by stylus profilometry, in order to obtain a true representation of the bulk film properties. The CAs measured after abrasion were decreased compared to the unworn films. Without any surfactant template, the CA was low, indicating poor encapsulation of fluorinated moieties. The subsurface CA measurement increased with template concentration, showing a maximum at a concentration of $x_{s}=8 \%$. This indicates that templating enables formation of additional internal surfaces for encapsulation of the fluorinated moieties, preventing them from migrating to the top surface.

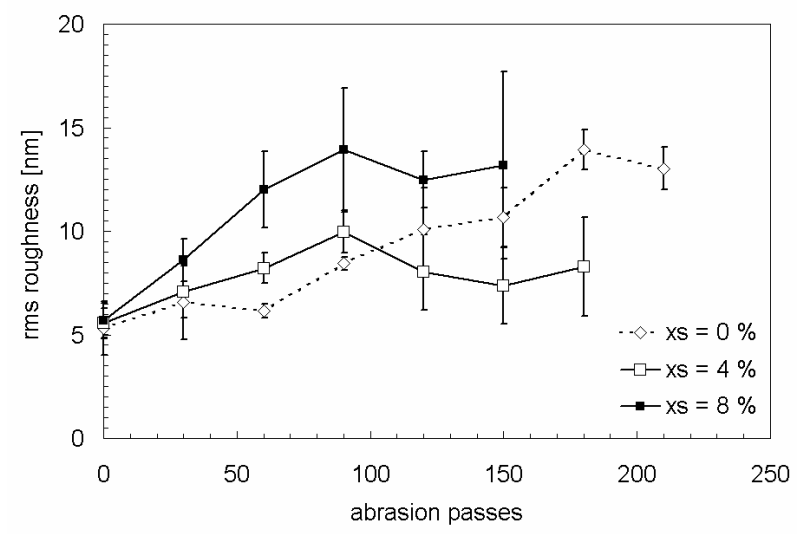

Figure 39. Roughness (rms) of functional films after abrasion by $0.3 \mu \mathrm{m}$ alumina slurry.

XPS analysis showed that the concentration of fluorine at the top surface of all films was high, which accounts for the strongly hydrophobic character of the virgin films. The top few tens of nanometers of film were removed by sputtering in order to reveal the composition of the film bulk in each sample. Some representative spectra are shown in Figure 40. Figure 40 (a) shows 
surface and subsurface (sputtered) spectra of the F1s level of a film that has not been templated. Likewise, Figure 40 (b) shows surface and subsurface spectra of the F1s level of a film that has been templated at a concentration $x_{s}=8 \%$. Comparison of the two plots shows that the subsurface spectrum from the templated film is substantially higher than the subsurface spectrum of the non-templated film. This indicates that templating indeed encapsulates the fluorinated functional moieties that lend hydrophobicity and lubricity to the interior surfaces. A schematic view of the templated film with intact top surface and removed top surface is shown in Figure 41, with the AFM tip moving laterally over the functional surfaces.
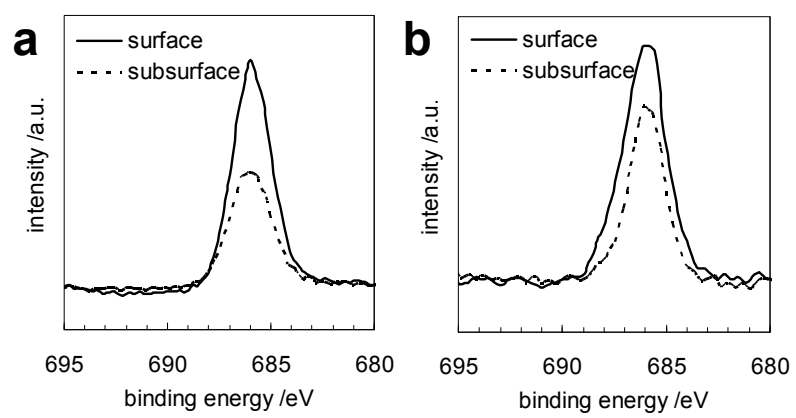

Figure 40. XPS spectra of F1s levels taken from top surface and sputtered, subsurface samples from films with (a) $x_{s}$ $=0 \%$ and $(\mathrm{b}) x_{s}=8 \%$.

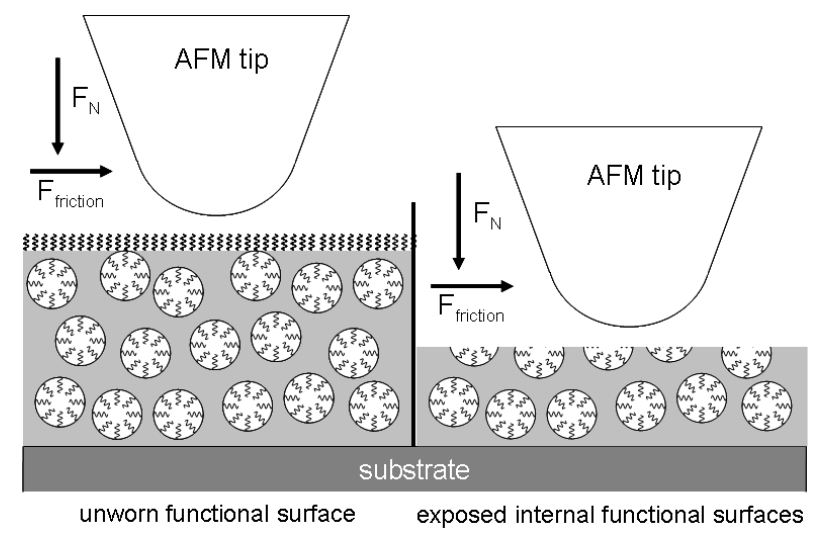

Figure 41. A schematic view of a template and internally functional film with intact top surface layer and after removal of the top layer.

Nitrogen adsorption-desorption isotherms are shown in Figure 42 (a). All samples showed IUPAC type IV isotherms, which are characteristic of mesoporous materials. As surfactant concentration increased, the total adsorbed volume was increased. This indicates that the porosity 
of the films is likewise increasing. BJH pore size distributions are shown in Figure 42(b). These distributions show that When $x_{s}$ is increased from $0 \%$ to $4 \%$, there is a large change in the pore structure: pores become larger and the distribution is greatly widened. However, increasing the surfactant concentration from $4 \%$ to $8 \%$ does not substantially change the pore size distribution, although from the adsorption isotherms we see that the total porosity has changed. These data suggest that the surfactant and fluorosilane have a synergistic effect on the porous structure of the films and the mechanism of fluorosilane encapsulation. Through cosurfactancy, the fluorosilane molecules arrange together with the surfactant to form the porous structure. Since the fluorinated moieties are hydrophobic they arrange on the interior pore surfaces, while the silanol ends are grafted to the matrix. X-ray diffraction results (not shown) indicate a disordered pore structure.
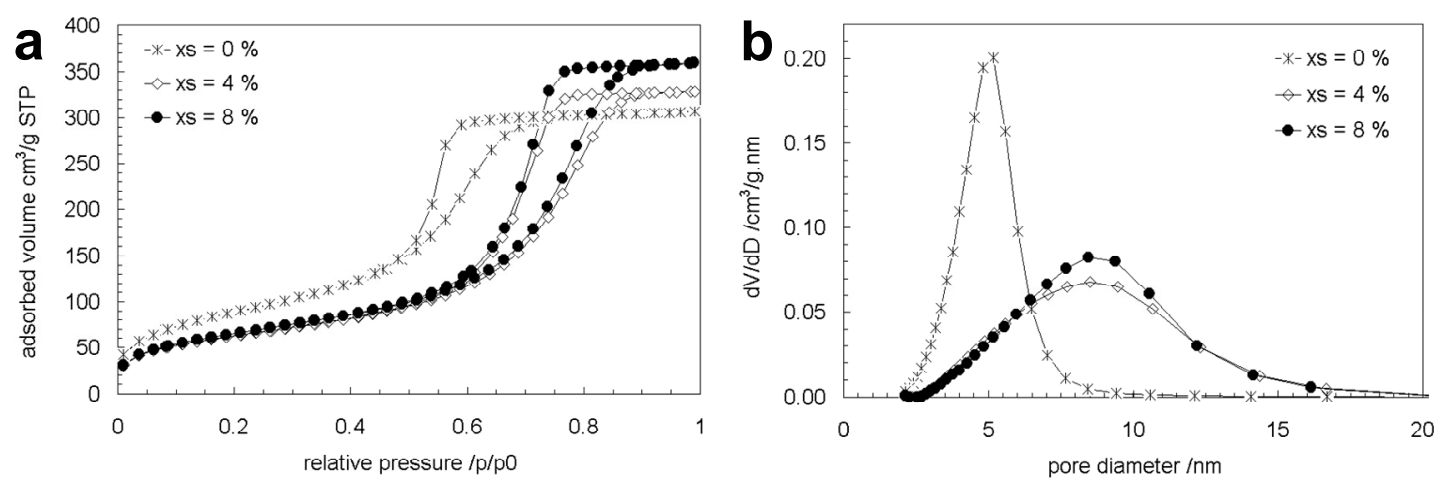

Figure 42. (a) Nitrogen adsorption-desorption isotherms on calcined films synthesized with different surfactant concentrations. (b) BJH pore size distributions of the same films.

\subsubsection{Micro-tribological study of internal surfaces}

The micro-friction properties of the abraded films, a cleaned glass slide, and the top surface of the unworn and non-templated film (labeled here as a FPES monolayer), were investigated by FFM. AFM tip pull-off force was determined in order to provide a measure of the adhesive forces between a tip reference surface and the film surfaces. Figure 43 (a) shows some representative force-distance curves of the AFM cantilever interacting with glass, FPES monolayer, and an abraded mesostructured fluorinated silica film. All curves have equal slopes during loading and unloading, which indicates that all the surfaces recover elastically during 
unloading [124]. Figure 43 (b) shows a summary of the adhesive forces for various compositions. The adhesive force is generally lowered as films become increasingly hydrophobic, which is a commonly observed trend [89]. This is attributed to lower intermolecular bonding forces between the film surface and either a liquid (in the case of contact angle measurements) or a solid (in the case of AFM tip retraction) that are present when fluorinated hydrophobic moieties are encapsulated, as was shown by the XPS spectra in Figure 40.

The film with $x_{s}=8 \%$ has a calculated adhesion force approximately equal to that of the FPES monolayer. However, the standard deviation of the measurements is much greater than that of the FPES monolayer. This variability indicates that the surface is comparatively more heterogeneous, which may be expected from a mesostructured film such as this.
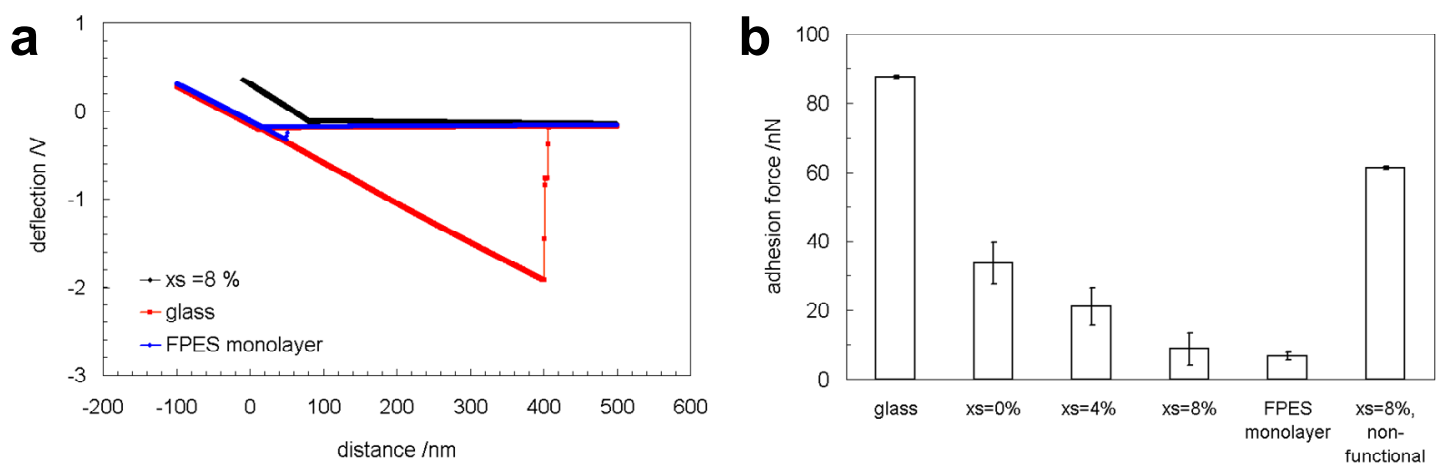

Figure 43. (a) Approach and retract force-distance curves, normal load $=5 \mathrm{nN}$. (b) Adhesive forces between an AFM tip and surfaces of glass, FPES monolayer, and abraded surfaces of mesostructured fluorinated and nonfluorinated silica films at $45 \% \mathrm{RH}$, normal load $=5 \mathrm{nN}$.

Figure 44 (a) shows plots of friction force versus normal load for the various surfaces investigated here. Relative friction coefficients in Figure 44 (b) were calculated from the slope of lines fit to these curves by a weighted least squares method and assuming Amontons' law [76]. Data were normalized to the calculated friction coefficient of the bare glass surface. We observe that films that are more hydrophobic are also lower friction due to the lubricating nature of fluorocarbon materials. As with the calculated adhesion forces, the film with $x_{s}=8 \%$ has a calculated relative friction coefficient nearly as low as that of the FPES monolayer, although its 
variability is substantially greater. The results shown here indicate that when the fluorinated film is sufficiently templated, the internal surfaces display low friction coefficients and tip adhesive forces comparable to that of a fluorinated monolayer. The film that was not functionalized but was templated was shown to have a relatively high coefficient of friction, although not as high as the cleaned glass slide and non-templated functional film.
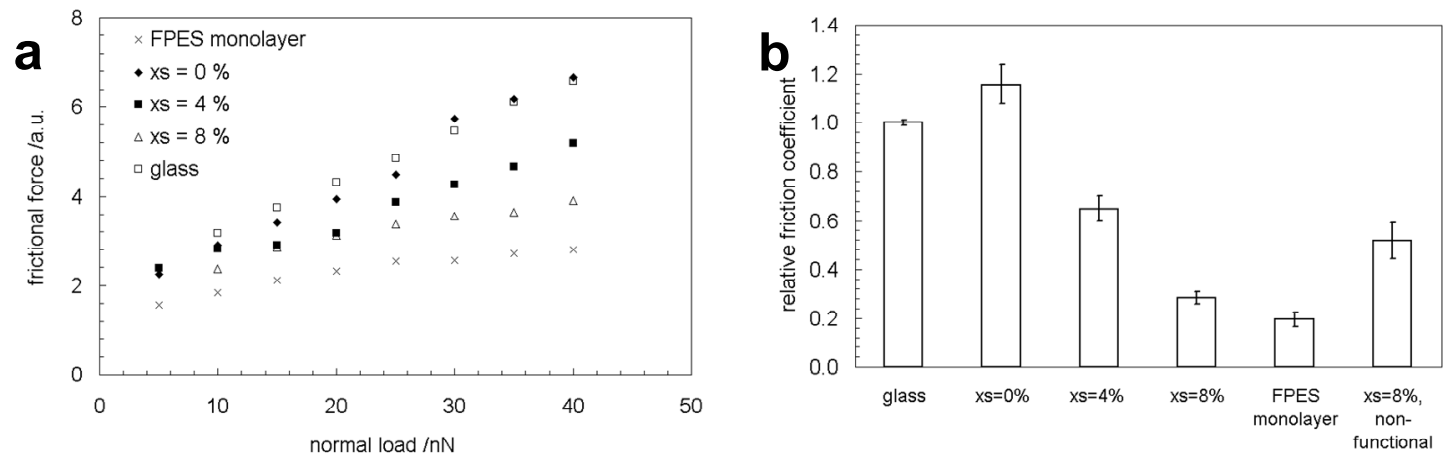

Figure 44. Friction force microscopy data from $500 \mathrm{~nm} \times 500 \mathrm{~nm}$ scans at a speed of $10 \mu \mathrm{m} / \mathrm{s}$. Specimens were bare glass, subsurfaces of mesostructures fluorinated films, a FPES monolayer, and a templated non-functional film. (a) Friction signal versus normal load curves, and (b) relative friction coefficients normalized to the friction coefficient of bare glass.

Comparing the friction coefficients from Figure 44 (a) and (b) and adhesive force data from Figure 43 (b), we note that the pull-off forces for the bare glass must necessarily be higher than the actual adhesive forces between the tip and surface materials, as has been described for hydrophilic $\mathrm{SiO}_{2}$ [89]. As was done in the work of Ren et al., we attribute this to the higher capillary forces acting between the tip and surface of hydrophilic materials, which increase the apparent pull-off force and adhesive behavior when compared to more hydrophobic surfaces where this capillary force has been minimized. 


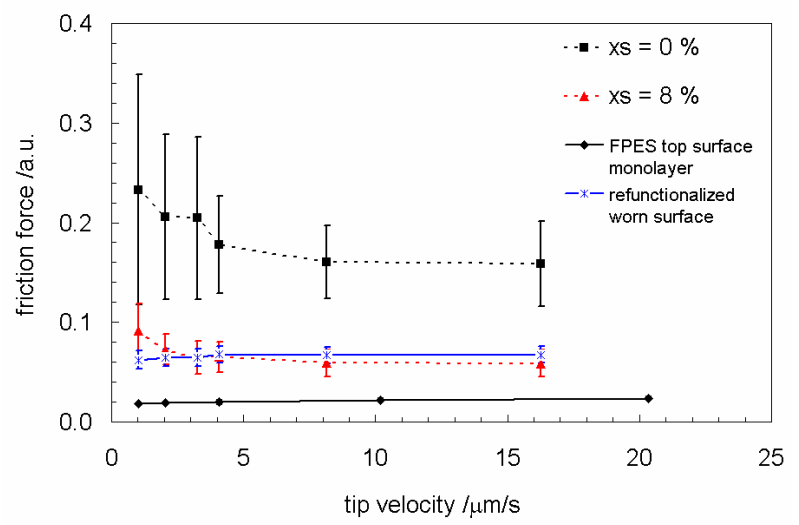

Figure 45. Friction force versus tip velocity for subsurface regions of a non-templated film, a templated film, the FPES monolayer on top of a virgin templated film, and a calcined surface re-functionalized with a FPES monolayer. Applied load $=20 \mathrm{nN}$.

To determine the effect of tip velocity on friction, a $20 \mathrm{nN}$ load was applied and surfaces were scanned at various speeds. The FPES monolayer surface was compared to that of a subsurface (abraded) region of a non-templated functional film and templated functional film with $x_{s}=8 \%$, and the results are plotted in Figure 45. These plots reveal that the surfaces have quite different friction-velocity relationships. Friction increased with velocity only slightly for the FPES monolayer, and with minimal variability in the measurements. Meanwhile, for the templated film friction decreased with velocity at low scan speeds and was more stable between intermediate and high speeds. These types of dependencies have been observed and described for various types of chemical interfaces $[127,131,132]$. The FPES monolayer relationship is characteristic of inert surfaces that interact only minimally with the tip [111,129,131], and the friction-velocity relationship is determined by the surface molecular mobility and kinetics of reorientation with respect to the tip velocity [132]. The behaviors of the interior functional surfaces of the other films are characteristic of materials that can have stronger interactions with the tip surface. In this case, the higher friction force at low velocity has been attributed to the formation of intermolecular bonds between the two surfaces. At higher velocity, bond formation is interrupted resulting in lower friction forces. In this case, the exposed internal surfaces of the fluorinated mesoporous film presented to the scanning probe is heterogeneous. As shown in the schematic in Figure 41 and the friction force micrographs in Figure 38 (b) and (c), this surface is composed of exposed functional pores and relatively non-functional pore walls. We speculate that the pores are low interaction/friction areas with a friction-velocity relationship similar to that of the FPES 
monolayer. The pore walls are higher interaction/friction surfaces with a negative frictionvelocity relationship. Even if the pores surfaces are fully functionalized, the combination of the exposed pore wall surfaces in close proximity results in the observations shown here.

Furthermore, the less strongly interacting (hydrophobic) surface of the film with $x_{s}=8 \%$ shows less of a difference in the frictional force at low and high speeds compared to the more strongly interacting (hydrophilic) surface of the film with $x_{s}=0 \%$. This reinforces the description of the film with $x_{s}=8 \%$ as having a character intermediate to that of the non-templated film and the smooth and fully fluorinated monolayer.

The comparison of these two friction-velocity relationships reveals a difference in the characteristics of the two films. Although at an arbitrary velocity the templated film and monolayer may exhibit similar friction coefficients, this is not the case at all velocities. This is a consequence of the incompletely fluorinated surface of the templated material. From the results in Figure 2, the surface of the film templated with $x_{s}=8 \%$ had a contact angle of approximately $90^{\circ}$. This was higher than that of a non-templated or partially-templated film, but still lower that the top surface layers $\left(\mathrm{CA}=105-110^{\circ}\right)$. This was attributed to the partial encapsulation of fluorosilanes, as evident from the XPS spectra in Figure 3. Although templating was able to encapsulate the surface-segregating fluorosilanes, the fluorine concentration at the top surface was still higher than that in the film bulk. Finally, the difference between the templated bulk materials and the FPES monolayer is revealed in the variability of the adhesion and microtribological measurements.

Table 2. Roughness (rms), water contact angle, and relative friction coefficient of abraded films synthesized with $x_{s}=8 \%$.

\begin{tabular}{llll}
\hline & $r_{r m s} / \mathrm{nm}$ & $\theta_{\mathrm{H} 2 \mathrm{O}} /{ }^{\mathrm{o}}$ & $\mu$ \\
\hline abraded & $13.2 \pm 4.5$ & 92 & $0.28 \pm 0.02$ \\
calcined $^{a,}$ & $14.0 \pm 4.7$ & $<10$ & $1.80 \pm 0.07$ \\
re-functionalized $^{a, b}$ & $13.2 \pm 2.1$ & 104 & $0.32 \pm 0.01$ \\
& & & \\
${ }^{a}{ }^{\text {calcined at } 400{ }^{\circ} \mathrm{C} \text { for } 10 \text { minutes }}$ & & \\
${ }^{b}$ with FPES monolayer &
\end{tabular}


In the case of these films, the effect of surface topography and chemistry are convoluted. As shown in Figure 39 and Table 1, surface roughness increases after a film has been abraded. Depending on the surfactant template concentration, the interior surfaces are more or less functional in terms of hydrophobicity, tip-surface adhesion, and relative friction coefficient. However, surface roughness is an important tribological factor, and its influence on measurable properties like the friction coefficient cannot be neglected. To distinguish the difference between topography and chemical contributions to friction, the fluorinated film with $x_{s}=8 \%$ was abraded to expose interior surfaces and then calcined at $400{ }^{\circ} \mathrm{C}$ for 10 minutes to burn off organics, including fluorosilanes. As reported in Table 1, the water contact angle on this surface was very low, and the friction coefficient very high, although the roughness had not changed. The same surface was re-functionalized with a FPES monolayer (FPES only, without the TEOS matrix), whereupon the contact angle increased greatly. The roughness of the refunctionalized surface was still not significantly changed, although the friction coefficient had increased slightly compared to the unworn, smooth monolayer that exists on the virgin top surface of all the fluorinated films. The friction-velocity relationship, shown in Figure 45, illustrates that the frictional force is higher than an unworn monolayer (nearly the same as that of the film with $x_{s}=$ $8 \%$ ), but that it has a very small dependence on velocity similar to that of the virgin monolayer. These data show that the friction coefficient of the re-functionalized surface does depend on roughness for an arbitrary scanning velocity, but that the surface is highly fluorinated and this is reflected in the friction-velocity profile.

\subsection{Conclusion}

A series of fluorinated sol-gel silica films were synthesized by co-condensation with and without a surfactant template to create internal mesoporosity. Surfactant template concentrations were varied to examine the effect of encapsulated organic functionality on the microtribological properties of films. Atomic force microscopy was used to probe the properties of virgin film surfaces and surfaces of the internal mesostructure after the top layer was removed by mild abrasion. Tip adhesion measurements and fixed-speed friction force microscopy indicated that highly templated films had interior low-friction functionality approaching that of conventional 
densely-packed monolayers. However, the dependence of friction on sliding speed revealed that fluorinated templated films have tribological properties intermediate to those of a non-functional surface and a conventional fluorinated monolayer. We proposed that this was because the templated films present a heterogeneous surface composed of functional pore regions and nonfunctional pore wall regions. Finally, scanning probe techniques may be used to explore the encapsulation of other types of chemical functionality within mesoporous materials. 


\section{General conclusions and outlook}

\subsection{Conclusions}

This study investigated the use of surfactant templated mesostructured sol-gel silica films as scaffolds for fluorinated silanes that provide sustained hydrophobic-oleophobic functionality even after exposure to abrasive wear. Fluorosilane and surfactant template concentrations were varied to elucidate the effect of composition on encapsulation of organic functionality and porosity on tribological performance. Surfactant templating was necessary in order for worn films to maintain non-wetting functionality through encapsulation of fluorosilanes. Templating was found to influence porosity, pore size, and mechanical properties. Tribological testing indicated that sustained functionality can mitigate the detrimental effects of porosity on hardness and wear resistance but only up to a point, whereupon the mechanical properties become too much degraded by multiple mechanisms.

\subsection{Future work}

\subsubsection{Enhancing mechanical properties through matrix reinforcement}

Increasing film hardness has the potential to further reduce wear rate. However, co-condensation of functional silanes with alkoxide precursors limits thermal processing and, consequently, matrix densification and mechanical properties of these hybrid films [41]. In considering the mechanical strength of mesostructured films, special attention must be given to the possibility of reinforcing the film structure through incorporation of hard nanoparticles such as silica or zirconia or with carbon nanotubes, since porosity tends to degrade the mechanical strength of materials. Using nanoparticles to reinforce mesoporous films has not been extensively studied, but the few reports in literature indicate improvements in mechanical properties and the ability to increase strength, stiffness, and the maximum attainable crack-free film thickness $[133,134]$. Some factors affecting mechanical strength include interfacial compatibility, interfacial strength, and dispersion effect of silica particles. The interaction of particles with surfactants and their distribution within the matrix will be of particular interest in this system. Particles may also migrate within the thickness of the film, arranging themselves at the various interfaces or 
remaining more continuously dispersed throughout the bulk. Relating mechanical properties such as Young's modulus $(E)$ and hardness $(H)$ and wear characteristics of nanoparticle reinforced mesoporous functional films still remains a relatively unexplored area.

\subsubsection{Effect of sol aging on chemical and mechanical properties}

In this study, sols were synthesized using a fixed aging time for consistency between batches. However, since encapsulation is based on surfactant templating, and sol aging has been shown to influence the efficacy of templating $[50,62,63,65]$, there is likely an effect of aging on the encapsulation of functional silanes. While dynamic light scattering has been used to quantify the extent of aging of silica sols [135], ${ }^{29} \mathrm{Si}$ liquid-state NMR provides more relevant details about the chemical structure of a sol and the influence of that structure on the hydrolysis and condensation of the silica framework.

\subsubsection{Tuning porosity and pore size distribution}

As mentioned in the conclusion of Chapter 3, encapsulation of fluorosilanes was accomplished by surfactant templating, as shown in Figure 19. However, templating also greatly increased the pore size, as shown in Figure 21, and the effects of chemical encapsulation and physical geometry are convoluted. There is likely a contribution of geometry to macroscopically measurable contact angle or surface energy. Furthermore, in the study reported here, surfactant concentration was the primary means of controlling porosity and pore size, and while increasing surfactant increased encapsulation, residual surfactant also increased surface energy. Various sources report on the ability of tuning porosity and pore size by using swelling agents like poly(propylene glycol), [70,136]. Swelling agents may be used to study the effect of surfactant concentration and porosity/pore size on encapsulation independently of each other.

\subsubsection{Investigate use with other types of functionality}

Surfactant templating of mesostructured functional materials has the potential to enhance the functional durability of other types of protective coatings, such as those designed for resistance to corrosion and biofouling. Quaternary ammonium silanes (QAS) are just one type of functional 
silanes that provide biofouling resistance. These are also surface-segregating components that tend to concentrate at the top surface of co-condensed films [126]. The use of surfactants to encapsulate an internally functional mesostructure could make QAS films more durable. In using this encapsulation technique, it is always necessary to consider the relative thermal stability of the functional group and the surfactant template. If the functional group decomposes at a temperature close to that of the surfactant, then the surfactant should be removed by another method, such as by solvent extraction. 


\section{References}

[1] M. Mani, R. Pillai, Impact of dust on solar photovoltaic (PV) performance: Research status, challenges and recommendations, Renewable \& Sustainable Energy Reviews 14 (9) (2010) 3124-3131.

[2] H. Elminir, A. Ghitas, R. Hamid, F. El-Hussainy, M. Beheary, K. Abdel-Moneim, Effect of dust on the transparent cover of solar collectors, Energy Conversion And Management 47 (18-19) (2006) 3192-3203.

[3] A. Hegazy, Effect of dust accumulation on solar transmittance through glass covers of plate-type collectors, Renewable Energy 22 (4) (2001) 525-540.

[4] A. Cannavale, F. Fiorito, M. Manca, G. Tortorici, R. Cingolani, G. Gigli, Multifunctional bioinspired sol-gel coatings for architectural glasses, Building And Environment 45 (2010) 1233-1243.

[5] A. Vilcnik, I. Jerman, A. Vuk, M. Kozelj, B. Orel, B. Tomsic, B. Simonic, J. Kovac, Structural Properties and Antibacterial Effects of Hydrophobic and Oleophobic Sol- Gel Coatings for Cotton Fabrics, Langmuir 25 (10) (2009) 5869-5880.

[6] M. Mauermann, U. Eschenhagen, T. Bley, J. Majschak, Surface modificationsApplication potential for the reduction of cleaning costs in the food processing industry, Trends in Food Science \& Technology 20 (2009) 9-15.

[7] K. Johns, G. Stead, Fluoroproducts - the extremophiles, Journal Of Fluorine Chemistry 104 (1) (2000) 5-18.

[8] T. Young, An essay on the cohesion of fluids, Philosophical Transactions of the Royal Society 95 (1805) 65-87.

[9] L. Gao, T. McCarthy, Teflon is hydrophilic. Comments on definitions of hydrophobic, shear versus tensile hydrophobicity, and wettability characterization, Langmuir 24 (17) (2008) 9183-9188.

[10] M. Kiuru, E. Alakoski, Low sliding angles in hydrophobic and oleophobic coatings prepared with plasma discharge method, Materials Letters 58 (16) (2004) 2213-2216.

[11] M. Stone, T. Nevell, J. Tsibouklis, Surface energy characteristics of poly (perfluoroacrylate) film structures, Materials Letters 37 (1-2) (1998) 102-105.

[12] H. Kobayashi, M. Owen, Surface properties of fluorosilicones, Trends polym. sci. 3 (10) (1995) 330-335.

[13] T. Kronberg, A. Ritschkoff, R. Mahlberg, J. Mannila, M. Kallio, A. Vesa, L. Hupa, Soilresistant surfaces for traditional ceramics, Journal Of The European Ceramic Society 27 (2-3) (2007) 1775-1780.

[14] M. Ma, R. Hill, Superhydrophobic surfaces, Current Opinions in Colloid \& Interface Science 11 (4) (2006) 193-202.

[15] A. Tuteja, W. Choi, M. Ma, J. Mabry, S. Mazzella, G. Rutledge, G. McKinley, R. Cohen, Designing superoleophobic surfaces, Science 318 (5856) (2007) 1618-1622.

[16] X. Li, D. Reinhoudt, M. Crego-Calama, What do we need for a superhydrophobic surface? A review on the recent progress in the preparation of superhydrophobic surfaces, Chemical Society Reviews 36 (8) (2007) 1350-1368.

[17] C. Sanchez, B. Julián, P. Belleville, M. Popall, Applications of hybrid organic-inorganic nanocomposites, Journal Of Materials Chemistry 15 (35-36) (2005) 3559-3592. 
[18] K. Tanaka, Y. Uchiyama, S. Toyooka, The mechanism of wear of polytetrafluoroethylene, Wear 23 (1973) 153-172.

[19] J. Youngblood, N. Sottos, Bioinspired Materials for Self-Cleaning and Self-Healing, MRS Bulletin 33 (2008) 732-741.

[20] T. Yoneda, T. Morimoto, Mechanical durability of water repellent glass, Thin Solid Films 351 (1-2) (1999) 279-283.

[21] S. Giessler, E. Just, R. Storger, Easy-to-clean properties-Just a temporary appearance?, Thin Solid Films 502 (1-2) (2006) 252-256.

[22] J. Mackenzie, Structures and properties of Ormosils, Journal Of Sol-Gel Science And Technology 2 (1) (1994) 81-86.

[23] M. Toselli, J. Gardella, M. Messori, A. Hawkridge, F. Pilati, C. Tonelli, Surface chemical analysis of polyepsilon-caprolactone-perfluoropolyether-polyepsilon-caprolactone triblock copolymers, Polymer International 52 (8) (2003) 1262-1274.

[24] B. Hong, J. Han, S. Kim, Y. Cho, M. Park, T. Dolukhanyan, C. Sung, Endurable waterrepellent glass for automobiles, Thin Solid Films 351 (1-2) (1999) 274-278.

[25] Z. Cui, Q. Wang, Y. Xiao, C. Su, Q. Chen, The stability of superhydrophobic surfaces tested by high speed current scouring, Applied Surface Science 254 (10) (2008) 2911 2916.

[26] J. Wright, N. Sommerdijk, Sol-gel materials: chemistry and applications, CRC press, 2001.

[27] C. Brinker, G. Scherer, Sol-gel science: the physics and chemistry of sol-gel processing, Academic Pr, 1990.

[28] H. Huang, B. Orler, G. Wilkes, Ceramers: Hybrid materials incorporating polymeric/oligomeric species with inorganic glasses by a sol-gel process, Polymer Bulletin 14 (6) (1985) 557-564.

[29] H. Schmidt, New type of non-crystalline solids between inorganic and organic materials, Journal of Non-Crystalline Solids 73 (1985) 681-691.

[30] H. Schmidt, E. Geiter, M. Mennig, H. Krug, C. Becker, R. Winkler, The sol-gel process for nano-technologies: new nanocomposites with interesting optical and mechanical properties, Journal Of Sol-Gel Science And Technology 13 (1) (1998) 397-404.

[31] J. Gallardo, P. Galliano, A. Duran, Thermal evolution of hybrid sol-gel silica coatings: a structural analysis, Journal Of Sol-Gel Science And Technology 19 (1) (2000) 393-397.

[32] M. Zelsmann, D. Truffier-Boutry, A. Francone, C. Alleaume, I. Kurt, A. Beaurain, B. Pelissier, B. Pépin-Donat, C. Lombard, J. Boussey, Double-anchoring fluorinated molecules for antiadhesion mold treatment in UV nanoimprint lithography, The Journal of Vacuum Science and Technology B 27 (2009) 2873.

[33] P. Van Der Voort, E. Vansant, Silylation of the silica surface a review, Journal of Liquid Chromatography \& Related Technologies 19 (17-18) (1996) 2723-2752.

[34] B. Mahltig, H. Bottcher, Modified silica sol coatings for water-repellent textiles, Journal Of Sol-Gel Science And Technology 27 (1) (2003) 43-52.

[35] J. Jung, J. Bae, B. Bae, Characterization and mesostructure control of mesoporous fluorinated organosilicate films, Journal Of Materials Chemistry 14 (13) (2004) 19881994.

[36] S. Tam-Chang, H. Biebuyck, G. Whitesides, N. Jeon, R. Nuzzo, Self-assembled monolayers on gold generated from alkanethiols with the structure RNHCOCH2SH, Langmuir 11 (11) (1995) 4371-4382. 
[37] S. Song, J. Zhou, M. Qu, S. Yang, J. Zhang, Preparation and tribological behaviors of an amide-containing stratified self-assembled monolayers on silicon surface, Langmuir 24 (1) (2008) 105-109.

[38] L. Nicole, C. Boissière, D. Grosso, A. Quach, C. Sanchez, Mesostructured hybrid organic-inorganic thin films, Journal Of Materials Chemistry 15 (35-36) (2005) 35983627.

[39] X. Feng, G. Fryxell, L. Wang, A. Kim, J. Liu, K. Kemner, Functionalized monolayers on ordered mesoporous supports, Science 276 (5314) (1997) 923.

[40] A. Stein, B. Melde, R. Schroden, Hybrid inorganic-organic mesoporous silicatesnanoscopic reactors coming of age, Advanced Materials 12 (19) (2000) 1403-1419.

[41] C. Fowler, S. Burkett, S. Mann, Synthesis and characterization of ordered organo-silicasurfactant mesophases with functionalized MCM-41-type architecture, Chemical Communications 1997 (18) (1997) 1769-1770.

[42] J. Beck, J. Vartuli, W. Roth, M. Leonowicz, C. Kresge, K. Schmitt, C. Chu, D. Olson, E. Sheppard, A new family of mesoporous molecular sieves prepared with liquid crystal templates, Journal Of The American Chemical Society 114 (27) (1992) 10834-10843.

[43] C. Kresge, M. Leonowicz, W. Roth, J. Vartuli, J. Beck, Ordered mesoporous molecular sieves synthesized by a liquid-crystal template mechanism, Nature 359 (6397) (1992) 710-712.

[44] Y. Lu, R. Ganguli, C. Drewien, M. Anderson, C. Brinker, W. Gong, Y. Guo, H. Soyez, B. Dunn, M. Huang, et al., Continuous formation of supported cubic and hexagonal mesoporous films by sol-gel dip-coating, Nature 389 (6649) (1997) 364-368.

[45] C. Brinker, Y. Lu, A. Sellinger, H. Fan, Evaporation-induced self-assembly: Nanostructures made easy, Advanced Materials 11 (7) (1999) 579-585.

[46] D. Grosso, F. Cagnol, G. Soler-Illia, E. Crepaldi, H. Amenitsch, A. Brunet-Bruneau, A. Bourgeois, C. Sanchez, Fundamentals of mesostructuring through evaporation-induced self-assembly, Advanced Functional Materials 14 (4) (2004) 309-322.

[47] D. Doshi, A. Gibaud, V. Goletto, M. Lu, H. Gerung, B. Ocko, S. Han, C. Brinker, Peering into the self-assembly of surfactant templated thin-film silica mesophases, Journal Of The American Chemical Society 125 (38) (2003) 11646-11655.

[48] G. Soler-Illia, P. Innocenzi, Mesoporous hybrid thin films: The physics and chemistry beneath, Chemistry-A European Journal 12 (17) (2006) 4478-4494.

[49] G. Soler-Illia, E. Crepaldi, D. Grosso, C. Sanchez, Block copolymer-templated mesoporous oxides, Current Opinion in Colloid \& Interface Science 8 (1) (2003) 109 126.

[50] S. Jung, T. Ha, H. Park, Investigation of the properties of organically modified ordered mesoporous silica films, Journal Of Colloid And Interface Science 320 (2) (2008) 527534.

[51] E. Lataste, A. Demourgues, H. Leclerc, J. Goupil, A. Vimont, E. Durand, C. Labrugere, H. Benalla, A. Tressaud, Access to Highly Fluorinated Silica by Direct F2 Fluorination: Chemical Compositions and FTIR Investigations, Journal of Physical Chemistry C 112 (29) (2008) 10943-10951.

[52] G. Osei-Prempeh, H. Lehmler, S. Rankin, B. Knutson, Synthesis of FluoroFunctionalized Mesoporous Silica and Application to Fluorophilic Separations, Industrial \& Engineering Chemistry Research 47 (3) (2008) 530-538. 
[53] J. Bae, J. Jung, S. Seo, B. Bae, Formation and thermal-induced changes of mesostructures in fluorinated organosilicate films, Microporous And Mesoporous Materials 98 (1-3) (2007) 283-291.

[54] C. Jacquiod, J. Berquier, L. Teyssedre, M. Azzopardi, Glazing with a functional, especially hydrophobic, mesoporous coating, uS Patent App. 09/884,936 (Jun. 21 2001).

[55] J. Ying, C. Mehnert, M. Wong, Synthesis and applications of supramolecular-templated mesoporous materials, Angewandte Chemie International Edition 38 (1999) 56-77.

[56] D. Grosso, A. Balkenende, P. Albouy, A. Ayral, H. Amenitsch, F. Babonneau, Twodimensional hexagonal mesoporous silica thin films prepared from block copolymers: detailed characterization and formation mechanism, Chemistry Of Materials 13 (5) (2001) $1848-1856$.

[57] K. Yamada, Y. Oku, N. Hata, Y. Seino, C. Negoro, T. Kikkawa, Structural and electrical properties of ultralow-k, disordered mesoporous silica films synthesized using nonionic templates, Journal Of The Electrochemical Society 151 (2004) F248.

[58] N. Coleman, G. Attard, Ordered mesoporous silicas prepared from both micellar solutions and liquid crystal phases, Microporous And Mesoporous Materials 44 (2001) 73-80.

[59] D. Zhao, P. Yang, N. Melosh, J. Feng, B. Chmelka, G. Stucky, Continuous mesoporous silica films with highly ordered large pore structures, Advanced Materials 10 (16) (1998) $1380-1385$.

[60] F. Babonneau, L. Leite, S. Fontlupt, Structural characterization of organically-modified porous silicates synthesized using CTA + surfactant and acidic conditions, Journal Of Materials Chemistry 9 (1) (1999) 175-178.

[61] F. Cagnol, D. Grosso, C. Sanchez, A general one-pot process leading to highly functionalised ordered mesoporous silica films, Chemical Communications 2004 (15) (2004) 1742-1743.

[62] A. Shimojima, N. Umeda, K. Kuroda, Synthesis of Layered Inorganic- Organic Nanocomposite Films from Mono-, Di-, and Trimethoxy (alkyl) silaneTetramethoxysilane Systems, Chemistry Of Materials 13 (10) (2001) 3610-3616.

[63] B. Alonso, A. Balkenende, P. Albouy, H. Amenitsch, M. Rager, F. Babonneau, Hybrid 3D Ordered Mesoporous Thin Films Made from Organosiloxane Precursors, Journal Of Sol-Gel Science And Technology 26 (1) (2003) 587-591.

[64] A. Shimojima, K. Kuroda, Direct Formation of Mesostructured Silica-Based Hybrids from Novel Siloxane Oligomers with Long Alkyl Chains, Angewandte Chemie International Edition 42 (34) (2003) 4057-4060.

[65] M. Matheron, T. Gacoin, J. Boilot, Stabilization of well-organized transient micellar phases in CTAB-templated silica and organosilica thin films, Soft Matter 3 (2) (2007) 223-229.

[66] S. Besson, T. Gacoin, C. Jacquiod, C. Ricolleau, D. Babonneau, J. Boilot, Structural study of 3D-hexagonal mesoporous spin-coated sol-gel films, Journal Of Materials Chemistry 10 (6) (2000) 1331-1336.

[67] D. Grosso, F. Babonneau, P. Albouy, H. Amenitsch, A. Balkenende, A. Brunet-Bruneau, J. Rivory, An in Situ Study of Mesostructured CTAB- Silica Film Formation during Dip Coating Using Time-Resolved SAXS and Interferometry Measurements, Chemistry Of Materials 14 (2) (2002) 931-939. 
[68] S. Besson, T. Gacoin, C. Ricolleau, C. Jacquiod, J. Boilot, Phase diagram for mesoporous CTAB-silica films prepared under dynamic conditions, Journal Of Materials Chemistry 13 (2) (2003) 404-409.

[69] N. Chemin, M. Klotz, V. Rouessac, A. Ayral, E. Barthel, Mechanical properties of mesoporous silica thin films: Effect of the surfactant removal processes, Thin Solid Films 495 (1-2) (2006) 210-213.

[70] H. Fan, H. Bentley, K. Kathan, P. Clem, Y. Lu, C. Brinker, Self-assembled aerogel-like low dielectric constant films, Journal Of Non-Crystalline Solids 285 (1-3) (2001) 79-83.

[71] S. Jung, H. Park, Concentration-dependent mesostructure of surfactant-templated mesoporous silica thin film, Thin Solid Films 494 (1-2) (2006) 320-324.

[72] C. Ting, H. Sheu, W. Wu, Porosity effects on properties of mesoporous silica low-k films prepared using tetraethylorthosilicate with different templates, Journal Of The Electrochemical Society 154 (2007) G1.

[73] D. Cairns, A. Kessman, P. Richter, F. Bottari, N. Randall, Mechanical and tribological investigations of sol-gel derived SiO2 optical coatings, Wear 265 (3-4) (2008) 411-416.

[74] C. Lages, E. Mendez, Contact angle measurements under thermodynamic equilibrium conditions, Analytical and Bioanalytical Chemistry 388 (8) (2007) 1689-1692.

[75] A. Stalder, http://bigwww.epfl.ch/demo/dropanalysis/index.htmlBIG $>$ Drop Analysis (09 2008). http://bigwww.epfl.ch/demo/dropanalysis/index.html

[76] V. Tsukruk, V. Bliznyuk, Adhesive and friction forces between chemically modified silicon and silicon nitride surfaces, Langmuir 14 (2) (1998) 446-455.

[77] S. Higgins, R. Kennard, N. Hill, J. DiCarlo, W. DeSisto, Preparation and characterization of non-ionic block co-polymer templated mesoporous silica membranes, Journal of Membrane Science 279 (1-2) (2006) 669-674.

[78] P. Alberius, K. Frindell, R. Hayward, E. Kramer, G. Stucky, B. Chmelka, General Predictive Syntheses of Cubic, Hexagonal, and Lamellar Silica and Titania Mesostructured Thin Films, Chemistry Of Materials 14 (8) (2002) 3284-3294.

[79] R. Williford, X. Li, R. Addleman, G. Fryxell, S. Baskaran, J. Birnbaum, C. Coyle, T. Zemanian, C. Wang, A. Courtney, Mechanical stability of templated mesoporous silica thin films, Microporous And Mesoporous Materials 85 (3) (2005) 260-266.

[80] T. Monde, H. Fukube, F. Nemoto, T. Yoko, T. Konakahara, Preparation and surface properties of silica-gel coating films containing branched-polyfluoroalkylsilane, Journal Of Non-Crystalline Solids 246 (1-2) (1999) 54-64.

[81] P. Fabbri, M. Messori, M. Montecchi, S. Nannarone, L. Pasquali, F. Pilati, C. Tonelli, M. Toselli, Perfluoropolyether-based organic-inorganic hybrid coatings, Polymer 47 (4) (2006) 1055-1062.

[82] H. Jeong, D. Kim, S. Lee, S. Kwon, K. Kadono, Preparation of water-repellent glass by sol-gel process using perfluoroalkylsilane and tetraethoxysilane, Journal of Colloid Interface Science 235 (1) (2001) 130-134.

[83] A. Telford, M. James, L. Meagher, C. Neto, Thermally Cross-Linked PNVP Films As Antifouling Coatings for Biomedical Applications, ACS Appl. Mater. Interfaces 2 (8) (2010) 2339-2408.

[84] K. Efimenko, J. Finlay, M. Callow, J. Callow, J. Genzer, Development and testing of hierarchically wrinkled coatings for marine antifouling, ACS Applied Materials \& Interfaces 1 (5) (2009) 1031-1040. 
[85] F. Boulmedais, B. Frisch, O. Etienne, P. Lavalle, C. Picart, J. Ogier, J. Voegel, P. Schaaf, C. Egles, Polyelectrolyte multilayer films with pegylated polypeptides as a new type of anti-microbial protection for biomaterials, Biomaterials 25 (11) (2004) 2003-2011.

[86] L. Cao, A. Jones, V. Sikka, J. Wu, D. Gao, Anti-icing superhydrophobic coatings, Langmuir 25 (21) (2009) 12444-12448.

[87] G. Xue, X. Huang, J. Dong, J. Zhang, The formation of an effective anti-corrosion film on copper surfaces from 2-mercaptobenzimidazole solution, Journal Of Electroanalytical Chemistry 310 (1-2) (1991) 139-148.

[88] Z. Tao, B. Bhushan, Surface modification of AFM silicon probes for adhesion and wear reduction, Tribology Letters 21 (1) (2006) 1-16.

[89] S. Ren, S. Yang, Y. Zhao, Micro-and macro-tribological study on a self-assembled duallayer film, Langmuir 19 (7) (2003) 2763-2767.

[90] D. Owens, R. Wendt, Estimation of the surface free energy of polymers, Journal Of Applied Polymer Science 13 (8) (1969) 1741-1747.

[91] J. Yeager, A. Dattelbaum, E. Orler, D. Bahr, D. Dattelbaum, Adhesive properties of some fluoropolymer binders with the insensitive explosive 1, 3, 5-triamino-2, 4, 6trinitrobenzene (TATB), Journal of colloid and interface science.

[92] A. Kessman, D. Huckaby, C. Snyder, S. Kukureka, D. Cairns, Tribology of water and oil repellent sol-gel coatings for optical applications, Wear 267 (1-4) (2009) 614-618.

[93] L. Zhao, Y. Yu, L. Song, M. Ruan, X. Hu, A. Larbot, Preparation of mesoporous titania film using nonionic triblock copolymer as surfactant template, Applied Catalysis A 263 (2) (2004) 171-177.

[94] M. Losurdo, M. Giangregorio, G. Bruno, F. Poli, L. Armelao, E. Tondello, Porosity of mesoporous silica thin films: Kinetics of the template removal process by ellipsometry, Sensor \& Actuators B 126 (1) (2007) 168-173.

[95] F. Kleitz, W. Schmidt, F. Sch?th, Calcination behavior of different surfactant-templated mesostructured silica materials, Microporous And Mesoporous Materials 65 (1) (2003) 129.

[96] Y. Zhu, T. Muller, J. Lercher, Single Step Preparation of Novel Hydrophobic Composite Films for Low-k Applications, Advanced Functional Materials 18 (21) (2008) 34273433.

[97] J. Jung, J. Bae, B. Bae, Preparation and Characterization of Structurally Stable Hexagonal and Cubic Mesoporous Silica Thin Films, Journal Of Sol-Gel Science And Technology 31 (1) (2004) 179-183.

[98] C. Boissiere, D. Grosso, S. Lepoutre, L. Nicole, A. Bruneau, C. Sanchez, Porosity and mechanical properties of mesoporous thin films assessed by environmental ellipsometric porosimetry, Langmuir 21 (26) (2005) 12362-12371.

[99] E. Barrett, L. Joyner, P. Halenda, The determination of pore volume and area distributions in porous substances. I. Computations from nitrogen isotherms, Journal of The American Chemical Society 73 (1) (1951) 373-380.

[100] L. Gelb, K. Gubbins, Pore size distributions in porous glasses: a computer simulation study, Langmuir 15 (2) (1999) 305-308.

[101] Y. Lu, G. Cao, R. Kale, S. Prabakar, G. Lopez, C. Brinker, Microporous silica prepared by organic templating: relationship between the molecular template and pore structure, Chemistry of Materials 11 (5) (1999) 1223-1229. 
[102] J. Pang, K. Qiu, Y. Wei, Preparation of mesoporous silica materials with non-surfactant hydroxy-carboxylic acid compounds as templates via sol-gel process, Journal Of NonCrystalline Solids 283 (1-3) (2001) 101-108.

[103] A. Kessman, D. Cairns, Microtribological Study of Internal Surfaces of Fluorinated Mesoporous Silica Films, Langmuir 27 (10) (2011) 5968-5975.

[104] M. Braun, L. Pilon, Effective optical properties of non-absorbing nanoporous thin films, Thin Solid Films 496 (2) (2006) 505-514.

[105] R. Swanepoel, Determination of the thickness and optical constants of amorphous silicon, Journal of Physics E: Scientific Instruments 16 (1983) 1214.

[106] J. Cisneros, Optical characterization of dielectric and semiconductor thin films by use of transmission data, Applied optics 37 (22) (1998) 5262-5270.

[107] P. Eaton, P. Graham, J. Smith, J. Smart, T. Nevell, J. Tsibouklis, Mapping the surface heterogeneity of a polymer blend: an adhesion-force-distribution study using the atomic force microscope, Langmuir 16 (21) (2000) 7887-7890.

[108] M. McDermott, J. Green, M. Porter, Scanning force microscopic exploration of the lubrication capabilities of n-alkanethiolate monolayers chemisorbed at gold: structural basis of microscopic friction and wear, Langmuir 13 (9) (1997) 2504-2510.

[109] H. Mizes, K. Loh, R. Miller, S. Ahuja, E. Grabowski, Submicron probe of polymer adhesion with atomic force microscopy: Dependence on topography and material inhomogeneities, Applied Physics Letters 59 (1991) 2901.

[110] V. Tsukruk, M. Everson, L. Lander, W. Brittain, Nanotribological properties of composite molecular films: C60 anchored to a self-assembled monolayer, Langmuir 12 (16) (1996) 3905-3911.

[111] S. Ren, S. Yang, J. Wang, W. Liu, Y. Zhao, Preparation and tribological studies of stearic acid self-assembled monolayers on polymer-coated silicon surface, Chemistry Of Materials 16 (3) (2004) 428-434.

[112] S. Song, S. Ren, J. Wang, S. Yang, J. Zhang, Preparation and tribological study of a peptide-containing alkylsiloxane monolayer on silicon, Langmuir 22 (14) (2006) 60106015.

[113] H. Kim, T. Koini, T. Lee, S. Perry, Systematic studies of the frictional properties of fluorinated monolayers with atomic force microscopy: comparison of CF3-and CH3terminated films, Langmuir 13 (26) (1997) 7192-7196.

[114] B. Booth, S. Vilt, C. McCabe, G. Jennings, Tribology of Monolayer Films: Comparison between n-Alkanethiols on Gold and n-Alkyl Trichlorosilanes on Silicon, Langmuir 25 (17) (2009) 9995-10001.

[115] J. Ou, J. Wang, S. Liu, J. Zhou, S. Yang, Self-Assembly and Tribological Property of a Novel 3-Layer Organic Film on Silicon Wafer with Polydopamine Coating as the Interlayer, Journal of Physical Chemistry C 113 (47) (2009) 20429-20434.

[116] S. Song, R. Chu, J. Zhou, S. Yang, J. Zhang, Formation and Tribology Study of AmideContaining Stratified Self-Assembled Monolayers: Influences of the Underlayer Structure, Journal Of Physical Chemistry C 112 (10) (2008) 3805-3810.

[117] Q. Zhang, L. Archer, Interfacial friction of surfaces grafted with one-and two-component self-assembled monolayers, Langmuir 21 (12) (2005) 5405-5413.

[118] Q. Zhang, L. Archer, Boundary lubrication and surface mobility of mixed alkylsilane selfassembled monolayers, The Journal of Physical Chemistry B 107 (47) (2003) 1312313132. 
[119] E. Meyer, R. Overney, D. Brodbeck, L. Howald, R. Luthi, J. Frommer, H. Guntherodt, Friction and wear of Langmuir-Blodgett films observed by friction force microscopy, Physical Review Letters 69 (12) (1992) 1777-1780.

[120] S. Patton, W. Cowan, K. Eapen, J. Zabinski, Effect of surface chemistry on the tribological performance of a MEMS electrostatic lateral output motor, Tribology Letters 9 (3) (2001) 199-209.

[121] A. Corwin, M. Street, R. Carpick, W. Ashurst, M. Starr, M. de Boer, Friction of different monolayer lubricants in MEMs interfaces, Sandia report SAND2005-7954, Sandia National Laboratories, Albuquerque, CA, USA.

[122] J. Kushmerick, M. Hankins, M. De Boer, P. Clews, R. Carpick, B. Bunker, The influence of coating structure on micromachine stiction, Tribology Letters 10 (1) (2001) 103-108.

[123] D. Kim, G. Zhavnerko, H. Ahn, D. Choi, Tribological properties of Langmuir-Blodgett films on silicon surface in microscale sliding contact, Tribology Letters 17 (2) (2004) 169-177.

[124] B. Bhushan, A. Kulkarni, V. Koinkar, M. Boehm, L. Odoni, C. Martelet, M. Belin, Microtribological characterization of self-assembled and Langmuir-Blodgett monolayers by atomic and friction force microscopy, Langmuir 11 (8) (1995) 3189-3198.

[125] Y. Xiu, L. Zhu, D. Hess, C. Wong, Sol-Gel Process Derived Superhydrophobic Silica Thin Films for Antistiction of MEMS Devices, Materials Research Society Symposium Proceedings 990 (2007) 303-312.

[126] E. Wong, M. Markowitz, S. Qadri, S. Golledge, D. Castner, B. Gaber, Hybrid organicinorganic quaternary ammonium organosilane functionalized mesoporous thin films, The Journal of Physical Chemistry B 106 (26) (2002) 6652-6658.

[127] N. Brewer, B. Beake, G. Leggett, Friction force microscopy of self-assembled monolayers: influence of adsorbate alkyl chain length, terminal group chemistry, and scan velocity, Langmuir 17 (6) (2001) 1970-1974.

[128] L. Li, Q. Yu, S. Jiang, Quantitative measurements of frictional properties of nalkanethiols on $\mathrm{Au}$ (111) by scanning force microscopy, Journal of Physical Chemistry B 103 (39) (1999) 8290-8295.

[129] Y. Liu, D. Evans, Q. Song, D. Grainger, Structure and frictional properties of selfassembled surfactant monolayers, Langmuir 12 (5) (1996) 1235-1244.

[130] R. Li, A. Alizadeh, W. Shang, Adhesion of liquid droplets to rough surfaces, Physical Review E 82 (4) (2010) 41608.

[131] J. Chen, I. Ratera, J. Park, M. Salmeron, Velocity dependence of friction and hydrogen bonding effects, Physical Review Letters 96 (23) (2006) 236102.

[132] N. Tambe, B. Bhushan, Friction model for the velocity dependence of nanoscale friction, Nanotechnology 16 (2005) 2309.

[133] J. Luo, H. Wen, Y. Chang, W. Wu, C. Chou, Mesoporous silica reinforced by silica nanoparticles to enhance mechanical performance, Journal Of Colloid And Interface Science 305 (2) (2007) 275-279.

[134] C. Tsai, H. Lu, C. Ting, W. Wu, B. Wan, Increasing mechanical strength of mesoporous silica thin films by addition of tetrapropylammonium hydroxide and refluxing processes, Thin Solid Films 517 (6) (2009) 2039-2043.

[135] B. Unger, M. Hahnert, R. Nitzsche, On Aging of Acid-Catalyzed Silica Sols?A Dynamic Light Scattering Study, Journal Of Sol-Gel Science And Technology 13 (1) (1998) 81-84. 
[136] M. Sorensen, R. Corkery, J. Pedersen, J. Rosenholm, P. Alberius, Expansion of the f127templated mesostructure in aerosol-generated particles by using polypropylene glycol as a swelling agent, Microporous and Mesoporous Materials 113 (1-3) (2008) 1-13. 


\section{Curriculum Vitae}

\section{Education}

Ph.D. candidate, Mechanical Engineering, expected August, 2011

Advisor: Dr. Darran Cairns

West Virginia University, Morgantown, WV

B.S. Chemical Engineering, 2002, magna cum laude

Northeastern University, Boston, MA

\section{Awards and Recognition}

2009 National Defense Science and Engineering Graduate Fellowship recipient (2009-2010 tenure year, AFOSR funded)

2009 National Science Foundation Graduate Research Fellowship recipient (2010-2011 tenure year)

2008 Visiting Academic, Summer Undergraduate Research Program, University of Birmingham, UK

2008 Swiger Doctoral Fellowship, West Virginia University, one of four awarded universitywide

2008 WVNano Graduate Bridge Award, West Virginia University

2007 WVNano Graduate Bridge Award, West Virginia University

2006 Winner of 3M Circle of Technical Excellence and Innovation Award for Excellence in Individual Technical Achievement for developing a tribological test methodology for ceramic coatings

\section{Research Experience \\ Research Assistant}

West Virginia University, Morgantown, WV, 2007-present

- Thesis title: "Mesostructured hydrophobic-oleophobic silica films for sustained functionality in tribological environments"

- Research led to developing a coating process (patent pending) for an industrial partner. The product was taken from conception through process transfer, scale-up, and commercialization: http://www.europtecusa.com/products/cleantouch.

- Supervised and mentored junior lab members including undergraduate research assistants.

\section{Research Engineer}

Alkermes, Cambridge, MA, 2006-2007

- Development and optimization of emulsion and suspension formulations and processes.

- Development of microencapsulation processes for timed release of pharmaceuticals.

- Development and optimization of microsphere drying processes, including analysis of data from SEM, AFM, XPS, and FTIR analysis of microspheres.

- Development of in situ drying and crystallization/phase characterization methods for mass spectrometry and Raman spectroscopy. 


\section{Materials Research Engineer}

3M, Methuen, MA, 2002-2006

- Led development of a test methodology to evaluate polishing wear resistance and durability of protective ceramic coatings for touch sensors. This work led to my receiving a Circle of Technical Excellence and Innovation Award in 2005.

- Led process development of inkjetting electrically conductive inks on glass substrates

- Development of techniques to characterize optical coating properties based on microscopic digital image analysis.

\section{Notable co-op experiences}

- Draper Laboratory, Cambridge, MA, April-August 2001. Chemical modification of conductive surfaces for MEMS chemical sensors.

- Shipley, Co. (Rohm \& Haas), Marlborough, MA, January-December 2002. Development of process for selective catalytic metallization of copper on organic surfaces.

\section{Economic Development}

- Developed coating technologies for local medium-sized glass companies - supporting technology transfer, workforce training, and process support.

- Product, process, and manufacturing technology: development of sol-gel corrosion-resistant thermal barrier coating to extend refractory pot life.

- Development of coating technologies for multiple functionalities of transparent glasses. Patent-pending with license agreement in place.

\section{Patents}

A.J. Kessman, D.R. Cairns, “Durable Hydrophobic-Oleophobic Coating,” patent pending.

\section{Supervisory Experience}

2010-2011 Andrew Hoover, undergraduate research assistant, West Virginia University.

2010 Elizabeth DeFusco, undergraduate research assistant, West Virginia University. Mechanical properties of porous functional films

2009-2010 Sarah Zimmerman, undergraduate research assistant, West Virginia University. Chemical and mechanical properties of functional films

2009 Sean Cronin, undergraduate research assistant, West Virginia University. Chemical and mechanical properties of functional films.

2008 Corey Snyder, undergraduate research assistant, West Virginia University. Chemical and mechanical properties of sol-gel films

2008 Visiting Academic, Summer Undergraduate Research Program, University of Birmingham, UK. Supervised five undergraduate researchers in materials characterization techniques.

2005-2006 Mauricio Lopez, engineering technician (3M). Fabrication and characterization of thin film touch sensors. 


\section{Publications}

Underlined signifies undergraduate student researcher

0. A.J. Kessman, E.E. DeFusco, A.W. Hoover, D.R. Cairns, "Effect of functional moiety and surfactant template concentrations on the structural, mechanical, and tribological properties of mesostructured hydrophobic silica films," in preparation.

0. A.J. Kessman, D.R. Cairns, "Anisotropically aligned and spaced mesostructured features from isotropic colloidal suspensions by extremely fast dip coating," in preparation.

0. T.S. Bejitual, K. Ramji, A.J. Kessman, K.A. Sierros, D.R. Cairns, "Corrosion of an amorphous indium tin oxide film on polyethylene teraphtalate in acrylic acid," submitted to Materials Chemistry and Physics..

1. A.J. Kessman, D.R. Cairns, "Block copolymer templated silica films with sustained hydrophobic-oleophobic functionality," Journal of Colloid and Interface Science; doi:10.1016/j.jcis.2011.05.026.

2. A.J. Kessman, D.R. Cairns, "Microtribological study of internal surfaces of fluorinated mesoporous silica films," Langmuir, 27 (2011) 5968-5975; doi: 10.1021/la2000238.

3. A.J. Kessman, S.N. Kukureka, D.R. Cairns, "Tribology of non-wetting fluorinated mesoporous silica films," Wear, doi:10.1016/j.wear.2010.12.066.

4. K.A. Sierros, T.S. Bejitual, S.Cronin, A.J. Kessman, S.N. Kukureka, D.R. Cairns, "Tribocorrosion of Ag and Ag-alloy ITO multilayers used in solar energy applications," Wear, doi:10.1016/j.wear.2010.12.077.

5. D.R. Cairns, M.S. Shafran, K.A. Sierros, W.W. Huebsch, A.J. Kessman, "Stimulusresponsive fluidic dispersions of rod shaped liquid-crystal polymer colloids," Materials Letters, 64 (2010) 1133-1136; doi: 10.1016/j.matlet.2010.02.021.

6. A.J. Kessman, D.R. Cairns, P.J. Richter, F.J. Bottari, "Mesostructured island formation in sol-gel $\mathrm{SiO}_{2}$ films through controlled, concentration-dependent flocculation of colloidal silica particles," Materials Letters 64 (2010) 258-260; doi:10.1016/j.matlet.2009.10.055.

7. A,J. Kessman, K. Ramji, N.J. Morris, D.R. Cairns "Zirconia sol-gel coatings on aluminasilica refractory material for improved corrosion resistance," Surface and Coatings Technology 204 (2009) 477-483; doi:10.1016/j.surfcoat.2009.08.024.

8. A.J. Kessman, D.K.P. Huckaby, C.R. Snyder, S.N. Kukureka, D.R. Cairns, "Tribology of water and oil repellent sol-gel coatings for optical applications," Wear 267 (2009) 614-618; doi:10.1016/j.wear.2008.12.088.

9. D.R. Cairns, A.J. Kessman, P.J. Richter, F.J. Bottari, N.X. Randall, "Mechanical and tribological investigations of sol-gel derived $\mathrm{SiO}_{2}$ optical coatings" Wear 265 (2008) 411416; doi:10.1016/j.wear.2007.11.028.

\section{Presentations}

1. A.J. Kessman, S.N. Kukureka, D.R. Cairns, "Tribology of Fluorinated Mesoporous Silica Films," $18^{\text {th }}$ International Conference on Wear of Materials (2011). (oral presentation)

2. K. A. Sierros, T. S. Bejitual, S. Cronin, A. J. Kessman, S. N. Kukureka, D. R. Cairns, "Tribocorrosion of Ag and Ag-alloy ITO multilayers used in solar energy applications," $18^{\text {th }}$ International Conference on Wear of Materials (2011). (oral presentation)

3. A.J. Kessman, D.R. Cairns, "Design and synthesis of mesoporous films for sustained organic functionality," Second International Conference on Multifunctional, Hybrid and Nanomaterials (2011). (poster presentation) 
4. A.J. Kessman, D.R. Cairns, "Chemical and mechanical properties of aged functional mesoporous silica films in tribological environments," Second International Conference on Multifunctional, Hybrid and Nanomaterials (2011). (poster presentation)

5. A.J. Kessman, "Preparing for graduate fellowship applications in STEM disciplines" oral presentation to students at West Virginia University, through WVU Office of Graduate Education and Life (2-28-2011).

6. A.J. Kessman, P.J. Richter, D.R. Cairns, "Soliton wave assisted controlled assembly of solgel derived mesostructured films," 2010 MRS Fall Meeting. (poster presentation)

7. A.J. Kessman, "Mesoporous hydrophobic-oleophobic films for sustained functionality in tribological environments," oral presentation to Sheldon research group, Brown University (11-16-2010).

8. A.J. Kessman, "Design and synthesis of mesoporous hydrophobic-oleophobic films for sustained functionality in tribological environments" WVNano seminar series, West Virginia University (10-15-2010). (invited oral presentation)

9. A.J. Kessman, D.K.P. Huckaby, C.R. Snyder, S.N. Kukureka, D.R. Cairns, "Tribology of water and oil repellent sol-gel coatings for optical applications," $17^{\text {th }}$ International Conference on Wear of Materials (2009). (oral presentation)

10. A.J. Kessman, "Nanotechnology in our world" Engineers of Tomorrow educational seminar on nanotechnology, West Virginia University (4-15-2008). (invited oral presentation)

\section{Teaching Experience}

2011 Teaching assistant for MAE 241 Dynamics \& Strength of Materials Lab. Duties including setting up lab experiments and brief theoretical lectures to class.

2011 Participated in Preparing Future Faculty seminar and workshops at WVU aimed at improving teaching skills for university-level instruction.

2010 Instructor for MAE 241 Engineering Statics, student evaluation = 4.3/5.0. Duties included curriculum/syllabus development and all teaching and grading responsibilities.

2009 Recitation instructor for MAE 243 Mechanics of Materials. Duties included selection of practice problems, full class instruction, and individual student tutorials.

2008-2011 Lab curriculum developer and instructor for MAE 493E / PHYS 293K Introduction to Nanotechnology (WVU). Duties included selection of suitable lab activities, writing handouts (theory and experimental sections), setting up physical apparatus, and group instruction.

\section{Professional Service}

- Peer reviewer for Applied Physics Letters, Wear, and Surface and Coatings Technology.

- Technical societies: American Chemical Society (Colloids and Surface Chemistry division), Materials Research Society, International Sol-Gel Society, Society for Information Display 


\section{International Collaborations}

- In the summer of 2008 I spent several weeks at the University of Birmingham under the direction of Dr. Stephen Kukureka in the department of Metallurgy and Materials. I conducted research and supervised several undergraduate students. Dr. Kukureka has collaborated on multiple papers since then.

- In the 2010-11 academic year, I participated in two courses through the Swedish Tribology School program. These courses, one at KTH and the other at Luleå University of Technology in Sweden, have led to a collaboration with Dr. Pär Marklund of the Division of Machine Elements at Luleå where we investigating the tribological properties of display coatings.

\section{Outreach and Volunteer Activities}

- Prepared and presented a seminar for undergraduate and early graduate students at West Virginia University on preparing for graduate fellowship applications in STEM disciplines (2011).

- Assisted with RET Site at West Virginia University. Duties included supervising teachers and leading lab activities involving deposition and characterization of various sol-gel coatings (summer 2011).

- Volunteer lab curriculum developer and instructor for 493E Introduction to Nanotechnology. Developed, set up, and led educational lab activities for freshman students in mathematics, science, and engineering (2008-2011).

- Volunteer lab curriculum developer and instructor for Engineers of Tomorrow summer school for middle and high school student groups (2009).

- Volunteer lab curriculum developer and instructor for Energy Day summer school for middle and high school students (2009).

- Day-to-day supervision of five undergraduate students as part of the University of Birmingham (UK) Metallurgy and Materials department summer research experience program for undergraduates (2008).

- Volunteer outreach coordinator: coordinating and implementing educational outreach in West Virginia middle schools on materials science of chocolate, ice cream, dye-sensitized solar cells, and aerogel insulation, while making sure those activities fit within WV content standards (2008). 